ORNLTM-13156

OAK RIDGE

NATIONAL

LABORATORY

MARTIN MARIETTA

MANAGED BY

MARTIN MARIETTA ENERGY SYSTEMS, INC.

FOR THE UNITED STATES

DEPARTMENT OF ENERGY

\section{sobryes \\ FEB 211 M \\ $08 \mathrm{rit}$}

\section{Chemically Enhanced Mixed Region Vapor Stripping of TCE-Contaminated Saturated Peat and Silty Clay Soils}

\author{
Olivia R. West \\ Paula A. Cameron \\ Andrew J. Lucero \\ Laurence J. Koran, Jr.
}

Environmental Sciences Division

Publication No. 4503 
This report has been reproduced directly from the best available copy.

Available to DOE and DOE contractors from the Office of Scientific and Technical Information, P.O. Box 62, Oak Ridge, TN 37831 ; prices available from (615) 576-8401, FTS 626-8401.

Available to the public from the National Technical Information Service, U.S. Department of Commerce, 5285 Port Royal Rd., Springfield, VA 22161.

This report was prepared as an account of work sponsored by an agency of the United States Government. Neither the United States Government nor any agency thereof, nor any of their employees, makes any warranty, express or implied, or assumes any legal liability or responsibility for the accuracy, completeness, or usefulness of any information, apparatus, product, or process disclosed, or represents that its use would not infringe privately owned rights. Reference herein to any specific commercial product, process, or service by trade name, trademark, manufacturer, or otherwise, does not necessarily constitute or imply its endorsement, recommendation, or favoring by the United States Government or any agency thereof. The views and opinions of authors expressed herein do not necessarily state or reflect those of the United States Government or any agency thereof. 
Enrivonmental Sciences Division

\title{
CHEMICALLY ENHANCED MIXED REGION VAPOR STRIPPING OF TCE-CONTAMINATED SATURATED PEAT AND SILTY CLAY SOILS
}

A Treatability Study for the In Situ Remediation of the NASA Michoud Rinsewater Impoundment

Olivia R. West, Paula A. Cameron

Environmental Sciences Division

Andrew J. Lucero, Laurence J. Koran, Jr.

Chemical Technology Division

Environmental Sciences Division

Publication No. 4503

Date Published: January, 1996

\author{
Prepared for \\ Martin A. Rowland \\ Facilities Site Remediation \\ Lockheed Martin Manned Space Systems \\ Michoud Assembly Facility \\ New Orleans, Louisiana 70219 \\ Prepared by \\ OAK RIDGE NATIONAL LABORATORY \\ Oak Ridge, Tennessee 37831-6036 \\ managed by \\ LOCKHEED MARTIN ENERGY SYSTEMS, INC. \\ for the \\ U.S. DEPARTMENT OF ENERGY \\ under contract DE-AC05-84OR-21400
}

\section{MASTER}


-

. 
LIST OF TABLES

LIST OF FIGURES

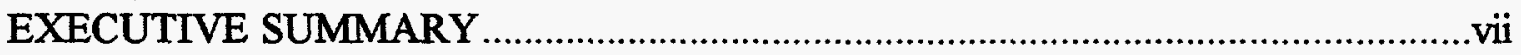

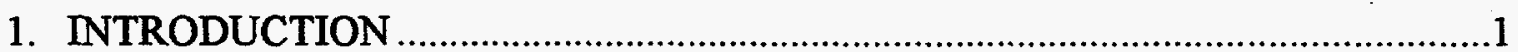

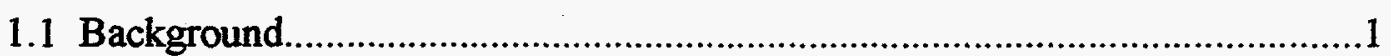

1.2 Objectives and Scope

2. EXPERIMENTAL APPROACH

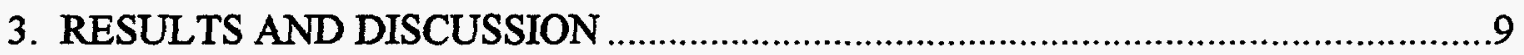

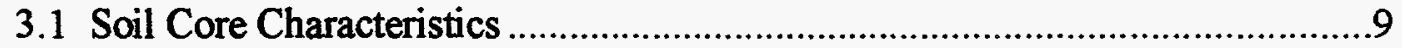

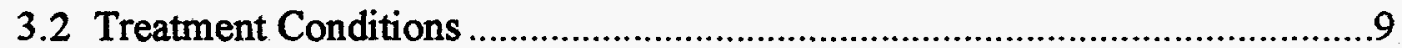

3.3 VOC Removal Rates and Effects of Treatment on Soil Physical

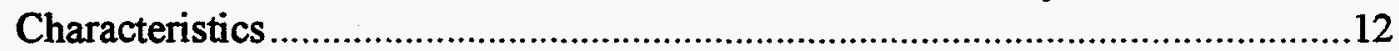

4. ASSESSMENT OF TECHNOLOGY FEASIBILITY .........................................21

4.1 Recommended Process Conditions and Remediation Cost Estimates ............21

4.2 Comparisons with Alternative Technologies ..............................................29

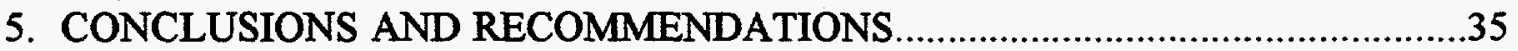

6. REFERENCES

APPENDIX A

APPENDIX B

APPENDIX C

APPENDIX D. . 


\section{LIST OF TABLES}

Table 1. Physical and contaminant characteristics of soil cores collected from the

Michoud Rinsewater Impoundment for this study

Page

Table 2. Treatment conditions for laboratory simulations of chemically enhanced mixed region vapor stripping.

Table 3. Trichloroethylene concentrations during laboratory simulations of chemically enhanced mixed region vapor stripping.

Table 3. Trichlorothyle

Table 4. Cis-1,2-dichloroethylene concentrations during laboratory simulations of chemically enhanced mixed region vapor stripping.

Table 5. Physical soil characteristics during and after laboratory simulations of chemically-enhanced mixed region vapor stripping...

Table 6. Trichloroethylene removal rate constants compared at different flow rates for cores treated with the same amount of $\mathrm{CaO}$.

Table 7. Cost per cubic yard of soil for chemically enhanced mixed region vapor stripping (MRVS) for given target percentage trichloroethylene (TCE) removals.

Table 8. In situ technologies for remediating trichloroethylene (TCE)contaminated soils

Table 9. Ex situ technologies for remediating trichloroethylene-contaminated soils 


\section{LIST OF FIGURES}

Page

Fig. 1. Schematic illustrating a model for transport of volatile organic compounds

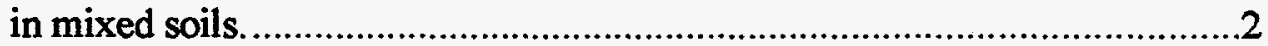

Fig. 2. Locations of boreholes from which soil cores were collected for this and previous treatability studies ....

Fig. 3. Schematic of laboratory apparatus for simulating chemically enhanced mixed region vapor-stripping.

Fig. 4. Percent of trichloroethylene removed after mixing with $\mathrm{CaO}$ and 60 minutes of vapor stripping vs initial (pre-mix) trichloroethylene soil concentration.

Fig. 5. Percent of trichloroethylene removed after mixing with $\mathrm{CaO}$ and $60 \mathrm{~min}$ of vapor stripping vs initial moisture content by dry weight, for cores treated with $65 \mathrm{~g}$ of $\mathrm{CaO}$.

Fig. 6. Aggregate size distribution in mixed cores from B10. Cores B10,10.0-10.5 and $B 10,11.0-11.5$ have larger aggregate sizes.

Fig. 7. Example of a piece-wise residual trichloroethylene vs treatment time curve.

Data shown taken from core B10,11.5-12. Line represents firstorder kinetic curves fit through the data, with one rate constant governing removal from 0 to 30 minutes, and a second rate constant governing removal from 30 to 360 minutes.

Fig. 8. Example of a single trichloroethylene vs treatment time curve. Data shown taken from core B10,11.0-11.5. Line represents a first-order kinetic curve fit through the data, with one rate constant governing removal from 0 to 360 minutes.

Fig. 9. Moisture content by dry weight as a function of depth. The locations of $\mathrm{B} 9,11.0-11.5$ and $\mathrm{B} 9,8.0-8.5$ have been switched. $\mathrm{CaO}$ loadings indicated beside data points.

Fig. 10. Percent of trichloroethylene remaining and removed as a function of treatment time for chemically-enhanced mixed region vapor stripping.

Fig. 11. Cost per soil column for chemically enhanced mixed region vapor stripping as a function of percentage trichloroethylene removed. (See text for assumptions).

Fig. 12. Grid used to estimate required time and cost for remediating the Michoud

Rinsewater Impoundment given a target residual trichloroethylene concentration. Square sub-areas are $30 \mathrm{ft} \times 30 \mathrm{ft}$. Numbers in squares are assumed initial trichloroethylene concentrations (in $\mathrm{mg} / \mathrm{kg}$ ) within each sub-area.

Fig. 13. Cost for remediating Michoud Rinsewater Impoundment vs target residual trichloroethylene concentrations. Effective remediation cost per cubic yard shown in parentheses.

Fig. A.1. Residual trichloroethylene (TCE) in soil vs vapor stripping time in core B9,8.5-9.0. 
Fig. A.2. Residual trichloroethylene (TCE) in soil vs vapor stripping time in core B9, 9.0-9.5.

Fig. A.3. Residual trichloroethylene (TCE) in soil vs vapor stripping time in core B9,9.5-10.0.

Fig. A.4. Residual trichloroethylene (TCE) in soil vs vapor stripping time in core B10,9.5-10.

Fig. A.5. Residual trichloroethylene (TCE) in soil vs vapor stripping time in core $\mathrm{B} 10,10.0-10.5$.

Fig. A.6. Residual trichloroethylene (TCE) in soil vs vapor stripping time in core B10,10.5-11.0.

Fig. A.7. Residual trichloroethylene (TCE) in soil vs vapor stripping time in core B10,11.0-11.5

Fig. A.8. Residual trichloroethylene (TCE) in soil vs vapor stripping time in core B10,11.5-12.0.

Fig. A.9. Residual trichloroethylene (TCE) in soil vs vapor stripping time in core B10,5.5-6.0

Fig. A.10. Residual trichloroethylene (TCE) in soil vs vapor stripping time in core B10,6.0-6.5

Fig. A.11. Residual trichloroethylene (TCE) in soil vs vapor stripping time in core B10,6.5-7.0.

Fig. A.12. Residual trichloroethylene (TCE) in soil vs vapor stripping time in core B9,8.0-8.5.

Fig. A.13. Residual trichloroethylene (TCE) in soil vs vapor stripping time in core B9,11.0-11.5

Fig. B.1. Temperature and residual trichloroethylene in soil vs vapor stripping time, core B10,11.5-12.

Fig. B.2. Temperature and residual trichloroethylene in soil vs vapor stripping time, core B10,11.0-11.5.

Fig. B.3. Temperature and residual trichloroethylene in soil vs vapor stripping time, core B10,5.5-6.0.

Fig. B.4. Temperature and residual trichloroethylene in soil vs vapor stripping time, core B10,6.0-6.5.

Fig. B.5. Temperature and residual trichloroethylene in soil vs vapor stripping time, core B10,6.5-7.0.

Fig. B.6. Temperature and residual trichloroethylene in soil vs vapor stripping time, core B9,8.0-8.5

Fig. B.7. Temperature and residual trichloroethylene in soil vs vapor stripping time, core B9,11.0-11.5.

Fig. C.1. Trichloroethylene contamination in subsurface soils from 0 to $4 \mathrm{ft}$ below the bottom of the impoundment concrete liner.

Fig. C.2. Trichloroethylene contamination in subsurface soils from 4 to $10 \mathrm{ft}$ below the bottom of the impoundment concrete liner.

Fig. C.3. Trichloroethylene contamination in subsurface soils from 10 to $15 \mathrm{ft}$ below the bottom of the impoundment concrete liner. 


\section{EXECUTIVE SUMMARY}

Chemically enhanced mixed region vapor stripping (MRVS) is an innovative approach for extending the applicability of MRVS to saturated, low-permeability soils contaminated with volatile organic compounds (VOCs). In this process, calcium oxide $(\mathrm{CaO})$ is mixed with saturated soil immediately prior to vapor stripping. The hydration reaction of calcium oxide $\left[\mathrm{CaO}+\mathrm{H}_{2} \mathrm{O}>\mathrm{Ca}\left(\mathrm{OH}_{2}\right)\right]$ removes free moisture from the soil matrix, resulting in an increase of air-filled soil porosity and an improvement in soil friability (i.e., the ability of the soil to break up into soil clumps or aggregates). Both the increased air-filled porosity and reduced soil aggregate sizes increase VOC removal efficiency of MRVS. Heat released during the exothermic hydration reaction can also increase the temperature of the soil, thereby improving VOC removal by increasing the fugacity of the contaminants.

The objective of this study was to evaluate MRVS, chemically enhanced with calcium oxide conditioning, for the in situ remediation of contaminated soils underlying an inactive hazardous waste facility located at the National Aeronautics Space Administration (NASA) Michoud Assembly Facility in New Orleans, Louisiana. This facility, known as the NASA Michoud Rinsewater Impoundment, is underlain by low permeability soils with moisture contents as high as $200-500 \%$ dry weight and with natural organic contents on the order of $20 \%$. These soil conditions have made remediation of this site by conventional in situ methods infeasible. Laboratory simulations of chemically enhanced MRVS were conducted on relatively undisturbed 4in-diam, 6-in-long soil cores collected from the site. Residual levels of the predominant VOCs [trichloroethylene (TCE) and cis-1,2-dichloroethylene (cis-1,2-DCE)] measured as a function of treatment time showed that TCE and cis-1,2-DCE removals were extremely rapid in the first $60 \mathrm{~min}$ after the cores were amended with a sufficient amount of $\mathrm{CaO}$. On average, $\sim 95 \%$ of initial TCE levels were removed within the first 60 minutes of vapor stripping from cores having initial concentrations of $\sim 3$ to $3000 \mathrm{mg} / \mathrm{kg}$. Removal rates were significantly lower when vapor stripping was continued beyond 60 minutes. A TCE removal curve (percent TCE removed as a function of treatment time) was developed by averaging the removal curves obtained from the MRVS tests. Based on this curve, it is estimated that $\sim 30$ and $\sim 300$ minutes of treatment is needed to remove $90 \%$ 
and $99 \%$ of initial TCE contamination. For example, starting with an initial concentration of $3000 \mathrm{mg} / \mathrm{kg}$, it would only require 30 minutes of MRVS to achieve a target residual of $300 \mathrm{mg} / \mathrm{kg}$. The same amount of time would be needed to go from 300 to $30 \mathrm{mg} / \mathrm{kg}$ of contamination. However, a significantly longer time ( 300 minutes) would be required to achieve a residual level of $30 \mathrm{mg} / \mathrm{kg}$ if the initial contaminant level were $3000 \mathrm{mg} / \mathrm{kg}$. This substantial increase in treatment time when remediation goals for TCE increase beyond $95 \%$ is a reflection of the bi-phasic removal patterns observed in the MRVS tests (i.e., rapid followed by slower TCE removal beyond 60 minutes of treatment). Rapid removals were accompanied by increased soil temperatures ranging from $40^{\circ} \mathrm{C}$ to $75^{\circ} \mathrm{C}$. The more gradual removals observed beyond $60 \mathrm{~min}$ of treatment may be a result of temperatures returning to ambient levels, as well as increased sorption on drier soils.

The amount of $\mathrm{CaO}$ required to achieve high removal rates is dependent on the initial moisture content of the soil; a $400-500 \mathrm{~kg} / \mathrm{m}^{3} \mathrm{CaO}$ loading is expected to be sufficient for the Michoud soils, which have moisture contents ranging from 26 to $534 \%$ dry weight. High $\mathrm{CaO}$ loading is needed to dehydrate the soil sufficiently and to achieve temperature increases necessary for rapid TCE removal. Some concerns exist regarding the volumetric expansion of the soil when this much $\mathrm{CaO}$ is added in situ. However, this may because of the unconsolidated nature and low density of the contaminated soil under the Rinsewater Impoundment. This concern can be best addressed through a field test.

Costs for chemically enhanced MRVS were estimated for remediation goals specified either as a percentage removal of TCE, or as target residual TCE concentration. Remediation costs are expected to be on the order of $\sim \$ 100 /$ ton to achieve a $95 \%$ removal goal using an 8-in-diam soil mixer for a treatment depth of $15 \mathrm{ft}$. For target residual levels of 5,50 , and $100 \mathrm{mg} / \mathrm{kg}$, remediation of the Michoud Rinsewater Impoundment is estimated to cost $\$ 2.6 \mathrm{M}, \$ 800 \mathrm{~K}$, and $\$ 400 \mathrm{~K}$, respectively. These were calculated by subdividing the site into subregions, and estimating treatment times for these subregions according to initial contaminant levels. The latter were taken from contour maps drawn from existing site characterization data. Better estimates can be obtained from vendors that can do soil mixing and calcium oxide additions, using the removal curve generated by the mixing experiments.

Two other technologies were identified as having the potential for remediating the highly saturated, low-permeability soils underlying the Rinsewater Impoundment. These technologies, electroosmosis and 2-Phase extraction, are fairly new and have not been 
applied to a wide variety of sites. Specific performance and cost data for remediating the Rinsewater Impoundment with these methods can only be obtained if laboratory and/or field tests were conducted.

To resolve the issue of contamination underlying the Michoud Rinsewater Impoundment, we recommend that (1) soil-mixing vendors be contacted to obtain better estimates for chemically enhanced MRVS on the basis of the removal data obtained from this work, (2) chemically enhanced MRVS be field tested, and (3) vendors that can provide electroosmosis and 2-Phase extraction be contacted for possible field tests. 


\section{INTRODUCTION}

\subsection{BACKGROUND}

Mixed region vapor stripping (MRVS) is an in situ technology for removing volatile organic compounds (VOCs) from low-permeability soils. Its effectiveness in unsaturated silty clays has been demonstrated in laboratory tests, field demonstrations, and at the full-scale cleanup of soil underlying the X-231B land treatment facility at the Portsmouth Gaseous Diffusion Plant [1-4]. On the basis of its successful application at the X-231B site, MRVS was considered as a potential in situ technology for cleaning up trichloroethylene (TCE)-contaminated soil underlying an inactive rinsewater impoundment at the National Aeronautics and Space Administration (NASA) Michoud Assembly Facility. Similar to the soils at the X-231B site, the soil underlying the Michoud Rinsewater Impoundment has extremely low permeabilities $\left(10^{-7}\right.$ to $10^{-8}$ $\mathrm{cm} / \mathrm{sec}$, [5]), which precluded the applicability of conventional soil vacuum extraction. However, in contrast to X-231B soil, which was unsaturated and consolidated, the NASA contaminated soils underlying the Michoud Rinsewater Impoundment are unconsolidated and have moisture contents as high as $\sim 500 \%$ dry weight ( $\sim 84 \%$ wet weight) [5] (see Sect. 3).

A set of scoping laboratory tests revealed that MRVS alone could not remove TCE contamination from the Michoud soils within a reasonable time frame [6]. During these tests, the mixed soil turned into a viscous soil paste instead of aggregating into small-diameter soil clumps. A previously developed model for VOC removal during MRVS showed that process efficiency improves when the mixed soil consists of smalldiameter soils aggregates with high air-filled porosities (Fig. 1), [1]. The extremely high moisture content of the Michoud soil contributed to both the paste-like mixed soil morphology and low air-filled porosities. Hence, high moisture contents were believed to be the primary reason behind the slow MRVS removal efficiencies reported by Lucero, et al. [6]. Calcium oxide conditioning was conceived during these tests as a means for reducing the moisture content of the soil. The hydration reaction of calcium oxide $[\mathrm{CaO}+$ $\mathrm{H}_{2} \mathrm{O} \rightarrow \mathrm{Ca}\left(\mathrm{OH}_{2}\right)$ ] removes free moisture from the soil matrix, resulting in increased airfilled soil porosities and improved soil friability (i.e., the ability of the soil to break up into soil clumps or aggregates). Heat released during the exothermic hydration reaction

can also increase the temperature of the soil, thereby improving VOC removal by increasing the fugacity of the contaminants. Chemically enhanced MRVS through calcium 
oxide conditioning showed promising results on a few soil cores during previous work [ 6 ]; however, a more comprehensive study of the process could not be conducted because of a lack of resources at the time.

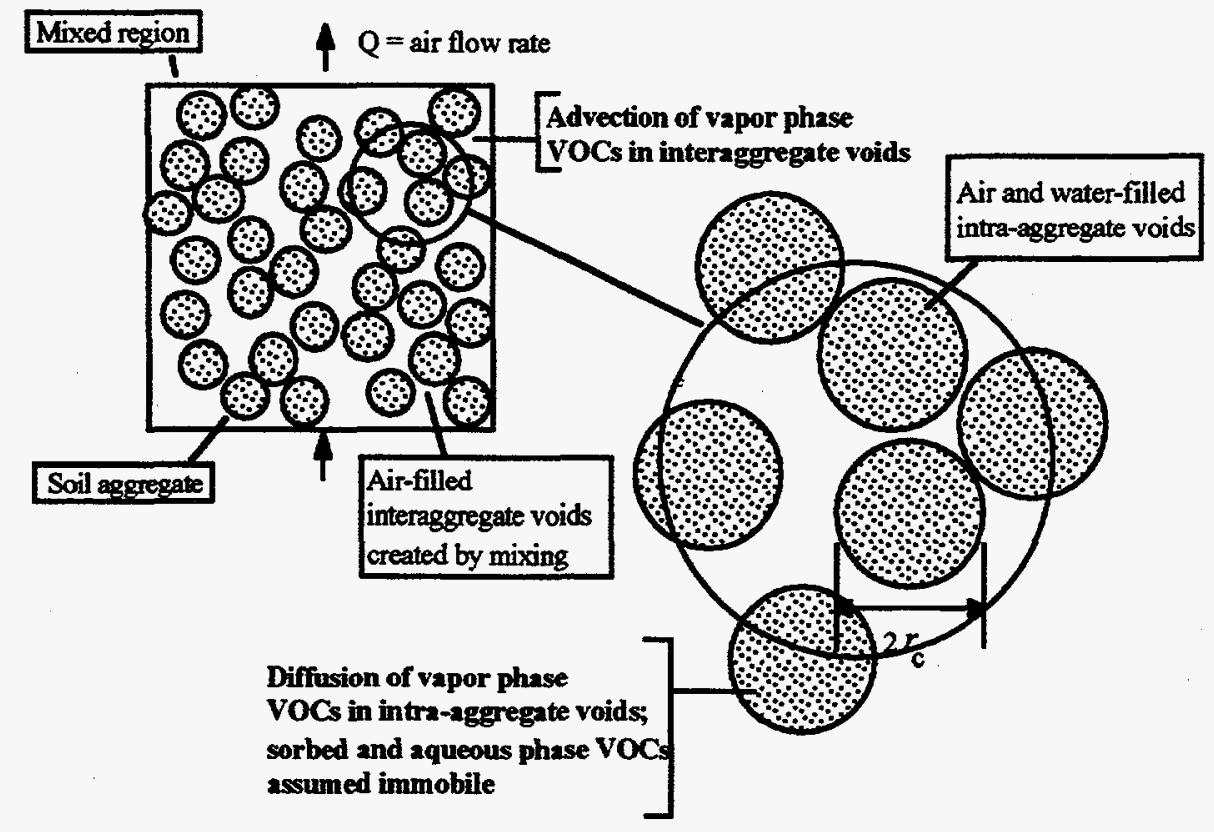

Fig. 1. Schematic illustrating a model for transport of volatile organic compounds in mixed soils.

Source: West, O. R., R. L. Siegrist, J. S. Gierke, S. W. Schmunk, A. J. Lucero, H. L. Jennings. "In Situ Mixed Region Vapor Stripping in Low Permeability Media: 1. Process Features and Laboratory Experiments." Environ. Sci. Technol. 29, 2191-2197 (1995).

\subsection{OBJECTIVES AND SCOPE}

The objective of this study was to conduct further testing of MRVS, chemically enhanced with calcium oxide conditioning, on field-contaminated soils collected from beneath the NASA Michoud Rinsewater Impoundment. In this study, residual soil VOC levels as a function of vapor stripping time were measured to quantify VOC removal rates. Physical and chemical soil parameters expected to affect MRVS efficiency were measured (e.g., moisture content before and after calcium oxide conditioning, soil temperature during mixing, total organic content). The effects of varying the calcium oxide loadings (i.e., mass of calcium oxide per unit volume of soil) as well as varying the 
vapor stripping flow rates on VOC removal were also evaluated. The results of this study will be used to determine whether acceptable removals can be achieved within reasonable treatment times, remediation costs being directly proportional to the latter.

The purpose of this report is to document the experimental results of this study, as well as to address issues that were raised after completion of the previous Michoud treatability work $[6,7]$. The experimental approach (Sect. 2) and results of chemically enhanced MRVS tests (Sect. 3) are described in detail, including a discussion of treatment mechanisms and how these are affected by the physical and chemical properties of the mixed soil (also in Sect. 3). The transferability of the laboratory test results to a full-scale application, as well as a projection of expected costs for achieving various remediation goals at the Michoud Rinsewater Impoundment, is presented (Sect. 4). The technical feasibility of chemically enhanced MRVS is compared to alternative technologies that have potential application at the site (Sect. 4). This document concludes with recommendations on how to resolve the issue of existing contamination at the Michoud Rinsewater Impoundment (Sect. 5). 



\section{EXPERIMENTAL APPROACH}

Field-contaminated soil cores were taken from three boreholes within the northern area of the NASA Michoud Rinsewater Impoundment (see Fig. 2 for boring locations). The cores were collected in 4-in.-diam, 6-in.-long stainless steel sleeves which were sealed immediately with Teflon-lined silicone sheets and aluminum plates clamped to each end of the sleeves. Previous testing at Oak Ridge National Laboratory (ORNL) has shown that this method of sealing can make sleeves air tight, thereby minimizing VOC losses from the soil during core shipment and storage. The cores were sent to ORNL in coolers filled with dry ice. The cores were stored at $4^{\circ} \mathrm{C}$ until testing.

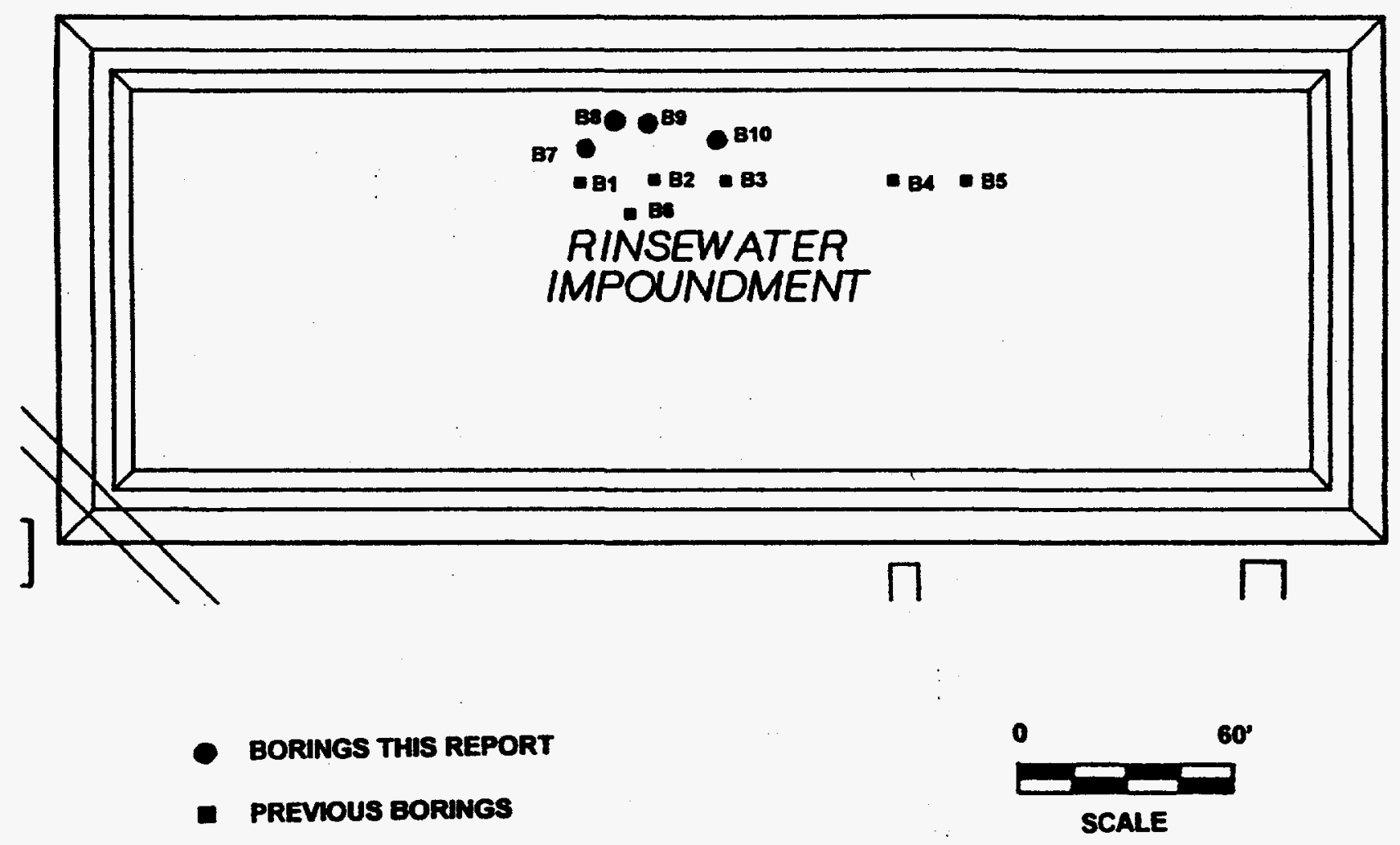

Fig. 2. Locations of boreholes from which soil cores were collected for this and previous treatability studies (B1 through B6 for previous study; B7 through B10 for this study; no cores were recovered from B7).

Chemically enhanced MRVS was conducted in the laboratory on the fieldcontaminated soil cores using the experimental apparatus schematically shown in Fig. 3. 
The apparatus consists of a soil mixer, which was used to blend calcium oxide into the soil cores, and a fretted funnel, to which the mixed soils were transferred and subsequently vapor stripped. Previously, soil mixing and vapor stripping were performed simultaneously with the soil mixer shown in Fig. $2[1,6]$. In these earlier experiments, air was delivered to the soil by flowing it through the soil mixer's swivel joint, then through its hollow shaft, and finally through a number of orifices along the mixing blades. Because of difficulties encountered with air leakage at the soil mixer's swivel joint, vapor stripping in the experiments described here was conducted in a fretted funnel. Better quantification of air flow through the mixed soil was achieved with this revised approach.

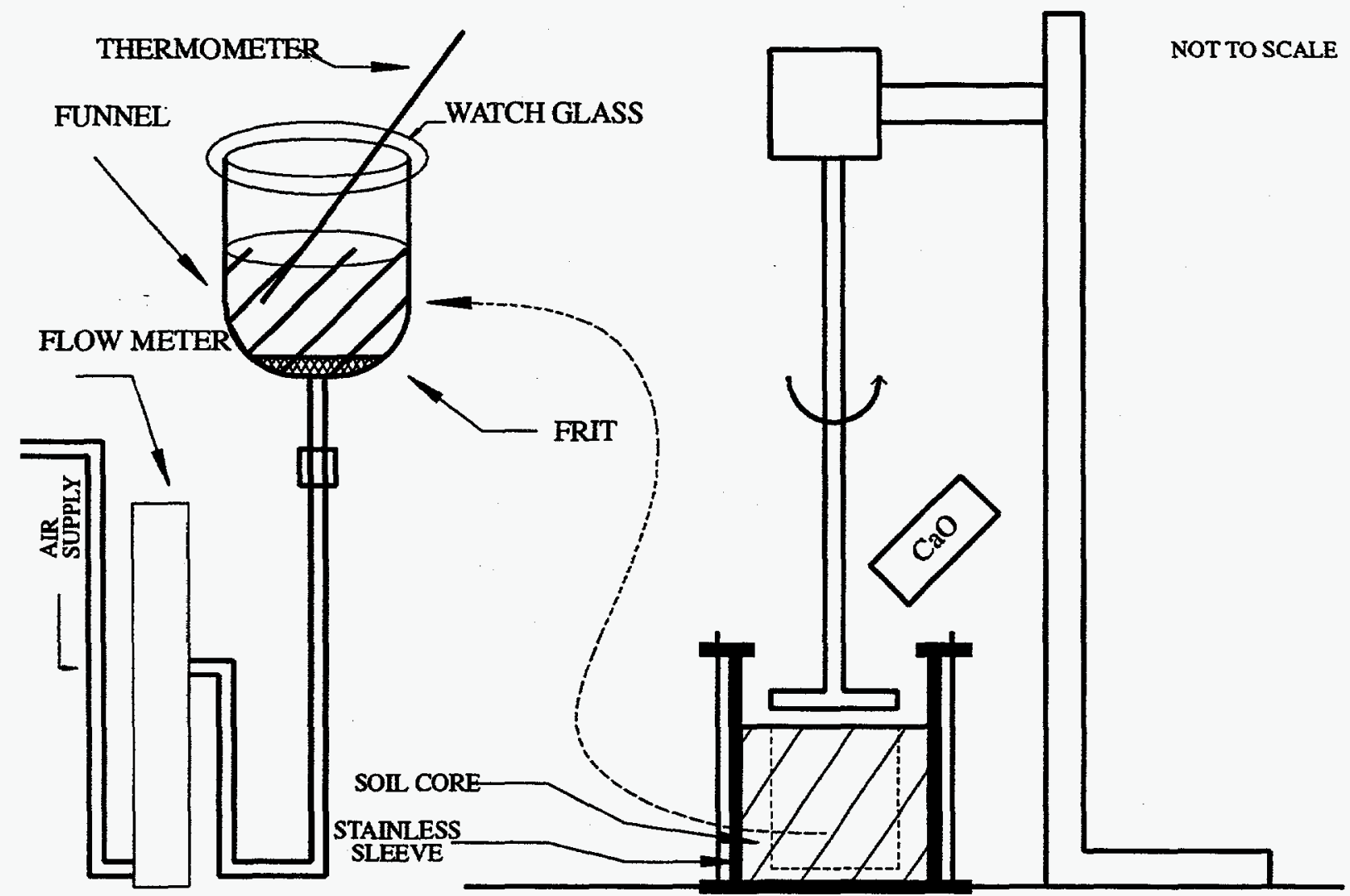

Fig. 3. Schematic of laboratory apparatus for simulating chemically enhanced mixed region vapor-stripping.

To keep track of soil VOC concentrations throughout the duration of core treatment, 2- to 3-g soil samples for VOC analysis were collected before mixing, after the 
mixed soil was transferred to the fretted funnel (time 0 min for vapor stripping), and at specific time intervals during the stripping process. For the first 11 of the 16 cores treated, vapor stripping was conducted for 360 min with VOC samples collected at 15 , $30,60,120,180,240$, and 360 min of treatment. Duplicate samples were collected before mixing and after 240 and 360 minutes of vapor stripping. Triplicate samples were collected at time 0 of vapor stripping, and single samples were collected for the rest of the time intervals. After it was determined that significant removals did not occur beyond 3 hours of vapor stripping, the remaining 5 of the 16 cores treated were vapor stripped for 180 min. Duplicate samples were taken at $0,15,30,60,120$, and $180 \mathrm{~min}$ of vapor stripping. VOC levels in the soil were measured by 24-h extractions of the soil samples with $10 \mathrm{~mL}$ of high-purity hexane and subsequent analysis of $1-\mu \mathrm{L}$ aliquots of the hexane extracts on a Hewlett Packard Model 5890 gas chromatograph/electron capture detector (GC/ECD). The GC/ECD was calibrated for TCE and cis-1,2-DCE; these were the two compounds that were predominantly found during the previous MRVS tests [6]. Instrument response was found to be linear for TCE concentrations in the hexane extracts ranging from $100 \mathrm{ppb}$ to $50,000 \mathrm{ppb}$; this approximately corresponds to soil concentrations ranging from $500 \mu \mathrm{g} / \mathrm{kg}$ to $10,000 \mu \mathrm{g} / \mathrm{kg}$. Whenever the concentrations in the hexane extracts exceeded $50,000 \mathrm{ppb}$, analyses were repeated with 1:100 dilutions.

Prior to mixing a soil core, soil physical parameters which were expected to affect MRVS removal efficiency $[l]$ were measured. These parameters were wet bulk density, moisture content, total organic content, and grain size distribution (percent silt, percent clay). Wet bulk density was estimated from the mass of the soil core divided by the volume of the sleeve. Moisture content was quantified from the change in mass of 20- to $30-\mathrm{g}$ soil samples after oven-drying for several days at $60^{\circ} \mathrm{C}$ or $100^{\circ} \mathrm{C}$. Total organic content (TOC) was measured with a Rosemount-Dohrmann DC-190 TOC analyzer equipped with a Model 183 TOC Boat Sampler. Soil samples were pretreated with hydrochloric acid to remove inorganic carbon before TOC analysis. Particle size analysis for selected soil cores was performed following ASTM methods.

Soil temperature was measured immediately after the soil was mixed and transferred to the fretted funnel. In the last 7 cores treated, soil temperature was monitored throughout the vapor stripping process. After vapor stripping, the soil aggregate size distribution was measured in the treated soil through dry sieve analysis. Moisture content samples were also collected and analyzed to determine the degree to which calcium oxide conditioning and vapor stripping reduced soil moisture. 


\section{RESULTS AND DISCUSSION}

\subsection{SOIL CORE CHARACTERISTICS}

The soil cores tested were all taken at depths ranging from 5.5 to $12 \mathrm{ft}$ below ground surface (see Table 1 for a summary of physical and contaminant properties). Bulk densities were highly variable, with very low values found in the shallower B9 cores, and slightly higher values at B8 and B10. Except for cores B10,11.5-12.0 and B9,8.0-8.51, zero compressive strengths were registered on a pocket penetrometer for the cores. Of the three borings, cores from B9 had the highest visible organic content consisting of partially decomposed plant material. Measured TOC values were consistent with this visual observation (see Table 1). Moisture contents were high for all the cores but tended to decrease with depth. The extremely high moisture contents in the B9 cores are probably caused by the presence of partially decomposed organic matter in these cores. Air-filled porosities were estimated from the wet bulk density, moisture content, and an assumed typical soil grain density of $2.6 \mathrm{~g} / \mathrm{cc}$. Estimated air-filled porosities were fairly low for all cores, indicating that these soils were close to or at saturation. TCE and cis1,2-DCE levels were quite variable. The cores from B8 had no detectable levels of TCE or cis-1,2-DCE. Cores collected from B9 ( $15 \mathrm{ft}$ from B8) had higher concentrations of VOCs, although levels changed more than an order of magnitude within 12 in. in this borehole (114 mg/kg TCE in B9,8.5-9.0 compared with $9 \mathrm{mg} / \mathrm{kg}$ TCE in B9,9.0-9.5). Cores from B10 were all very highly contaminated; core B10,9.5-10.0 had the highest TCE concentrations ( $3072 \mathrm{mg} / \mathrm{kg}$ ).

\subsection{TREATMENT CONDITIONS}

Table 2 shows calcium oxide $(\mathrm{CaO})$ loadings, air flow rates, and mixing times used on the treated cores. $\mathrm{CaO}$ loadings are reported in terms of absolute mass added to the cores (column 2), and in terms of mass of $\mathrm{CaO}$ added per unit volume of soil treated (column 3). The latter unit is more useful for estimating and specifying $\mathrm{CaO}$ loadings in field applications. Air flow rates were set either at $300 \mathrm{~mL} / \mathrm{min}$ or $600 \mathrm{~mL} / \mathrm{min}$ (column 4 , corresponding to normalized flow rates of 1 and $2 \mathrm{~min}^{-1}$ (column 5). These values are

1 Core B9,8.0-8.5 and B9,11.0-11.5 may have been mislabelled in the field. If the cores were switched, then the moisture content and VOC concentration in B9 would follow the same decreasing trend with depth observed in the cores from B10. The stiffer consistency of B9,8.0-8.5 is also more consistent with the consistency of $\mathrm{B} 10,11.5-12$. 
comparable to the normalized flow rates used during the MRVS demonstration at the X231B Unit [2].

Table 1. Physical and contaminant characteristics of soil cores collected from the Michoud Rinsewater Impoundment for this study

\begin{tabular}{|c|c|c|c|c|c|c|c|c|}
\hline Core & $\begin{array}{c}\text { Wet Bulk } \\
\text { Density } \\
(g / c)\end{array}$ & $\begin{array}{c}\text { Moisture } \\
\text { content } \\
\text { (dry weight } \\
\%)\end{array}$ & $\begin{array}{l}\text { Air-filled } \\
\text { porosity } a\end{array}$ & $\begin{array}{l}\text { Silt } \\
\text { (\%) }\end{array}$ & $\begin{array}{l}\text { Clay } \\
\text { (\%) }\end{array}$ & $\begin{array}{c}\text { Total } \\
\text { organic } \\
\text { content } \\
\text { (\%) }\end{array}$ & $\begin{array}{c}\mathrm{TCE}^{b} \\
(\mathrm{mg} / \mathrm{kg})\end{array}$ & $\begin{array}{c}\text { cis-1,2- } \\
\text { DCE } \\
(\mathrm{mg} / \mathrm{kg})\end{array}$ \\
\hline B8 6.5-7.0 & 1.12 & 290 & 6 & & & 14.42 & nd & \\
\hline B8 8-8.5 & 1.30 & 102 & 10 & & & 2.95 & nd & nd \\
\hline B8 8.5-9 & 1.34 & 97 & 8 & & & 1.48 & nd & nd \\
\hline B9 8-8.5 & 1.51 & 26 & 23 & & & & 144 & 21 \\
\hline B9 8.5-9.0 & 1.17 & 487 & saturated & 6 & 78 & 21.65 & 114 & 128 \\
\hline B9 $9.0-9.5$ & 1.32 & 103 & 8 & & & 2.34 & 9 & 74 \\
\hline B9 9.5-10 & 1.47 & 69 & 7 & & & 1.04 & 3 & 47 \\
\hline B9 $11.0-11.5$ & 1.27 & 312 & saturated & & & & 398 & 138 \\
\hline $\mathrm{B} 105.5-6.0$ & 1.00 & 532 & 10 & & & & 945 & 287 \\
\hline B10 6.0-6.5 & 1.04 & 183 & 19 & & & & 1302 & 718 \\
\hline B10 6.5-7.0 & 1.14 & 154 & 14 & & & & 775 & 221 \\
\hline B10 9.5-10 & 1.20 & 177 & 7 & 21 & 75 & 4.52 & 3072 & 328 \\
\hline B10 10-10.5 & 1.39 & 88 & 6 & & & 1.12 & 407 & 159 \\
\hline B10 $10.5-11$ & 1.44 & 71 & 8 & & & 0.80 & 220 & 230 \\
\hline B10 11-11.5 & 1.43 & 105 & 0 & & & 1.58 & 269 & 180 \\
\hline B10 11.5-12 & 1.58 & 50 & 7 & 61 & 29 & 0.56 & 172 & 86 \\
\hline
\end{tabular}

$a$ Values are estimates.

$b$ TCE = Trichloroethylene

$c$ cis-1,2-DCE $=$ cis-1,2-Dichloroethylene

Core B8,6.5-7.0 was the first core treated in this study. The amount of $\mathrm{CaO}$ used for this core $\left(30 \mathrm{~g}\right.$ or $\left.100 \mathrm{~kg} / \mathrm{m}^{3}\right)$ was clearly inadequate, since the soil remained pasty and did not aggregate even after the $\mathrm{CaO}$ was mixed into the core. For the rest of the cores, $\mathrm{CaO}$ amounts were increased if the soil remained slurry-like and pasty after the predetermined amount of $\mathrm{CaO}$ was added. For the next core treated (B9,8.5-9.0), $\mathrm{CaO}$ was added until the soil appeared dry and aggregated (with small aggregate diameters) after mixing. This core required $91.5 \mathrm{~g}\left(305 \mathrm{~kg} / \mathrm{m}^{3}\right)$ of $\mathrm{CaO}$ to achieve the desired physical effects on the mixed soil. In the next three cores tested (B8,8.0-8.5; B8,8.5-9.0; B9,9.0$9.5), 100 \mathrm{~g}$ of $\mathrm{CaO}\left(333 \mathrm{~kg} / \mathrm{m}^{3}\right)$ was used. This amount was then reduced to $\sim 65-\mathrm{g}(217$ $\mathrm{kg} / \mathrm{m}^{3}$ ) for B9,9.5-10.0 and B10,10.0-10.5 through B10,11.5-12. Because these cores were not as water-filled as the previous cores, $65 \mathrm{~g}$ of $\mathrm{CaO}$ was adequate to achieve the 
desired aggregated soil texture. A 65-g CaO loading was attempted for B10,9.5-10; however, the soil remained very soft and slurry-like, so additional $\mathrm{CaO}$ was added until the soil appeared to drier and aggregated. A total of $242 \mathrm{~g}$ of $\mathrm{CaO}\left(807 \mathrm{~kg} / \mathrm{m}^{3}\right)$ was applied to B10,9.5-10. Cores B10,5.5-6.0 and B10,6.0-6.5 had moisture contents higher than B10,9.5-10; these cores were treated with $250 \mathrm{~g}$ of CaO $\left(833 \mathrm{~kg} / \mathrm{m}^{3}\right)$. Only $200 \mathrm{~g}$ of $\mathrm{CaO}\left(667 \mathrm{~kg} / \mathrm{m}^{3}\right)$ were required to achieve the aggregated soil texture in cores $\mathrm{B} 10,6.5$ 7.0 and $\mathrm{B} 9,11.0-11.5$.

Table 2. Treatment conditions for laboratory simulations of chemically enhanced mixed region vapor stripping

\begin{tabular}{|l|c|c|c|c|c|}
\hline Core & $\begin{array}{c}\text { Mass of } \\
\text { calcium oxide } \\
\text { added (g) }\end{array}$ & $\begin{array}{c}\text { Mass of CaO } \\
\text { per unit soil } \\
\text { volume } \\
\left(\mathrm{kg} / \mathrm{m}^{3}\right)\end{array}$ & $\begin{array}{c}\text { Air flow rate } \\
\text { (mL/min) }\end{array}$ & $\begin{array}{c}\text { Air flow rate } \\
\text { per unit soil } \\
\text { volume }^{a} \\
\left(\text { min }^{-1}\right)\end{array}$ & $\begin{array}{c}\text { Mixing time } \\
\text { (min) }\end{array}$ \\
\hline B8 6.5-7.0 & 30 & 100 & 300 & 1.00 & \\
B8 8-8.5 & 100 & 333 & 300 & 1.00 & \\
B8 8.5-9 & 100 & 333 & 300 & 1.00 & 10 \\
\hline B9 8.0-8.5 & 100 & 333 & 600 & 2.00 & 10 \\
B9 8.5-9.0 & 91.5 & 305 & 300 & 1.00 & 8 \\
B9 9.0-9.5 & 100 & 333 & 300 & 1.00 & 12 \\
B9 9.5-10 & 65 & 217 & 300 & 1.00 & 5 \\
B9 11.0-11.5 & 200 & 667 & 600 & 2.00 & 10 \\
\hline B10 5.5-6.0 & 250 & 833 & 600 & 2.00 & 10 \\
B10 6.0-6.5 & 250 & 833 & 600 & 2.00 & 10 \\
B10 6.5-7.0 & 200 & 667 & 600 & 2.00 & 10 \\
B10 9.5-10 & 242 & 807 & 300 & 1.00 & 20 \\
B10 10-10.5 & 60 & 200 & 300 & 1.00 & 8 \\
B10 10.5-11 & 65 & 217 & 600 & 2.00 & 3 \\
B10 11-11.5 & 65 & 217 & 300 & 1.00 & 9 \\
B10 11.5-12 & 65 & 217 & 600 & 2.00 & 5 \\
\hline
\end{tabular}

$a^{a}$ Estimated from an average treated soil volume of $300 \mathrm{cc}$.

The first 11 of the 16 cores treated were mixed until the $\mathrm{CaO}$ appeared to be wellblended into the soil. Mixing time for these cores varied (column 6, Table 2) because some of the cores required additional applications of $\mathrm{CaO}$. The last five cores treated were all mixed for $10 \mathrm{~min}$ before vapor stripping. 
Air flow rates were selected to correspond with values for air flow rate per unit soil volume that are reasonable for field applications. Air flow rates during the MRVS field demonstration at the X-231B Unit ranged from $1000 \mathrm{cfm}$ to $1400 \mathrm{cfm}$ [2]. Soil mixers were $10 \mathrm{ft}$ in diameter and were used to treat soils to a depth of $15 \mathrm{ft}$. These process parameters correspond to values of air flow rate per unit soil volume ranging from 0.85 to $1.2 \mathrm{~min}^{-1}$. Higher VOC removals are not necessarily achieved by increasing air flow rates since VOC transport rate may be limited by diffusion through the soil aggregates [1]. Varying air flow rates were used in this study to determine whether VOC removals for Michoud soils could be diffusion-limited.

\subsection{VOC REMOVAL RATES AND EFFECTS OF TREATMENT ON SOIL PHYSICAL CHARACTERISTICS}

Tables 3 and 4 contain average values for TCE and cis-1,2-DCE levels, respectively, in the treated cores before mixing, immediately prior to, and after 60 and 360 minutes of vapor stripping (180-minutes for some cores). The following discussion focuses on TCE removal since cis-1,2-DCE removals were substantially more rapid than TCE. ${ }^{2}$ Significant decreases in contamination even before vapor stripping were noted for all the B9 cores and for core B10,9.5-10.0 (compare "pre-mix" and " $t=0$ minutes" VOC levels in Table 3). These removals may have been brought about by large increases in temperature when the $\mathrm{CaO}$ was initially mixed with the soil (see Table 5 and Appendix B). Soil from B10,9.5-10, which was amended with $242 \mathrm{~g}$ of $\mathrm{CaO}$, was at $66^{\circ} \mathrm{C}$ when vapor stripping began. This high temperature coupled with 20 -minutes of mixing may have brought about the 3 orders of magnitude decrease in contamination. Slight or no changes in VOC content immediately after mixing were noted for cores B10,10.0-10.5 through B10,11.5-12.0. Temperatures did not increase beyond $35^{\circ} \mathrm{C}$ in these cores, possibly due to the fact that only $65 \mathrm{~g}$ of $\mathrm{CaO}$ was added to these cores.

\footnotetext{
2 Appendix A contains TCE vs treatment time data for all cores treated.
} 
Table 3. Trichloroethylene concentrations during laboratory simulations of chemically enhanced mixed region vapor stripping

\begin{tabular}{|c|c|c|c|c|c|}
\hline \multirow[b]{2}{*}{ Core } & \multicolumn{5}{|c|}{ Trichloroethylene $(\mathrm{mg} / \mathrm{kg})$} \\
\hline & Pre-mix ${ }^{a}$ & $\begin{array}{l}\mathrm{t}=0 \\
\min ^{b}\end{array}$ & $\begin{array}{c}\mathrm{t}=60 \\
\min ^{c}\end{array}$ & $\begin{array}{c}\mathrm{t}=180 \\
\min ^{d}\end{array}$ & $\begin{array}{c}\mathrm{t}=360 \\
\min ^{e}\end{array}$ \\
\hline B8 6.5-7.0 & nd $f$ & nd & nd & & nd \\
\hline B8 8-8.5 & nd & nd & nd & & nd \\
\hline B8 8.5-9 & nd & nd & nd & & nd \\
\hline B9 8.0-8.5 $g$ & 143.83 & 29.42 & 4.67 & 3.13 & \\
\hline B9 8.5-9.0 & 113.61 & 24.05 & 10.63 & & 1.30 \\
\hline B9 9.0-9.5 & 8.75 & 0.52 & 0.17 & & 0.10 \\
\hline B9 9.5-10 & 3.23 & 0.82 & 0.10 & & 0.06 \\
\hline B9 $11.0-11.5 \mathrm{~g}$ & 398.13 & 25.92 & 1.20 & 12.78 & \\
\hline B10 5.5-6.0 g & 945.48 & 118.65 & 11.07 & 17.16 & \\
\hline B10 6.0-6.5 g & 1302.27 & 654.88 & 55.28 & 18.40 & \\
\hline B10 6.5-7.0 g & 775.18 & 507.51 & 90.24 & 14.27 & \\
\hline B10 9.5-10 & 3071.82 & 60.89 & 4.71 & & 10.79 \\
\hline B10 10-10.5 & 407.24 & 253.94 & 87.40 & & 2.81 \\
\hline B10 10.5-11 & 228.83 & 156.54 & 6.00 & & 2.01 \\
\hline B10 11-11.5 & 397.19 & 368.40 & 285.85 & & 44.27 \\
\hline B10 11.5-12 & 216.51 & 110.25 & 12.91 & & 5.49 \\
\hline
\end{tabular}

$a_{\text {Pre-mix concentration; average of } 2 \text { samples. }}$

$b$ Concentration at start of vapor stripping; average of 2 or 3 samples.

$c$ Concentration after $60 \mathrm{~min}$ of vapor stripping; 1 sample or average of 2 samples.

$d$ Concentration after $180 \mathrm{~min}$ of vapor stripping; average of 2 samples.

e Concentration after $360 \mathrm{~min}$ of vapor stripping; average of 2 samples.

$f_{\mathrm{nd}}=$ not detected; detection limit $\approx 1 \mu \mathrm{g} / \mathrm{kg}$.

$g$ Test stopped after 180 min of vapor stripping. 
Table 4. Cis-1,2-dichloroethylene concentrations during laboratory simulations of chemically enhanced mixed region vapor stripping

\begin{tabular}{|c|c|c|c|c|c|}
\hline \multirow[b]{2}{*}{ Core } & \multicolumn{5}{|c|}{ cis-1,2-Dichloroethylene (mg/kg) } \\
\hline & Pre-mix ${ }^{a}$ & $\begin{array}{l}\mathrm{t}=0 \\
\min ^{b}\end{array}$ & $\begin{array}{c}\mathrm{t}=60 \\
\min ^{c}\end{array}$ & $\begin{array}{c}\mathrm{t}=180 \\
\min ^{d}\end{array}$ & $\begin{array}{c}\mathrm{t}=360 \\
\min ^{e}\end{array}$ \\
\hline B8 6.5-7.0 & $\mathrm{ndf}$ & nd & nd & & $\mathrm{nd}$ \\
\hline B8 8-8.5 & nd & nd & nd & & nd \\
\hline B8 8.5-9 & nd & nd & nd & & nd \\
\hline B9 8.0-8.5 g & 20.81 & nd & nd & nd & \\
\hline B9 8.5-9.0 & 128.47 & 11.34 & 2.27 & & 0.29 \\
\hline B9 9.0-9.5 & 74.22 & 2.25 & 0.11 & & nd \\
\hline B9 9.5-10 & 46.51 & 7.73 & nd & & nd \\
\hline B9 $11.0-11.5 \mathrm{~g}$ & 137.91 & 2.47 & nd & nd & \\
\hline B10 5.5-6.0 g & 286.79 & nd & nd & $\overline{\mathrm{nd}}$ & \\
\hline B $106.0-6.5 g$ & 718.09 & 36.96 & nd & nd & \\
\hline B $106.5-7.0 \mathrm{~g}$ & 220.53 & 47.78 & 1.69 & nd & \\
\hline B10 9.5-10 & 328.01 & 3.94 & nd & & nd \\
\hline B10 10-10.5 & 158.84 & 185.42 & 13.67 & & nd \\
\hline B10 10.5-11 & 229.72 & 184.17 & 0.15 & & nd \\
\hline B10 11-11.5 & 189.75 & 155.87 & 20.95 & & 1.53 \\
\hline B10 11.5-12 & 180.94 & 91.88 & 0.26 & & 0.75 \\
\hline
\end{tabular}

a Pre-mix concentration; average of 2 samples.

$b$ Concentration at start of vapor stripping; average of 2 or 3 samples.

c Concentration after 60 min of vapor stripping; 1 sample or average of 2 samples.

$d$ Concentration after $180 \mathrm{~min}$ of vapor stripping; average of 2 samples.

$e$ Concentration after $360 \mathrm{~min}$ of vapor stripping; average of 2 samples.

$f_{\mathrm{nd}}=$ not detected; detection limit $\approx 1 \mu \mathrm{g} / \mathrm{kg}$.

$g$ Test stopped after $180 \mathrm{~min}$ of vapor stripping.

One of the issues raised after the treatability studies reported by Lucero et al. [6] was whether VOC removal efficiencies were dependent on initial levels of TCE in the soil. This was not found to be true in the tests conducted for this study, as shown in Fig. 4 where TCE removal efficiency is plotted against the pre-mix soil TCE concentration. In this figure, TCE removal efficiency for each core was calculated as follows:

$$
\% \text { Removal }_{60 / \text { pre-mix }}=\left(1-\frac{C_{\text {ave }, t=60}}{C_{\text {ave,pre-mix }}}\right) \times 100
$$


where $C_{a v e, p r e-m i x}$ and $C_{a v e, t=60}$ are the average TCE concentrations before mixing and after 60 min of vapor stripping, respectively. In general, removals on the order of $90 \%$ were achieved for most of the cores, with initial contaminant levels ranging from 3071 $\mathrm{mg} / \mathrm{kg}$ down to $3.75 \mathrm{mg} / \mathrm{kg}$. Low removals of $28 \%$ and $78 \%$ were noted for B10,10.0-10.5 and B10,11.0-11.5. These were the same two cores for which VOC content did not change significantly immediately after being mixed with $\mathrm{CaO}$. As mentioned previously, this may be caused by the inadequate amount of $\mathrm{CaO}(65 \mathrm{~g})$ that was added to these cores. Of the five cores treated with $65 \mathrm{~g}$ of $\mathrm{CaO}$, these two had the highest moisture contents (see Fig. 5). Even though the soil appeared aggregated, the amount of $\mathrm{CaO}$ may not have been adequate to reduce the moisture in these cores. Slow removals in cores $B 10,10.0-10.5$ and $B 10,11.0-11.5$ are also consistent with their aggregate sizes which tended to be larger than those of the rest of the B10 cores (see Table 5 and Fig. 6). Temperatures that did not exceed $35^{\circ} \mathrm{C}$ may also have contributed to the low removals in these cores.

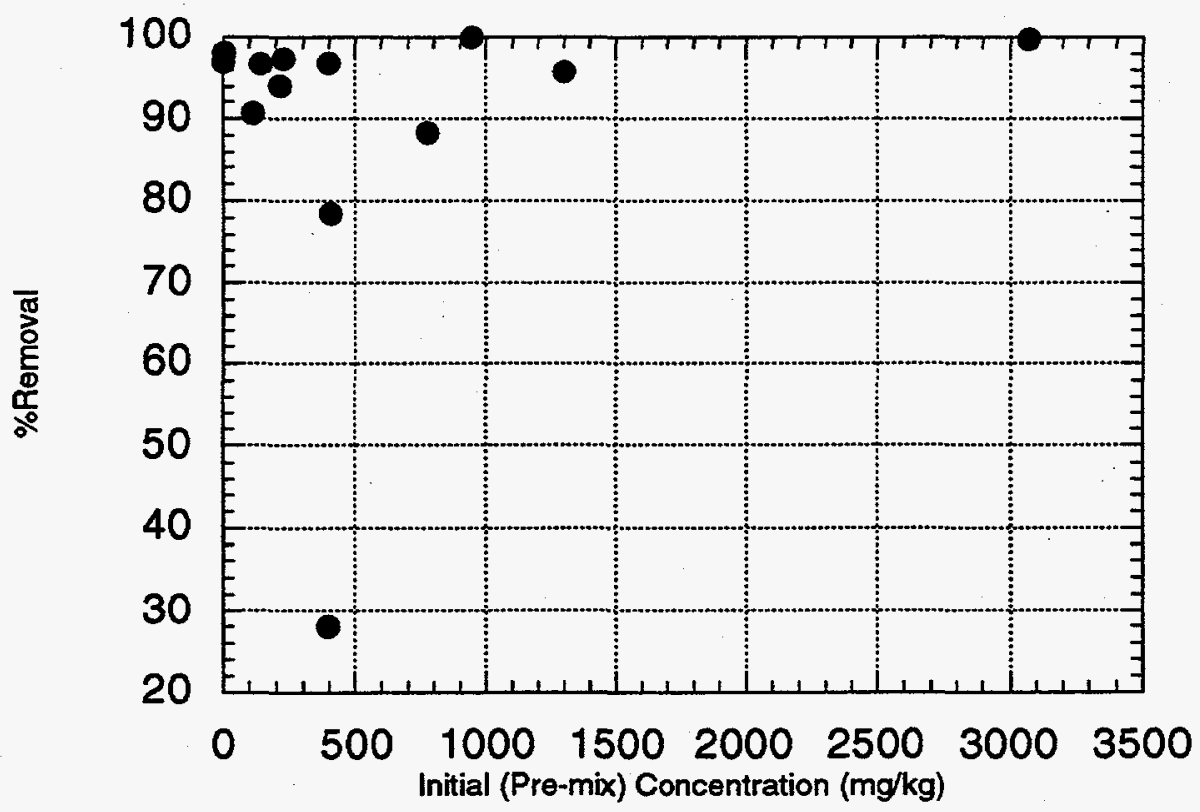

Fig. 4. Percent of trichloroethylene removed after mixing with $\mathrm{CaO}$ and 60 minutes of vapor stripping vs initial (pre-mix) trichloroethylene soil concentration. 


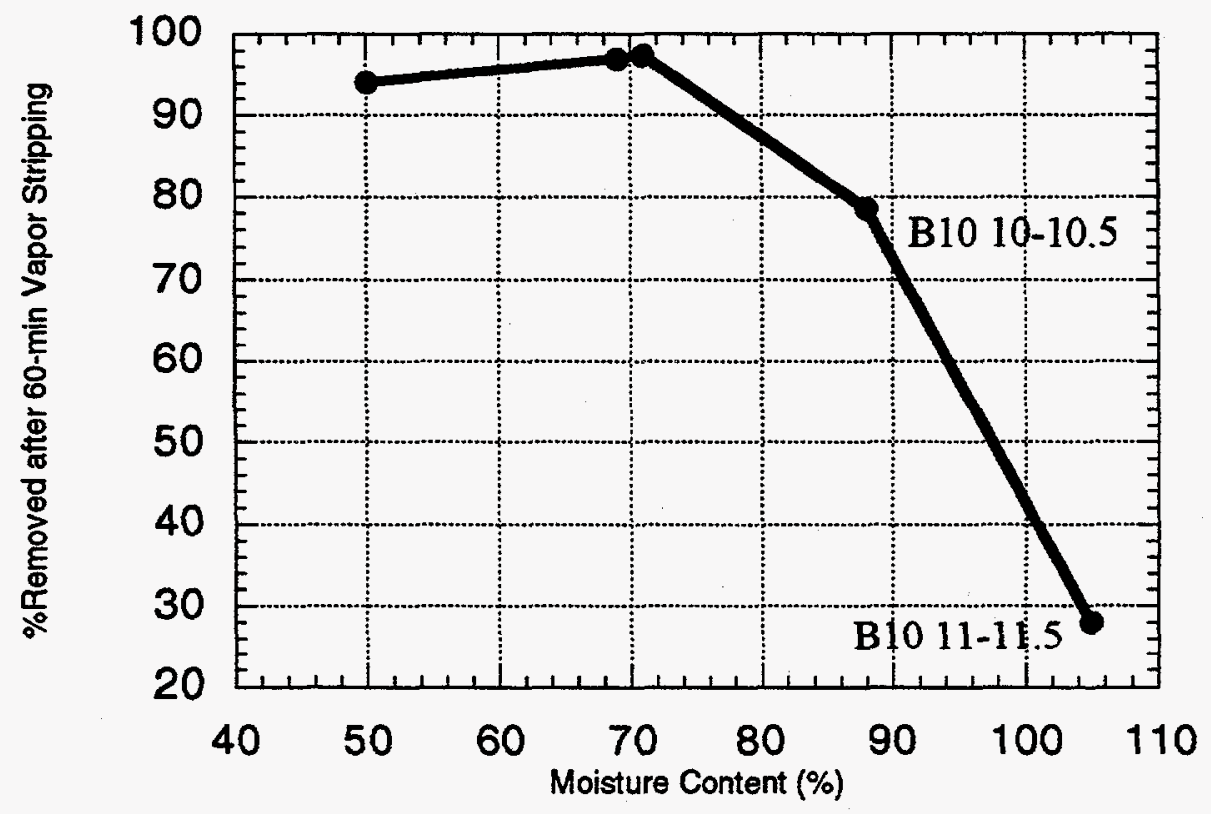

Fig. 5. Percent of trichloroethylene removed after mixing with $\mathrm{CaO}$ and $60 \mathrm{~min}$ of vapor stripping vs initial moisture content by dry weight, for cores treated with $65 \mathrm{~g}$ of $\mathrm{CaO}$.

For most of the cores treated, VOC removals were fairly rapid within the first 30 to $60 \mathrm{~min}$ of vapor stripping, but were significantly lower thereafter (refer to Appendix A). This trend is illustrated in Fig. 7, where residual TCE levels in core B10,11.5-12 are plotted on a log-scale vs vapor stripping time. In this figure, the dashed line represents a piece-wise first-order kinetic curve [i.e., (residual TCE)/(initial TCE) $=\exp (-k t)$ where $k$ is a rate constant and $t$ is vapor stripping time], in which one rate constant is assumed to govern removal within the first $30 \mathrm{~min}$ of vapor stripping, and a second rate constant governs removal after $30 \mathrm{~min}$. Removals in cores B10,10.0-10.5 and B11,11.0-11.5 were more gradual over $360 \mathrm{~min}$ of vapor stripping (see Fig. 8). The effects of the vapor stripping flow rate were evaluated by comparing removal rate constants among cores treated with the same $\mathrm{CaO}$ loadings (see Table 6). If $\mathrm{VOC}$ removal were diffusionlimited, then removal rates are not expected to increase with increasing flow rate. No such trends were observed in the cores that were treated with $100 \mathrm{~g}$ or $250 \mathrm{~g}$ of $\mathrm{CaO}$ (see Table 6). There appeared to be an increase of removal with higher flow rates in the cores treated with $65 \mathrm{~g}$ of $\mathrm{CaO}$. However, it was noted previously that the low removals in cores B10,10.0-10.5 and B10,11-11.5 (which were vapor stripped at $300 \mathrm{~mL} / \mathrm{min}$ ) may have 
been due to an inadequate amount of $\mathrm{CaO}$ added to these cores. The latter could have been the main influence over the apparent trends with flow rate, given that no such trends were observed in the cores treated with $100 \mathrm{~g}$ and $250 \mathrm{~g}$ of $\mathrm{CaO}$.

Table 5. Physical soil characteristics during and after laboratory simulations of chemically-enhanced mixed region vapor stripping.

\begin{tabular}{|l|ccc|c|c|}
\hline Core & $\begin{array}{c}\text { Post-treatment } \\
\text { Moisture } \\
\text { Content } \\
(\%)\end{array}$ & $\begin{array}{c}\text { Reduction in } \\
\text { Moisture } \\
\text { Content } \\
(\%)\end{array}$ & $\begin{array}{c}\text { Temperature } \\
\left({ }^{\circ} \mathrm{C}\right)\end{array}$ & $\begin{array}{c}\text { Post-treatment } \\
\mathrm{pH}^{b}\end{array}$ & $\begin{array}{c}\text { Sieve diameter } \\
\text { at 50\% } \\
\text { passing (mm) }\end{array}$ \\
\hline \hline B8 8.0-8.5 & 148 & 142 & & 12.8 & clumpy \\
B8 8-8.5 & 67 & 35 & & & 2.6 \\
B8 8.5-9 & 52 & 45 & & & 1.9 \\
\hline B9 8.0-8.5 & 17 & 8 & 57 & & \\
B9 8.5-9.0 & 82 & 405 & 72 & 13.3 & 3.7 \\
B9 9.0-9.5 & 53 & 50 & 41 & 10.3 & 2.3 \\
B9 9.5-10 & 48 & 21 & 42 & 10.2 & 4.7 \\
B9 11.0-11.5 & 57 & 254 & 53 & & \\
\hline B10 5.5-6.0 & 66 & 466 & 58 & & \\
B10 6.0-6.5 & 61 & 123 & 75 & & \\
B10 6.5-7.0 & 52 & 102 & 60 & & \\
B10 9.5-10 & 52 & 125 & 66 & 12.4 & 3.0 \\
B10 10-10.5 & 68 & 20 & 33 & 11.4 & 4.2 \\
B10 10.5-11 & 48 & 23 & 37 & 11.4 & 1.9 \\
B10 11-11.5 & 67 & 38 & 29 & 12.1 & 6.3 \\
B10 11.5-12 & 40 & 10 & 36 & 12.3 & 3.3 \\
\hline
\end{tabular}

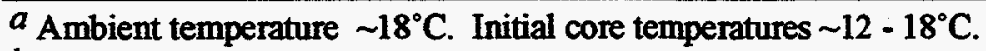

$b^{b}$ Pre-treatment $\mathrm{pH}$ of soil ranged from 5.9 to 8.1. 


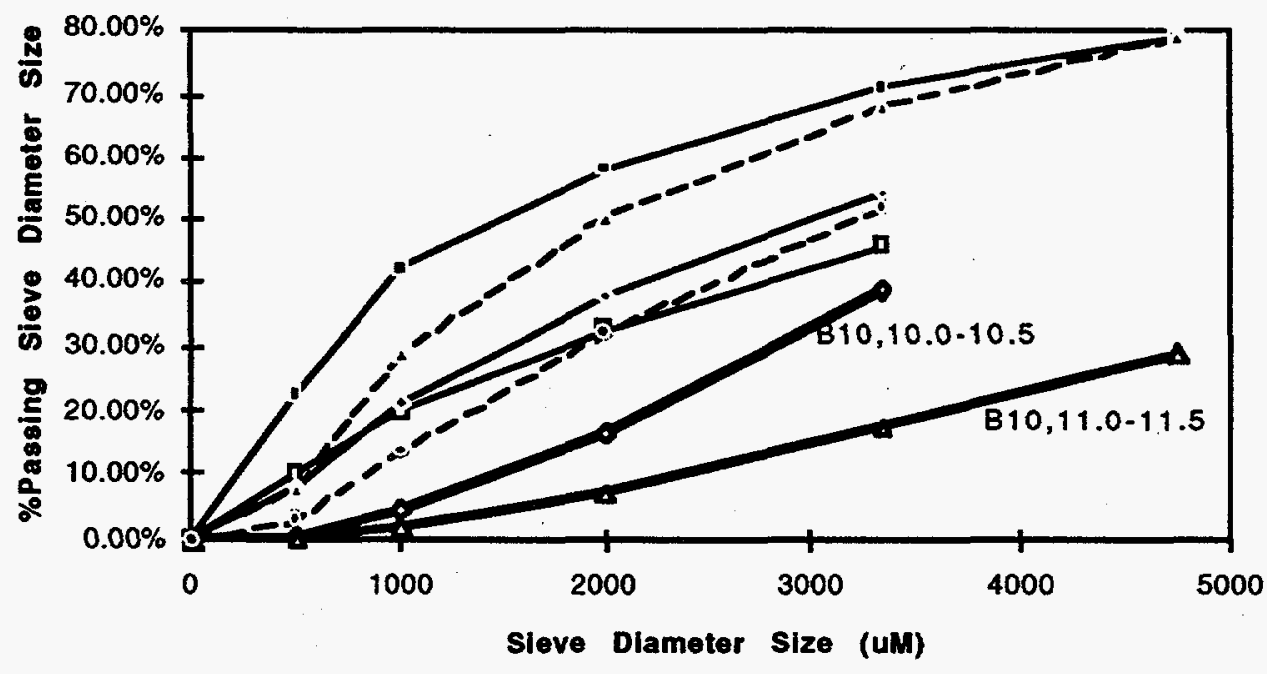

Fig. 6. Aggregate size distribution in mixed cores from B10. Cores B10,10.0-10.5 and B10,11.0-11.5 have larger aggregate sizes.

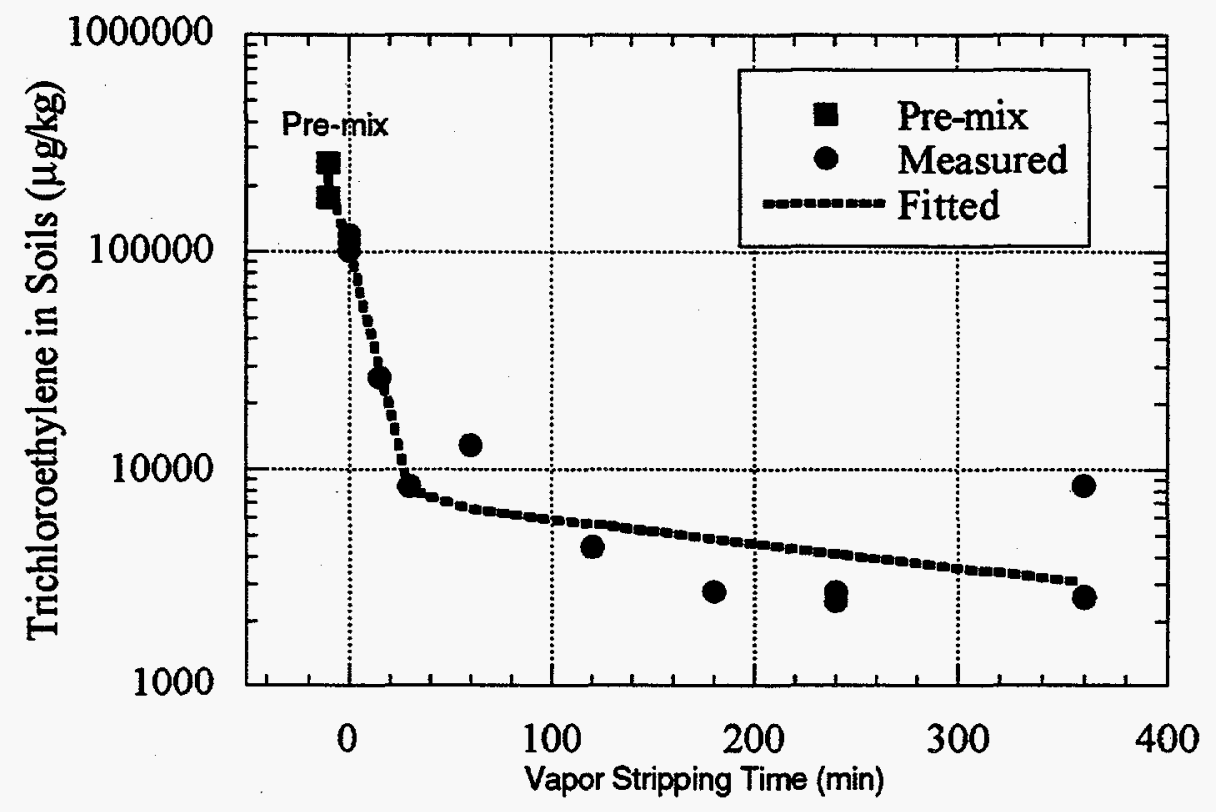

Fig. 7. Example of a piece-wise residual trichloroethylene vs treatment time curve. Data shown taken from core B10,11.5-12. Line represents first-order kinetic curves fit through the data, with one rate constant governing removal from 0 to 30 minutes, and a second rate constant governing removal from 30 to 360 minutes. 


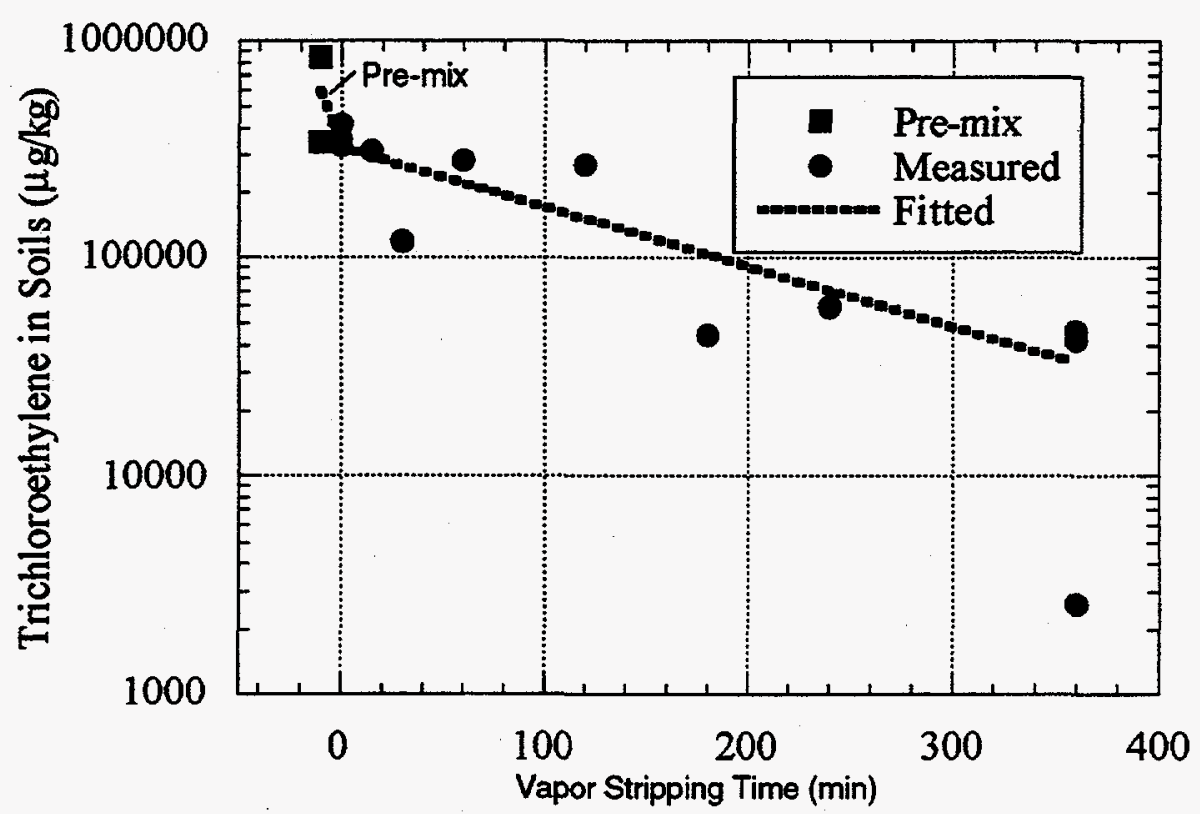

Fig. 8. Example of a single trichloroethylene vs treatment time curve. Data shown taken from core B10,11.0-11.5. Line represents a first-order kinetic curve fit through the data, with one rate constant governing removal from 0 to 360 minutes.

Table 6. Trichloroethylene removal rate constants compared at different flow rates for cores treated with the same amount of $\mathrm{CaO}$

\begin{tabular}{|c|c|c|c|}
\hline CaO Loading & Core & $\begin{array}{l}\text { Flow rate } \\
(\mathrm{mL} / \mathrm{min})\end{array}$ & $\begin{array}{l}\text { Trichloroethylene removal } \\
\text { rate constant during first 30- } \\
\text { min of vapor stripping } \\
\left(\min ^{-1}\right)\end{array}$ \\
\hline $91.5-100 \mathrm{~g}$ & $\begin{array}{l}\text { B9 8.0-8.5 } \\
\text { B9 8.5-9.0 } \\
\text { B9 9.0-9.5 }\end{array}$ & $\begin{array}{l}600 \\
300 \\
300\end{array}$ & $\begin{array}{l}0.0263 \\
0.0595 \\
0.0383\end{array}$ \\
\hline $65 \mathrm{~g}$ & $\begin{array}{l}\text { B9 } 9.5-10.0 \\
\text { B10 } 10.0-10.5 \\
\text { B10 } 10.5-11.0 \\
\text { B10 } 11.0-11.5 \\
\text { B10 } 11.5-12.0\end{array}$ & $\begin{array}{l}300 \\
300 \\
600 \\
300 \\
600\end{array}$ & $\begin{array}{l}0.0363 \\
0.0092 \\
0.0964 \\
0.0063 \\
0.0870\end{array}$ \\
\hline $242-250 \mathrm{~g}$ & $\begin{array}{l}\text { B10 } 5.5-6.0 \\
\text { B10 } 6.0-6.5 \\
\text { B10 9.5-10.0 }\end{array}$ & $\begin{array}{l}600 \\
600 \\
300\end{array}$ & $\begin{array}{l}0.0379 \\
0.1287 \\
0.0909\end{array}$ \\
\hline
\end{tabular}


We hypothesized that stronger sorption of TCE on partially dehydrated $\mathrm{CaO}$ treated soil was the reason behind reduced removal rates after 30 to $60 \mathrm{~min}$ of vapor stripping. Water can compete with VOCs for sorption sites on mineral surfaces, such that higher VOC vapor phase partition coefficients have been measured at low soil moisture contents $[8]$. In the last core treated (B9,11.0-11.5), the stripping air was humidified by passing it through a heated water bath before it came in contact with the mixed soil. We thought that this would keep the soil partially moist to prevent higher sorption of TCE on dried soil. VOC removals were not dramatically improved with this approach (see Appendix A). Furthermore, residual VOC levels in the soil were more erratic compared to the previous cores that were treated with dry air.

The hypothesis of stronger TCE sorption on CaO-treated soil was also tested in an experiment where equal amounts of TCE were injected into vials containing equal masses of uncontaminated field-moist soil, $\mathrm{CaO}$-treated soil, and pure $\mathrm{CaO}$. The loading in the CaO-treated soil was equivalent to the $65-\mathrm{g} \mathrm{CaO}$ loadings in the core experiments $\left(217 \mathrm{~kg} / \mathrm{m}^{3}\right)$. After a $24-\mathrm{h}$ equilibration in a $25^{\circ} \mathrm{C}$ water bath, TCE content in the headspace of the vials was measured by taking $20-\mu \mathrm{L}$ vapor-phase samples that were then injected into a GC/ECD. No statistically significant differences were found between the headspace TCE concentrations in the vials with untreated and CaO-treated soil. However, a significant reduction of headspace TCE did occur in the vials with $\mathrm{CaO}$ alone. This experiment showed that higher TCE sorption may occur on pure $\mathrm{CaO}$ and that partitioning on soil treated with $\mathrm{CaO}\left(220 \mathrm{~kg} / \mathrm{m}^{3}\right)$ was not different from untreated soil. This experiment still does not preclude the possibility of higher sorption at higher $\mathrm{CaO}$ loadings, especially where unreacted $\mathrm{CaO}$ may be present.

The apparent bi-phasic removal curves observed in a majority of the cores treated so far is an interesting phenomenon that may be attributed either to temperature or sorption effects. Further experimentation beyond the scope of this treatability work would be required to investigate the reasons for this. However, such a study may not be required for the field application of chemically enhanced MRVS. Results show that the technology can be expected to remove VOCs quite effectively within $1 \mathrm{to} 2 \mathrm{~h}$ of treatment if the soil is amply mixed with an adequate amount of $\mathrm{CaO}$ and aggregate sizes are sufficiently small. 


\section{ASSESSMENT OF TECHNOLOGY FEASIBLITY}

\subsection{RECOMMENDED PROCESS CONDITIONS AND REMEDIATION COST ESTIMATES}

The experiments described in the previous section have shown that chemically enhanced MRVS can effectively remove TCE and cis-1,2-DCE from the highly saturated, highly organic soils underlying the Michoud Rinsewater Impoundment. Treatment effectiveness depends on selecting adequate $\mathrm{CaO}$ loadings corresponding to the moisture content of the soil. $\mathrm{CaO}$ loadings required to achieve an aggregated mixed soil vary not only with depth but also with borehole [e.g. less $\mathrm{CaO}$ was required in $\mathrm{B} 9$ compared with $\mathrm{B} 10$ (see Fig. 9)]. CaO loadings ranged from 213 to $813 \mathrm{~kg} / \mathrm{m}^{3}$ in cores from $\mathrm{B} 10$, and 200 to $667 \mathrm{~kg} / \mathrm{m}^{3}$ in cores from B9. In an actual field application, metering the amount of $\mathrm{CaO}$ at different depths may be difficult. However, because the mixer can essentially homogenize a soil column over the mixing depth, the required $\mathrm{CaO}$ loading can be estimated from the average of the extreme loadings used in the experiments. By using this approach, the $\mathrm{CaO}$ required for Michoud soils is estimated to be $400-500 \mathrm{~kg} / \mathrm{m}^{3}$.

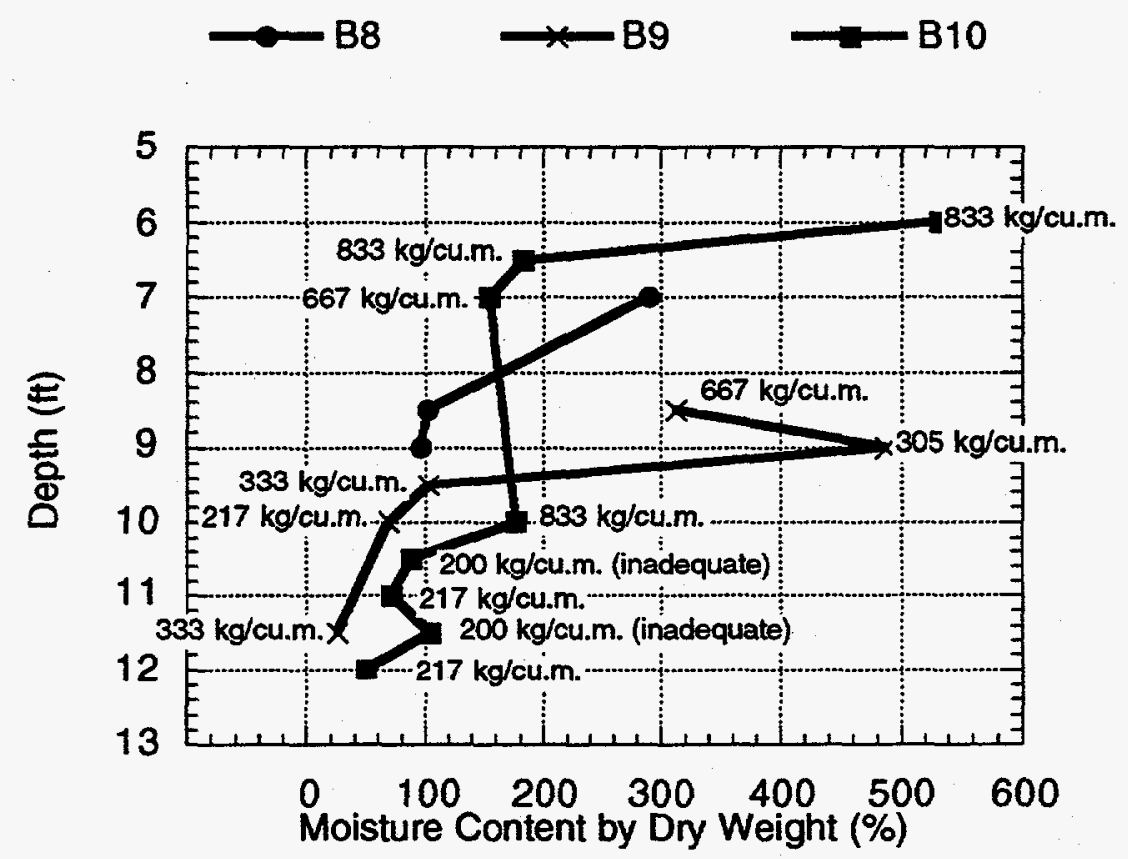

Fig. 9. Moisture content by dry weight as a function of depth. The locations of $\mathrm{B} 9,11.0-11.5$ and $\mathrm{B} 9,8.0-8.5$ have been switched. CaO loadings indicated beside data points. 
One of the concerns when having to use such a high loading of $\mathrm{CaO}$ is the volumetric expansion that can result while mixing the soil. For the highly saturated cores, which required significant amounts of $\mathrm{CaO}$, the soil did not expand substantially and maintained its slurry-like structure until the soil began to aggregate. At this point, enough $\mathrm{CaO}$ had been added to the soil. Volumetric expansion may not pose a significant problem in the field because of the unconsolidated nature of the Michoud soils. However, this can only be verified by a field application.

A second concern is the increase in soil $\mathrm{pH}$ when large amounts of $\mathrm{CaO}$ are added to the soil (Table 5). Before field testing chemically enhanced MRVS, the possibility of elevated soil $\mathrm{pH}$ should be discussed with environmental regulators. This may not be an issue since lime subsurface application is a common geotechnical and agricultural practice.

The costs associated with chemically enhanced MRVS include the following major components: (1) mobilization, (2) reagent cost, (3) operation of soil mixer, (4) demobilization, and (5) waste disposal. Of these five components, the cost for operating a soil mixer is the only one which is directly proportional to treatment time. For a given set of process conditions (i.e., $\mathrm{CaO}$ loadings and flow rates), the target residual contaminant level (or contaminant removal) is a function of treatment time. The required treatment time for a full-scale soil column to achieve a given percentage of TCE removal was estimated from the mixing experiments and is shown in Fig. 10. This estimate assumes that removal patterns observed in the mixing experiments can be used to predict field removals under similar $\mathrm{CaO}$ and normalized flow rate conditions. In the laboratory tests, the flow rates were 300 and $600 \mathrm{~mL} / \mathrm{min}$ to vapor strip a soil volume of $\sim 300 \mathrm{cc}$. Hence, the removal curve in Fig. 10 would be applicable to an 8-ft-diameter, 15-ft-deep soil column $\left(\sim 750 \mathrm{ft}^{3}\right)$ that is vapor stripped with air at 750 to $1500 \mathrm{cfm}$. The removal curve was assumed to consist of three parts, corresponding to the observed trend in TCE vs treatment time data from the mixing experiments. The first portion of this curve (0-10 min) corresponds to the removals measured immediately after $\mathrm{CaO}$ was blended into the cores. TCE residual after $10 \mathrm{~min}$ was taken from the average of the ratio between the $\mathrm{t}=$ 0 and pre-mix TCE concentrations (excluding values from B10,10.0-10.5 and B10,11.011.5 for which $\mathrm{CaO}$ loading was inadequate). The second (10 $\mathrm{min}<\mathrm{t}<40 \mathrm{~min}$ ) and third ( $\mathrm{t}>40 \mathrm{~min}$ ) parts of the curve correspond to the removals observed during and after 30minutes of vapor stripping, respectively. These are modeled as first-order kinetic curves, with rate constants taken from the average of the rate constants measured in the experiments (excluding values from $\mathrm{B} 10,10.0-10.5$ and $\mathrm{B} 10,11.0-11.5$ ). 
The removal model in Fig. 10 predicts that percentage removals increase rapidly within the first 40-min of treatment. Additional removals gained after 40 min of MRVS are not expected to be significant. The cost for remediating a full-scale soil column can be estimated by assuming a daily cost for operating the soil mixing equipment (e.g., an 8-ftdiam soil mixer), and the time per day that the mixer is in use for remediation (e.g., $4 \mathrm{~h}$ or $240 \mathrm{~min}$ ). At a daily cost of $\$ 10,000$, the cost per minute of treatment is $\sim \$ 42$. This cost was combined with the removal model in Fig. 10, to produce a curve that defines the cost per soil column as a function of percentage TCE removed (Fig. 11). Treatment costs change gradually for target percentage removals $<95 \%$, but escalate rapidly at removals $>$ $95 \%$. For example, it would cost $\$ 1000$ per soil column for a target removal of $90 \%$ (see Fig. 9). At $95 \%$, this cost increases to $\$ 2000$. At $99 \%$, the cost increases 6 times to $\$ 12,000$. This cost trend is an effect of the reduced removal rates that were observed in the experiments after $60 \mathrm{~min}$ of treatment.

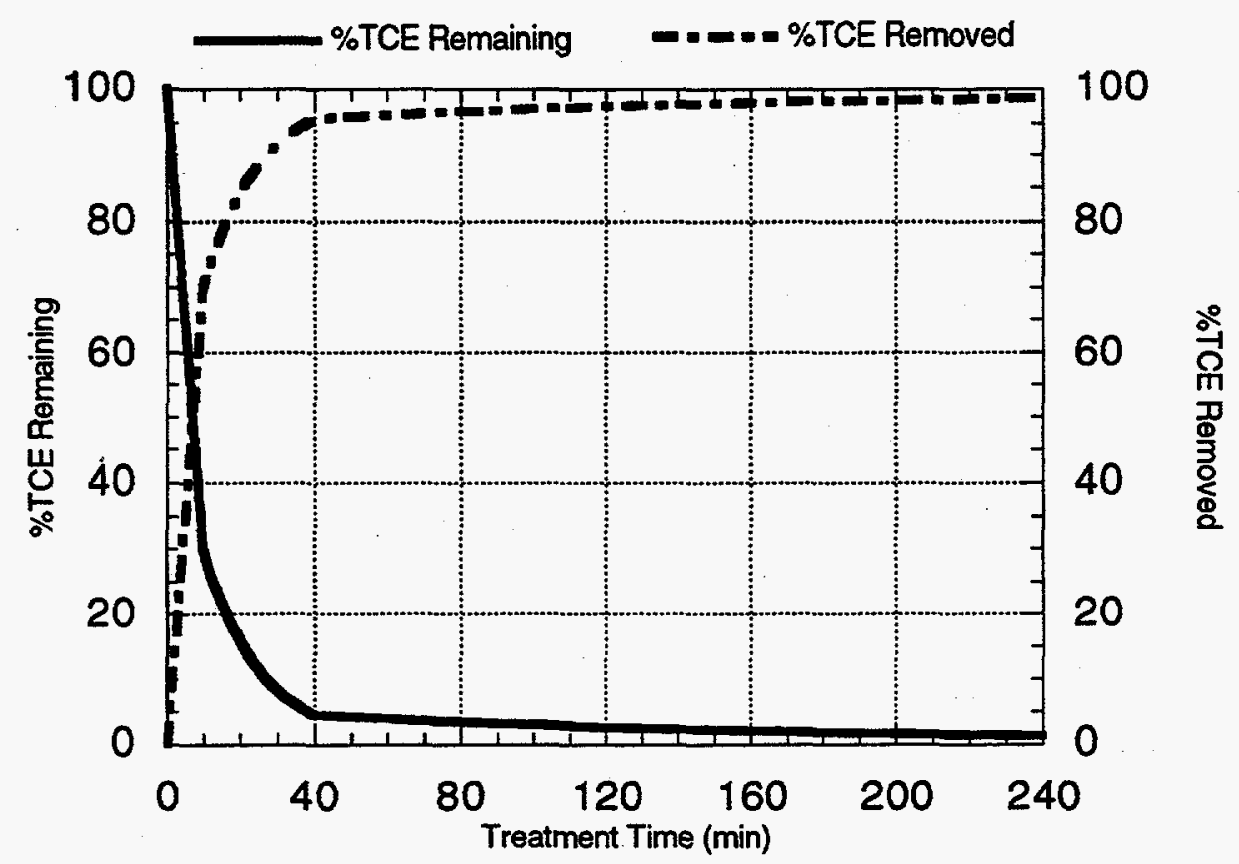

Fig. 10. Percent of trichloroethylene remaining and removed as a function of treatment time for chemically-enhanced mixed region vapor stripping. 


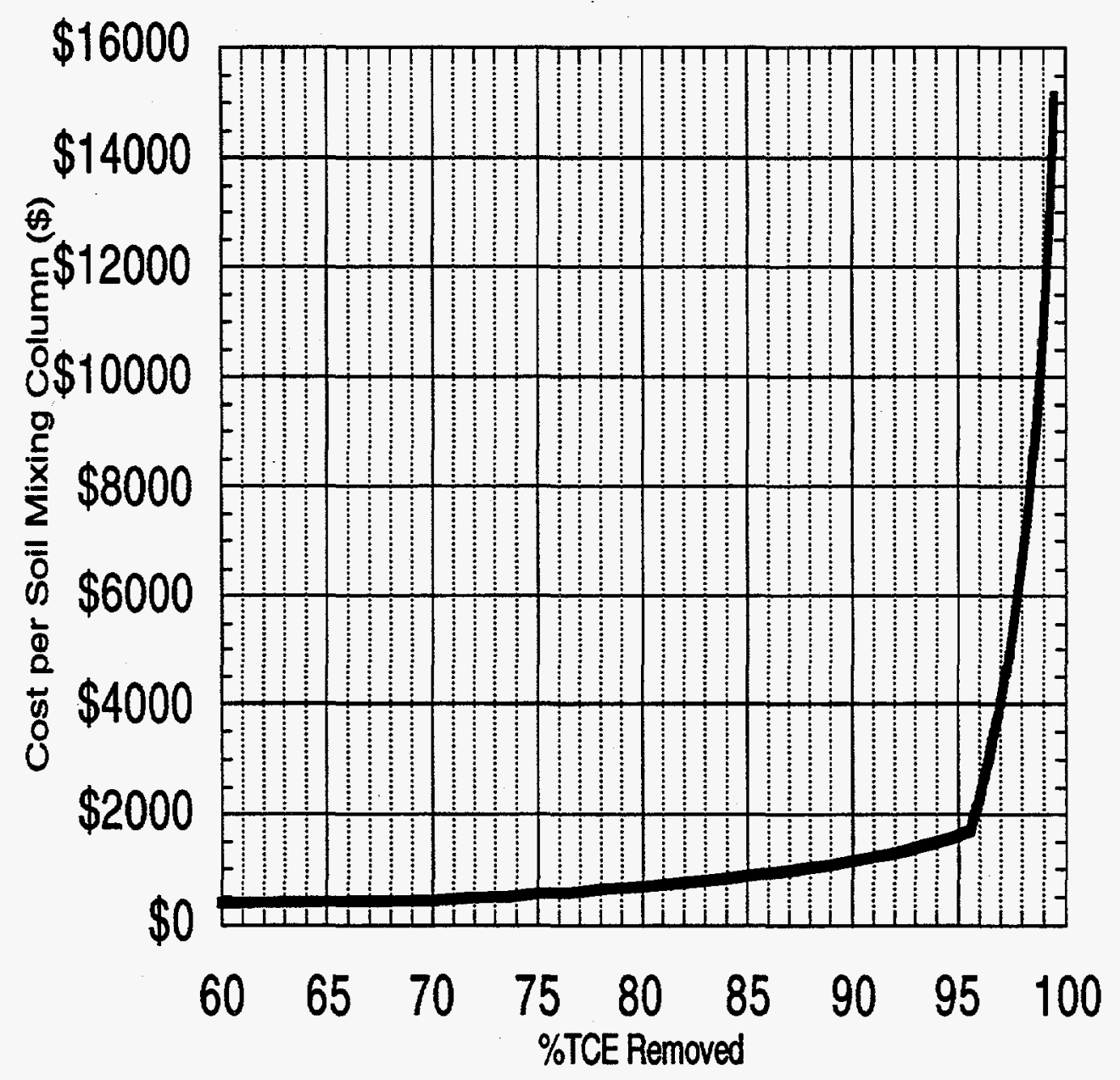

Fig. 11. Cost per soil column for chemically enhanced mixed region vapor stripping as a function of percentage trichloroethylene removed. (See text for assumptions)

The cost for remediating the entire Michoud Rinsewater Impoundment will depend on the treatment goals, which may take one of the following forms:

(1) a minimum percentage removal over a region of interest. Since removal rates appear to be independent of initial concentrations, this kind of treatment goal can be achieved by subjecting the entire region of interest to the same treatment time. The disadvantage of this approach is that regions with initially high contaminant levels may 
still have relatively elevated post-treatment levels. However, the overall effect of these "hot spots" to the environment may be minimal if the volume of these hot spots is small.

(2) a minimum percentage removal of total contaminant mass over a region of interest. This approach, which is similar to what was used at the full-scale cleanup of the $\mathrm{X}-231 \mathrm{~B}$ Unit, is equivalent to saying that the average contaminant concentration within the region of interest must be reduced by a minimum amount. This average may be decreased either by remediating the entire site for the same amount of time to achieve an overall percentage reduction [the same as no. (1)], or, remediation may be limited to the "hot spots." In the latter approach, more time may be spent remediating the hot spots, but the total amount of time spent would be the same or less than the time spent using approach no. (1). Estimating the time required to remediate a region of interest would require that the distribution of contaminants be known a priori.

(3) a target maximum residual concentration within the entire region of interest. As in no. (2), the required total treatment time would depend very strongly on the distribution of contamination within the region of interest.

The cost for treating a cubic yard of soil for specified target percentage removals (remediation goal no. (1) above) can be directly calculated from costs per soil column shown in Fig. 11 (Table 7).

Table 7. Cost per cubic yard of soil for chemically enhanced mixed region vapor stripping (MRVS) for given target percentage trichloroethylene (TCE) removals

\begin{tabular}{|c|c|c|c|c|c|}
\hline $\begin{array}{l}\text { Target } \\
\text { percentage } \\
\text { TCE } \\
\text { removal } \\
\text { (\%) }\end{array}$ & $\begin{array}{l}\text { Cost per soil } \\
\text { column for } \\
\text { operating soil } \\
\text { mixer }^{a}\end{array}$ & $\begin{array}{l}\text { Cost per cubic yard } \\
\text { of soil for } \\
\text { operating soil } \\
\text { mixer } b\end{array}$ & $\begin{array}{l}\text { Remediation cost } \\
\text { per cubic yard of } \\
\text { soilc }\end{array}$ & $\begin{array}{l}\text { Residual TCE } \\
\text { concentration } \\
\text { (mg/kg) } \\
\text { assuming } \\
\text { initial level of } \\
3000 \mathrm{mg} / \mathrm{kg}\end{array}$ & $\begin{array}{c}\text { Residual TCE } \\
\text { concentration } \\
\text { (mg/kg) } \\
\text { assuming } \\
\text { initial level of } \\
300 \mathrm{mg} / \mathrm{kg}\end{array}$ \\
\hline 90 & $\$ 1000$ & $\$ 36 / y^{3}{ }^{3}$ & $\$ 63 / y^{3}{ }^{3}$ & 300 & 30 \\
\hline 95 & $\$ 2000$ & $\$ 71 / y d^{3}$ & $\$ 98 / y^{3}{ }^{3}$ & 150 & 15 \\
\hline 99 & $\$ 12000$ & $\$ 429 / y^{3}{ }^{3}$ & $\$ 456 / y^{3}{ }^{3}$ & 30 & 3 \\
\hline
\end{tabular}

${ }^{a}$ Taken from Fig. 11 of this report.

${ }^{b}$ An 8-ft-diam, 15-ft-deep soil column has a volume of $28 \mathrm{yd}^{3}$.

$c^{c}$ Includes reagent cost $=\$ 27 / \mathrm{yd}^{3}$ assuming $\$ 80 /$ ton of $\mathrm{CaO}$

The cost for remediating the Michoud Rinsewater Impoundment given a specified target residual TCE concentration (approach no. (3)) was estimated from the removal curve in Fig. 10, and from contaminant contour maps derived from existing site 
characterization data [6,9]. A grid consisting of $30-\mathrm{ft}$ by $30-\mathrm{ft}$ squares (see Fig. 12) was overlaid on a map of the Michoud Rinsewater Impoundment. TCE concentrations at three depth ranges within each square sub-area were then read off of the contaminant contour maps (see Appendix $\mathrm{C}$ for contour maps), and the highest concentration was assumed to be the initial TCE concentration within the entire depth of the sub-area (see Fig. 12). Knowing the initial concentration for a square sub-area and the target residual concentration, the treatment time required for each square sub-area can be estimated from the removal curve in Fig. 10. The total treatment time required for remediation is the sum of the treatment times for all the square sub-areas. Total cost for the operation of the soil mixer can be calculated from this total treatment time, assuming that an 8-ft-diam soil mixer is used and that the cost for operating this mixer is $\$ 10,000$ per day. Costs for $\mathrm{CaO}$ can be calculated based on the amount of soil that requires treatment. This is then added to the total cost for soil mixer operation to arrive at a final estimate for remediation cost of the Michoud Rinsewater Impoundment as a function of the target residual TCE concentration (see Fig. 13, detailed calculations are contained in Appendix D of this report). The large increase with lower target residuals is due to longer treatment times as well as higher soil volumes that would require treatment. 


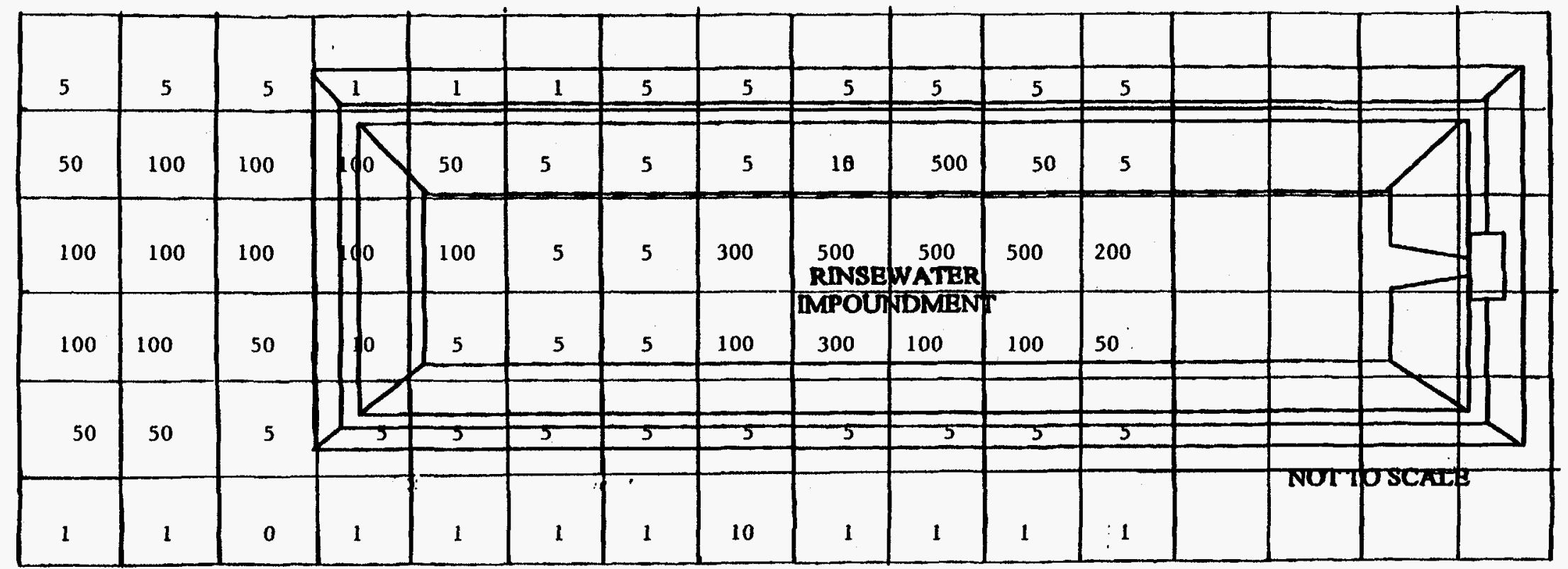

Fig. 12. Grid used to estimate required time and cost for remediating the Michoud Rinsewater Impoundment given a target residual trichloroethylene concentration. Square subareas are $30 \mathrm{ft} \times 30 \mathrm{ft}$. Numbers in squares are assumed initial trichloroethylene concentrations (in $\mathrm{mg} / \mathrm{kg}$ ) within each sub-area. 


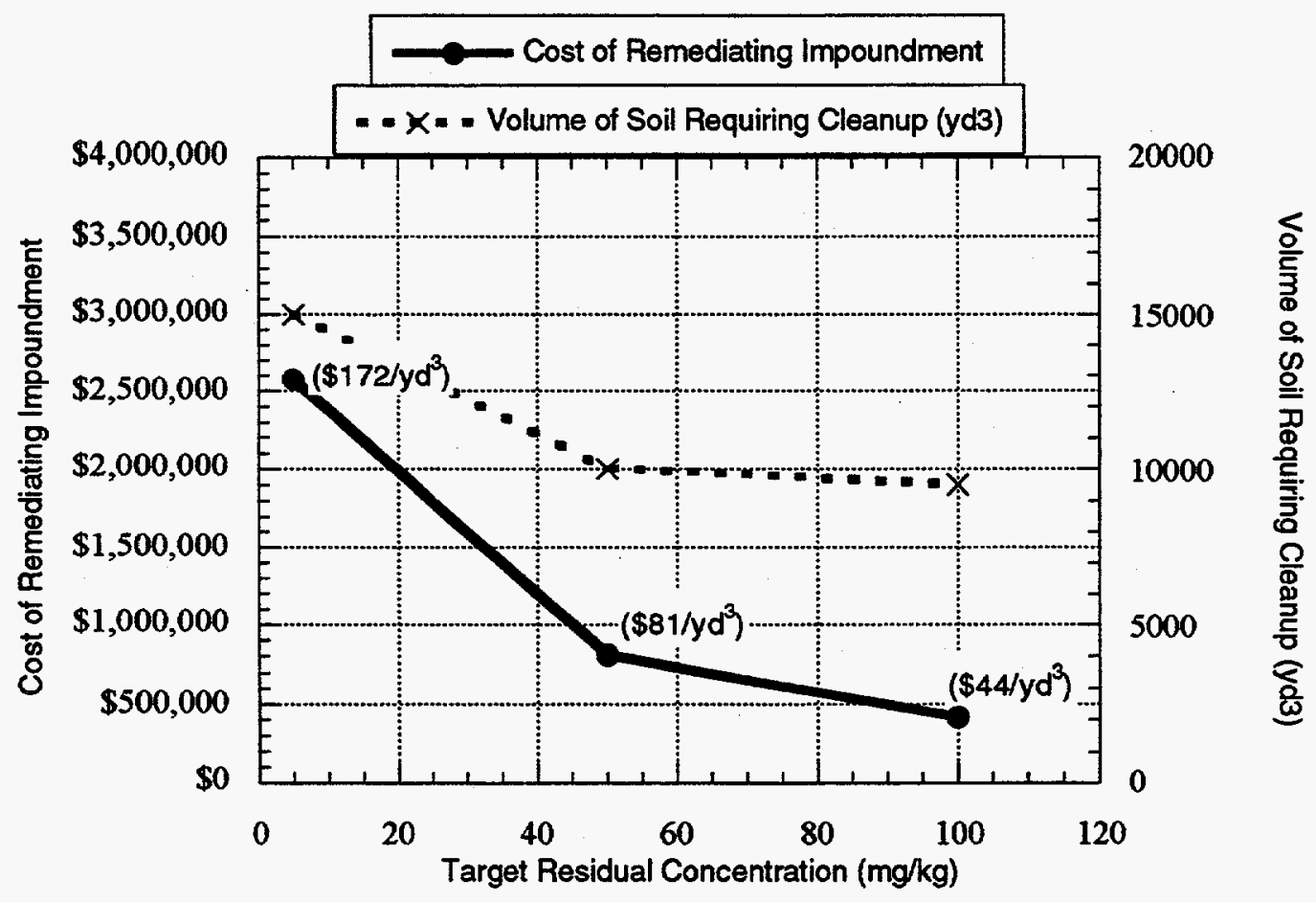

Fig. 13. Cost for remediating Michoud Rinsewater Impoundment vs target residual trichloroethylene concentrations. Effective remediation cost per cubic yard shown in parentheses. 


\subsection{COMPARISONS WITH ALTERNATIVE TECHNOLOGIES}

Tables 8 and 9 contain lists of alternative in situ and ex situ technologies, respectively, for remediating TCE-contaminated soils. The tables also include (1) a description of the treatment mechanism; (2) the status of each technology (bench-, pilot-, or full-scale); and (3) anticipated feasibility for remediating the highly organic, highly saturated soil underlying the Michoud Rinsewater Impoundment. Technologies that were unlikely to achieve remediation goals were given a "low" feasibility rating. "Medium" feasibility was assigned to technologies that are potentially applicable to the site. A "high" rating would have been given to technologies that have a high probability of achieving remediation goals, but because of uncertainties in treatment performance brought about by difficult in situ conditions (high moisture and organic soil content), none of the technologies listed in Tables 8 or 9 were given this rating.

Of the eight in situ technologies listed in Table 8, electroosmosis and 2-Phase extraction were considered to be potentially capable of overcoming the difficult soil conditions underlying the Michoud Rinsewater Impoundment. Both of these technologies are fairly new ( $<2$ years) and have not been tested under a wide variety of conditions. Hence, laboratory and/or field pilot tests at the Michoud Rinsewater Impoundment may have to be conducted to establish technical feasibility with a higher degree of certainty. Better estimates for costs associated with these technologies can also be obtained from pilot tests.

Information regarding the four ex situ technologies in Table 9 was found in the VISITT 4.0 database [11], a compilation of vendor information developed by the U.S. Environmental Protection Agency. For thermal desorption, some vendors listed in the VISITT 4.0 database state that moisture contents greater than $20-30 \%$ and high clay/silt content significantly reduce process throughput [11]. Thus, costs for treating the Michoud soil by thermal desorption are expected to be on the higher end of the $\$ 50$ $400 /$ ton range contained in the database. The reduced throughput is likely a result of the higher energy required to heat soils with a high water content, as well as difficulties in handling very wet soils. Soil dewatering before thermal desorption is possible but would also add to treatment cost. Solvent extraction is an alternative to thermal desorption, with costs listed in database ranging from $\$ 100-400 /$ ton. One of the vendors states that costs increase with moisture contents $>70 \%$; this cost increase may occur in the remediation of 
Michoud soils which have moisture contents as high as $500 \%$ (see Fig. 11). Chemical oxidation by Fenton's reagent was offered by one vendor in the database. This vendor mentioned that reaction rates may be significantly reduced if soils have a high clay content, which is also true for the Michoud soils.

Table 8. In situ technologies for remediating trichloroethylene (TCE)-contaminated soils

\begin{tabular}{|c|c|c|c|}
\hline Technology & $\begin{array}{l}\text { Technology description and } \\
\text { treatment mechanism }\end{array}$ & $\begin{array}{l}\text { Technology } \\
\text { status }\end{array}$ & $\begin{array}{l}\text { Feasibility at Rinsewater } \\
\text { Impoundment } \\
\text { (low, medium, high) }\end{array}$ \\
\hline $\begin{array}{l}\text { Mixed region chemical } \\
\text { oxidation }[6,10]\end{array}$ & $\begin{array}{l}\text { TCE degraded by strong oxidizers } \\
\left(\mathrm{KMnO}_{4} \text { or } \mathrm{H}_{2} \mathrm{O}_{2}\right) \text {. }\end{array}$ & $\begin{array}{l}\text { Full-scale for } \\
\mathrm{H}_{2} \mathrm{O}_{2} \\
\text { Bench-scale for } \\
\mathrm{KMnO}_{4}\end{array}$ & $\begin{array}{l}\text { (Low to Medium) } \\
\text { Natural soil organics will compete } \\
\text { with TCE for oxidants; larger } \\
\text { amounts of oxidants may be } \\
\text { needed. }\end{array}$ \\
\hline $\begin{array}{l}\text { Mixed region reductive } \\
\text { dechlorination by iron } \\
\text { filings } \\
{[6]}\end{array}$ & $\begin{array}{l}\text { TCE dechlorinated by zero-valence } \\
\text { iron. }\end{array}$ & $\begin{array}{l}\text { Preliminary } \\
\text { bench-scale }\end{array}$ & $\begin{array}{l}\text { Technology has not been explored } \\
\text { sufficiently) } \\
\text { Incomplete dechlorination produces } \\
\text { vinyl chloride, which is more toxic } \\
\text { than TCE. }\end{array}$ \\
\hline $\begin{array}{l}\text { Mixed region } \\
\text { bioremediation } \\
[1]]\end{array}$ & $\begin{array}{l}\text { TCE aerobically or anaerobically } \\
\text { degraded either by indigenous or } \\
\text { engineered microorganisms. }\end{array}$ & $\begin{array}{l}\text { Bench- to full- } \\
\text { scale }\end{array}$ & $\begin{array}{l}\text { (Low) } \\
\text { Extremely high levels of TCE may } \\
\text { be toxic to degrading organisms. }\end{array}$ \\
\hline $\begin{array}{l}\text { Mixed region steam } \\
\text { stripping } \\
{[11]}\end{array}$ & $\begin{array}{l}\text { TCE volatilized by increasing soil } \\
\text { temperature through steam injection }\end{array}$ & Full-scale & $\begin{array}{l}\text { (Low) } \\
\text { High soil moisture content will } \\
\text { require large amounts of energy } \\
\text { (i.e., steam) to increase soil } \\
\text { temperature. Condensed steam will } \\
\text { add water to a soil that already has } \\
\text { a very high moisture content. }\end{array}$ \\
\hline $\begin{array}{l}\text { Soil vacuum extraction } \\
\text { (SVE) enhanced by } \\
\text { hydraulic or pneumatic } \\
\text { fracturing } \\
{[11]}\end{array}$ & $\begin{array}{l}\text { TCE volatilized by SVE; } \\
\text { low-permeability formations are } \\
\text { fractured hydraulically or } \\
\text { pneumatically to increase air } \\
\text { conductivities. }\end{array}$ & Full-scale & $\begin{array}{l}\text { (Low) } \\
\text { Due to high-plasticity and moisture } \\
\text { content, soils are not likely to } \\
\text { fracture. Hydraulic or pneumatic } \\
\text { pressures used to induce borehole } \\
\text { fracturing would probably result in } \\
\text { plastic deformations around the } \\
\text { borehole instead. }\end{array}$ \\
\hline $\begin{array}{l}\text { Soil vacuum extraction } \\
\text { (SVE) enhanced by AC- } \\
\text { or radio-frequency } \\
\text { heating } \\
{[11,12]}\end{array}$ & $\begin{array}{l}\text { TCE volatilized by SVE; soil is } \\
\text { heated to increase fugacity of TCE. }\end{array}$ & Full-scale & $\begin{array}{l}\text { (Low) } \\
\text { The heat capacity of water is } \sim 5 \\
\text { times the heat capacity of dry soil } \\
\text { particles [13], therefore, large } \\
\text { amounts of energy will be required } \\
\text { to heat high-moisture content soil. }\end{array}$ \\
\hline
\end{tabular}


Table 8. (continued)

\begin{tabular}{|c|c|c|c|}
\hline Technology & $\begin{array}{l}\text { Technology description and } \\
\text { treatment mechanism }\end{array}$ & $\begin{array}{l}\text { Technology } \\
\text { status }\end{array}$ & $\begin{array}{l}\text { Feasibility at Rinsewater } \\
\text { Impoundment } \\
\text { (low, medium, high) }\end{array}$ \\
\hline $\begin{array}{l}\text { Electroosmosis: } \\
\text { "Lasagna" process } \\
\text { [14] }\end{array}$ & $\begin{array}{l}\text { Electrokinetics used to induce } \\
\text { migration of water/TCE through } \\
\text { trapping (carbon adsorption) or } \\
\text { degradation (zero-valence iron) } \\
\text { barriers. }\end{array}$ & $\begin{array}{l}\text { Pilot-scale } \\
\end{array}$ & $\begin{array}{l}\text { (Medium) } \\
\text { This technology has been pilot- } \\
\text { tested recently but data are currently } \\
\text { unavailable. Since treatment is at } \\
\text { ambient temperature, treatment time } \\
\text { may be lengthy as a result of the } \\
\text { high organic content of the soil. }\end{array}$ \\
\hline $\begin{array}{l}\text { 2-Phase Extraction } \\
\text { [15] }\end{array}$ & $\begin{array}{l}\text { TCE volatilized by high-vacuum } \\
\text { pumps (as much as } 28 \text {-in. } \mathrm{Hg} \text {, } \\
\text { which draw soil water and vapor } \\
\text { from low-permeability soils }\end{array}$ & Full-scale & $\begin{array}{l}\text { (Medium) } \\
\text { Soil appears to have a high water- } \\
\text { holding capacity so dewatering may } \\
\text { be difficult even at high vacuums. } \\
\text { Since treatment is at ambient } \\
\text { temperature, treatment time may be } \\
\text { lengthy as a result of the high } \\
\text { organic content of the soil. }\end{array}$ \\
\hline
\end{tabular}


Table 9. Ex situ technologies for remediating trichloroethylene-contaminated soils

\begin{tabular}{|c|c|c|c|}
\hline Technology & Treatment mechanism & $\begin{array}{l}\text { Technology } \\
\text { status }\end{array}$ & $\begin{array}{l}\text { Feasibility at Rinsewater } \\
\text { Impoundment } \\
\text { (low, medium, high) }\end{array}$ \\
\hline Thermal desorption [11] & $\begin{array}{l}\text { TCE volatilized from soil, which is } \\
\text { heated in rotary kilns to temperature } \\
\text { above boiling point of } \\
\text { contaminants. }\end{array}$ & Full-scale & $\begin{array}{l}\text { Low to Medium) } \\
\text { Some thermal desorption units can } \\
\text { only handle soils with moisture } \\
\text { contents }<20-30 \% \text { so that soil must } \\
\text { be dewatered prior to treatment. } \\
\text { For undewatered soils, energy } \\
\text { requirements will be high to heat } \\
\text { soil to desired temperatures. }\end{array}$ \\
\hline Chemical oxidation $[I I]$ & $\begin{array}{l}\text { TCE degraded by strong oxidizers } \\
\left(\mathrm{H}_{2} \mathrm{O}_{2}\right) \text {. }\end{array}$ & $\begin{array}{l}\text { Full-scale for } \\
\mathrm{H}_{2} \mathrm{O}_{2}\end{array}$ & $\begin{array}{l}\text { (Low to Medium) } \\
\text { Natural soil organics will compete } \\
\text { with TCE for oxidants; larger } \\
\text { amounts of oxidants may be } \\
\text { needed. }\end{array}$ \\
\hline $\begin{array}{l}\text { Solvent extraction } \\
\text { [1I] }\end{array}$ & $\begin{array}{l}\text { TCE is extracted from the soil by } \\
\text { liquefied gas solvents. }\end{array}$ & Full-scale & $\begin{array}{l}\text { (Low to Medium) } \\
\text { One vendor claims it can be used } \\
\text { for sludge. Another vendor states } \\
\text { that costs become high with } \\
\text { moisture contents }>70 \% \text {. Mostly } \\
\text { used for semi-volatile organics, } \\
\text { probably due to cost. }\end{array}$ \\
\hline $\begin{array}{l}\text { Biodegradation } \\
[1]]\end{array}$ & $\begin{array}{l}\text { TCE is biodegraded by indigenous } \\
\text { or non-native bacteria. }\end{array}$ & Full-scale & $\begin{array}{l}\text { (Low) } \\
\text { High levels of TCE may be toxic to } \\
\text { bacteria. TCE degradation rates } \\
\text { may not be rapid enough to achieve } \\
\text { high soil throughput. }\end{array}$ \\
\hline
\end{tabular}

Based on the rough-order-of-magnitude estimates given in the previous section, chemically enhanced MRVS compares favorably with the ex situ methods listed in Table 9 if remediation goals are set to $95 \%$ removal. The estimated cost for chemically enhanced MRVS is $\sim \$ 100 /$ ton ( 1 ton is $\sim 1$ cu.yd. of soil) This is lower than costs for the ex situ methods given in Table 9 , which may range from $\$ 200$ to $\$ 400 /$ ton given the high moisture and clay content of the Michoud soil.

Comparing chemically enhanced MRVS with electroosmosis and 2-Phase extraction is more difficult because of the lack of data from applications of the latter technologies at other sites. TCE removal with chemically enhanced MRVS may be more rapid since temperatures are elevated and moisture contents are reduced, both due to the hydration reaction of $\mathrm{CaO}$. However, without testing equivalent to the experiments described in this report, saying with certainty that chemically enhanced MRVS would 
achieve remediation goals faster and at a lower cost than electroosmosis or 2-Phase vacuum extraction is not feasible at this point. 



\section{CONCLUSIONS AND RECOMMENDATIONS}

Chemically enhanced mixed region vapor stripping is a viable technology for in situ remediation of TCE-contaminated soils underlying the Michoud Rinsewater Impoundment. This conclusion is based on laboratory simulations of MRVS performed on 16 field-contaminated cores collected from the study site. Residual levels of predominant VOCs (TCE and cis-1,2-DCE) measured as a function of treatment time showed that TCE and cis-1,2-DCE removals were very rapid in the first 60 minutes after the cores were amended with a sufficient amount of $\mathrm{CaO}$. Removal rates were significantly lower when vapor stripping was continued beyond 60 minutes. A TCE removal curve (percent TCE removed as a function of treatment time) was developed by averaging the removal curves obtained from the MRVS tests. Based on this curve, it is estimated that $\sim 30$ and $\sim 300$ minutes of treatment is needed to remove $90 \%$ and $99 \%$ of initial TCE contamination. For example, starting with an initial concentration of 3000 $\mathrm{mg} / \mathrm{kg}$, only 30 minutes of chemically enhanced MRVS is required to achieve a target residual of $300 \mathrm{mg} / \mathrm{kg}$. The same amount of time would be needed to go from 300 to 30 $\mathrm{mg} / \mathrm{kg}$ of contamination. However, a significantly longer time (300 minutes) would be required to achieve a residual level of $30 \mathrm{mg} / \mathrm{kg}$ if the initial contaminant level were 3000 $\mathrm{mg} / \mathrm{kg}$. This substantial increase in treatment time when remediation goals for TCE increase beyond $95 \%$ is a reflection of the bi-phasic removal patterns observed in the MRVS tests (i.e., rapid followed by slower TCE removal beyond 60 minutes of treatment). Rapid removals were accompanied by increased soil temperatures ranging from $40^{\circ} \mathrm{C}$ to $75^{\circ} \mathrm{C}$. The more gradual removals observed beyond 60 min of treatment may be a result of temperatures returning to ambient levels, as well as increased sorption on drier soils.

The amount of $\mathrm{CaO}$ required to achieve high removal rates was found to be dependent on the initial moisture content of the soil; a $400-500 \mathrm{~kg} / \mathrm{m}^{3} \mathrm{CaO}$ loading is expected to be sufficient for the Michoud soils, which have moisture contents ranging from 26 to $534 \%$ dry weight. This high $\mathrm{CaO}$ loading is needed to dehydrate the soil sufficiently and to achieve temperature increases necessary for rapid TCE removal. Some concerns exist regarding the volumetric expansion of the soil when this much $\mathrm{CaO}$ is added in situ. However, this may not occur due to the unconsolidated nature and low density of the contaminated soil under the Michoud Rinsewater Impoundment. This concern can be best addressed through a field test. 
Chemically enhanced MRVS was estimated to cost $\sim \$ 100 /$ ton for a remediation goal of $95 \%$ TCE removal. This is lower than anticipated costs for ex situ methods (e.g., excavation followed by on-site treatment), which are potentially more costly than normal to implement due to the extremely high moisture content of the Michoud soils. Two other technologies were identified as having the potential for remediating the highly saturated, low-permeability soils underlying the Rinsewater Impoundment. These technologies, electroosmosis and 2-Phase extraction, are fairly new and have not been applied to a wide variety of sites. Specific performance and cost data for remediating the Rinsewater Impoundment using these methods can only be obtained if laboratory and/or field tests are conducted.

On the issue of addressing existing contamination at the Michoud Rinsewater Impoundment, we recommend the following:

(1) Vendors that can provide soil mixing and calcium oxide delivery should be contacted to obtain more accurate cost estimates for chemically enhanced MRVS on the basis of the removal curve generated from this work. Once better cost estimates for this technology are established, NASA Michoud can make a decision on whether the technology should be field tested.

(2) Field testing of chemically enhanced MRVS can be provided by ORNL. ORNL can design the field experiment, hire and supervise a contractor to conduct soil mixing and $\mathrm{CaO}$ delivery, and collect samples for performance assessment. The scope of this field test can be adjusted to accommodate NASA Michoud's budget constraints. Alternatively, NASA Michoud can hire a soil-mixing vendor who would be willing to work with ORNL staff to develop process parameters in the field. In the latter case, ORNL can assist NASA Michoud in evaluating the field performance of the technology. The possibility of continuing the full-scale cleanup should be considered when contracting the services of the soil mixing vendor in case the field test is successful. This way, mobilization and demobilization costs would not have to incurred twice like they would be if the full-scale cleanup were not done immediately after field testing.

(3) Vendors who provide 2-Phase extraction and electroosmosis services should be contacted to explore the possibilities of field testing these technologies. Some of these 
vendors may be willing to provide order-of-magnitude estimates given some information regarding the Michoud site. 



\section{REFERENCES}

[1] West, O. R., R. L. Siegrist, J. S. Gierke, S. W. Schmunk, A. J. Lucero, and H. L. Jennings. 1995. In situ mixed region vapor stripping in low permeability media: 1. Process features and laboratory experiments. Environ. Sci. Technol. 29:21912197.

[2] Siegrist, R. L., O. R. West, M. I. Morris, D. A. Pickering, D. W. Greene, C. A. Muhr, D. T. Davenport, and J. S. Gierke, . 1995. Environ Sci. Technol. 29:21982207.

[3] Gierke, J. S., C. Wang, O. R. West, and R. L. Siegrist. 1995. In situ mixed region vapor stripping in low-permeability media. 3. Modeling of field tests. Environ. Sci. Technol. 29:2208-2216.

[4] West, O. R.; James, B. R.; Bayne, C. K.; Siegrist, R. L. 1994. Performance verification in soil mixing and vapor stripping of VOC contaminated soils. pp. 497-499. In D. W. Tedder (ed.), Emerging Technologies in Hazardous Waste Management VI. American Chemical Society, Washington, D. C.

[5] $\mathrm{CH}^{2} \mathrm{M}$ Hill Southeast, Inc. 1989. Field investigation and contaminant assessment, rinsewater impoundment and appurtenant structures, NASA Michoud Assembly Facility. Prepared for Martin Marietta Manned Space Systems, Facilities Engineering Department.

[6] Lucero, A. J., Gilbert, V. P.; Hewitt, J. D.; Koran, L. J. Jr; Jennings, H. L.; Donaldson, T. L.; West, O. R.; Cline, S. R.; Marshall, D. S. 1995. Treatability of TCE-contaminated clay soils at the rinsewater impoundment, Michoud Assembly Facility. ORNL/TM-12931. Oak Ridge National Laboratory.

[7] Martin Marietta Manned Space Systems. 1995. Statement of Work, IDOD No. 3100-94-001M, rev. C.

[8] Ong, S. K. and L. W. Lion. 1991. Mechanisms for trichloroethylene vapor sorption onto soil minerals. J.Environ. Qual. 20:180-188.

[9] $\mathrm{CH}^{2} \mathrm{M}$ Hill Southeast, Inc. 1990. Supplemental closure investigation: Field investigation and contaminant assessment, rinsewater impoundment and appurtenant structures, NASA Michoud Assembly Facility. Prepared for Martin Marietta Manned Space Systems, Facilities Engineering Department. 
[10] Gates, D. D., Siegrist, R. L. 1993. X-231B technology demonstration for in situ treatment of contaminated soils: Laboratory evaluation of chemical oxidation using hydrogen peroxide. ORNL/TM-12259. Oak Ridge National Laboratory.

[11] U. S. Environmental Protection Agency Office of Solid Waste and Emergency Response. 1994. VISITT 4.0 database.

[12] Siegrist, R. L., Morris, M. I., Donaldson, T. L., Palumbo, A. V., Herbes, S. E., Jenkins, R. A., Morrissey, C. M., Harris, M. T. 1993. X-231B technology demonstration for in situ treatment of contaminated soils: Technology evaluation and screening. ORNL/TM-12257. Oak Ridge National Laboratory.

[13] Foth, H. D. 1978. Fundamentals of Soil Science. 6th ed. John Wiley and Sons, New York.

[14] Ho, S. V. and P. H. Brodsky. 1994. Integrated in situ technology for soil remediation -- The lasagna process. In D. W. Tedder (ed.), Emerging Technologies in Hazardous Waste Management VI. American Chemical Society, Washington, D. C.

[15] Duffney, E. N., Gayle, B. P., Narkunas, J., and Siegfried, J. E. 1994. Accelerated environmental remediation by the 2-PHASE extraction process, Case study: Xerox CRC Facility. Xerox Corporation, Atlanta, GA. 
APPENDIX A.

RESIDUAL TRICHLOROETHYLENE VS VAPOR STRIPPING TIME 
• 


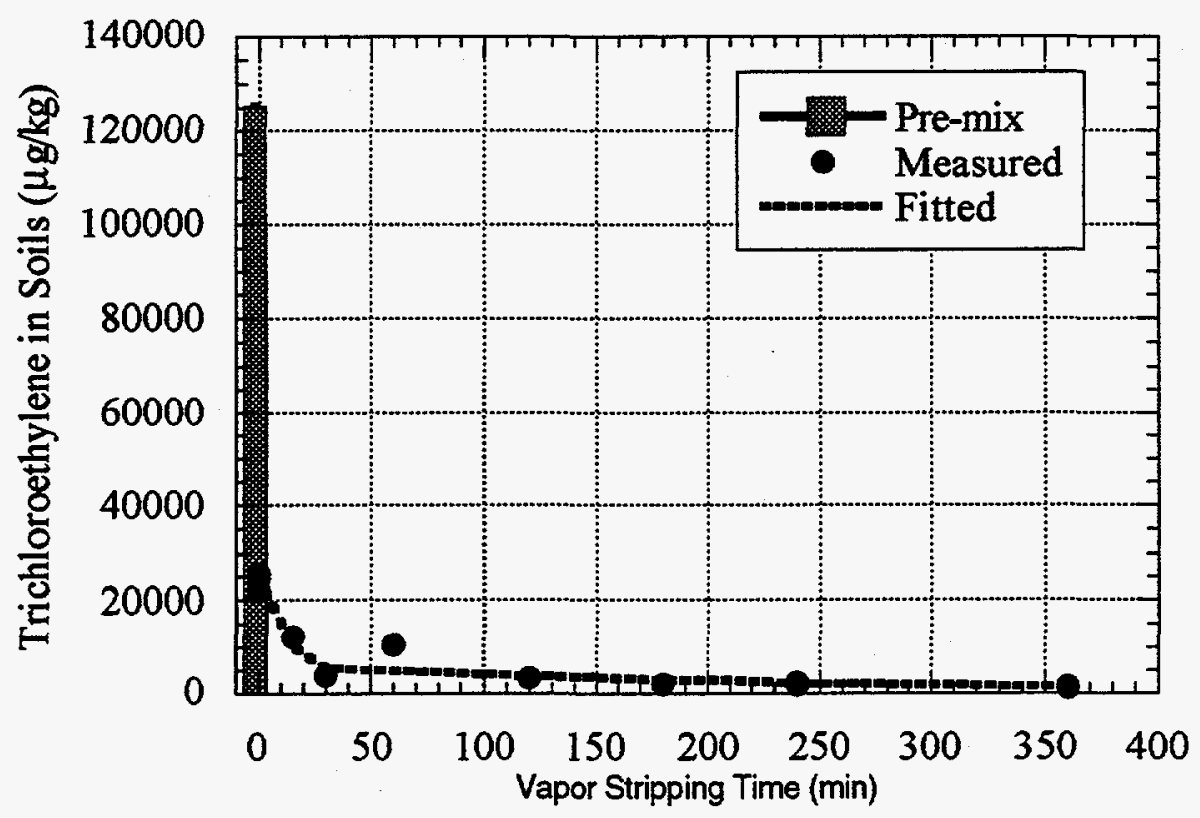

(a)

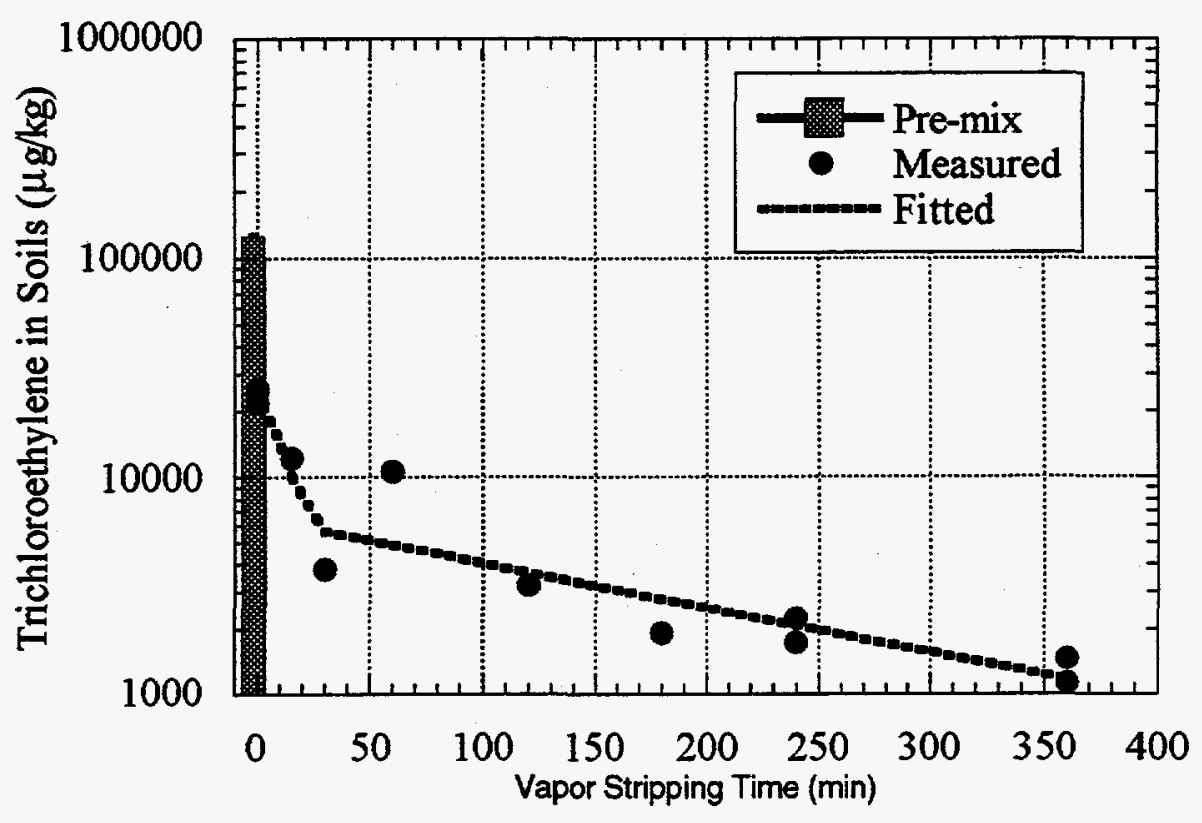

(b)

Fig. A.1. Residual trichloroethylene (TCE) in soil vs vapor stripping time in core B9,8.59.0; (a) TCE plotted on a normal scale, (b) TCE plotted on a log scale. 


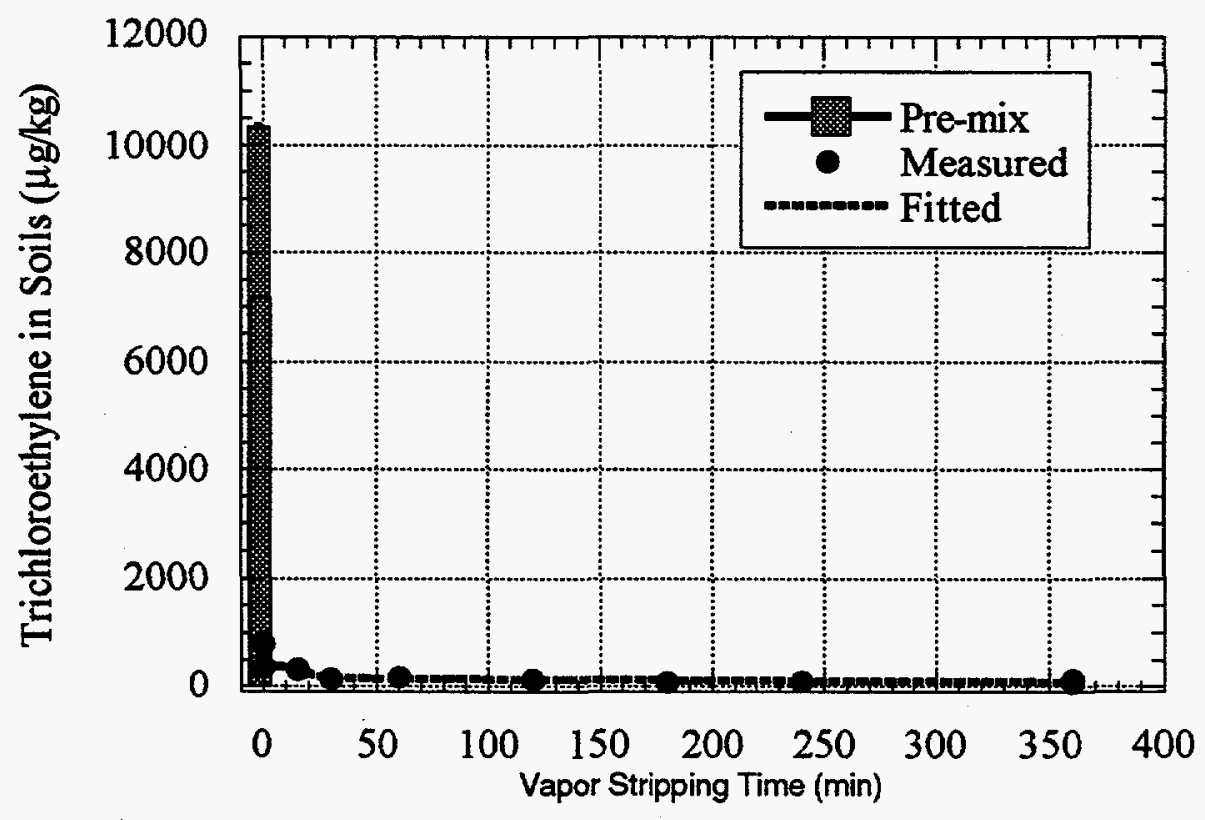

(a)

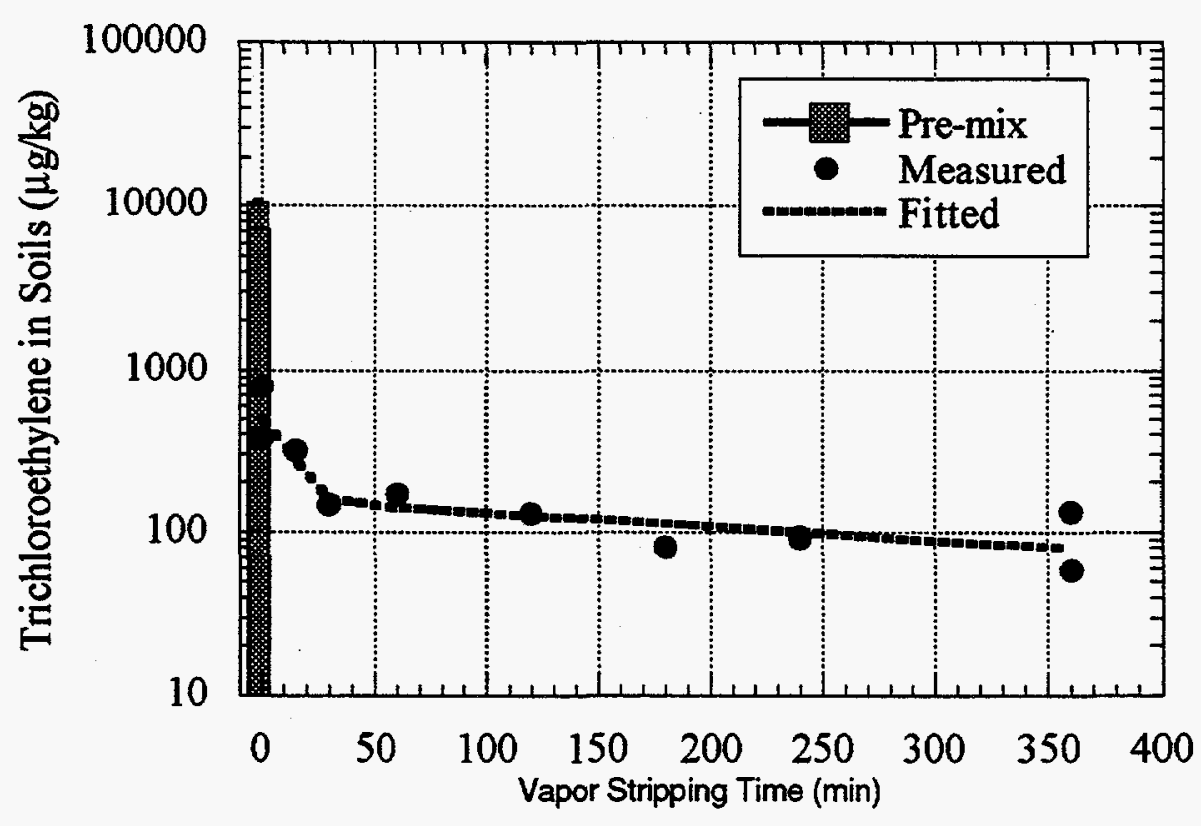

(b)

Fig. A.2. Residual trichloroethylene (TCE) in soil vs vapor stripping time in core B9, 9.0-9.5; (a) TCE plotted on a normal scale, (b) TCE plotted on a log scale. 


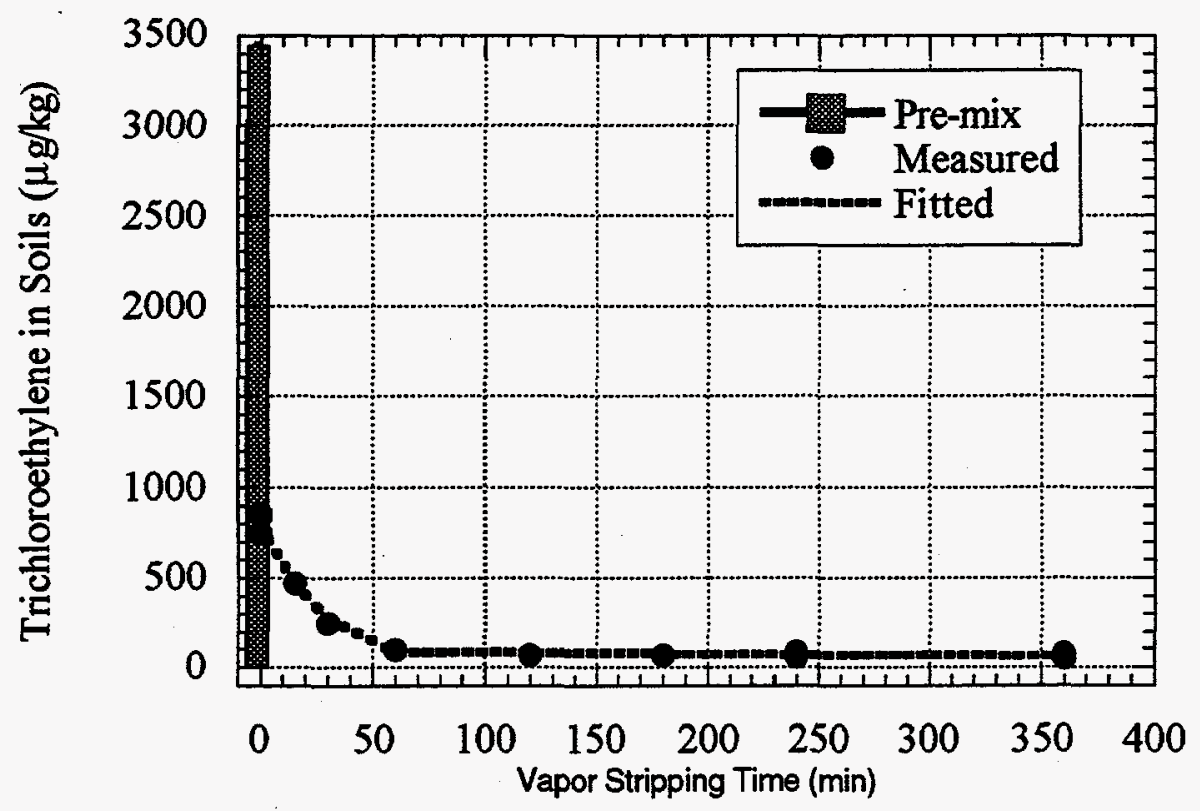

(a)

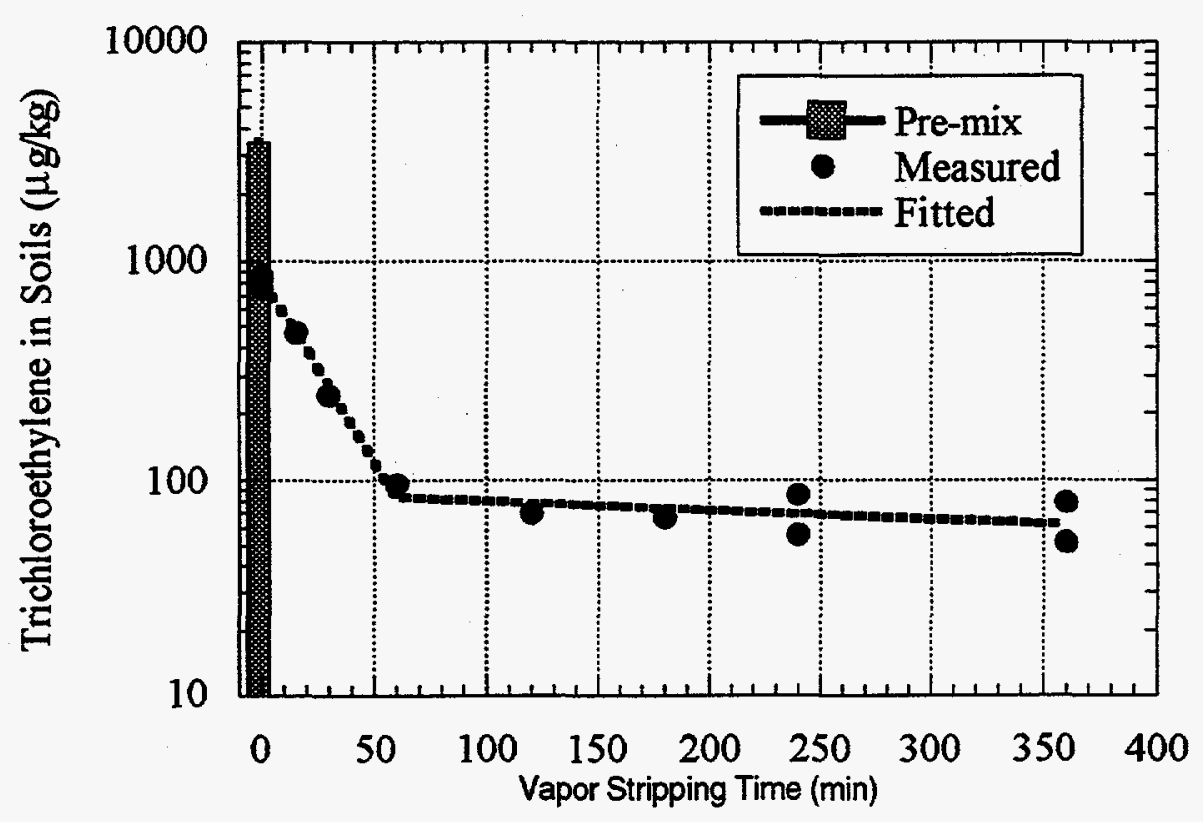

(b)

Fig. A.3. Residual trichloroethylene (TCE) in soil vs vapor stripping time in core B9,9.510.0; (a) TCE plotted on a normal scale, (b) TCE plotted on a log scale. 

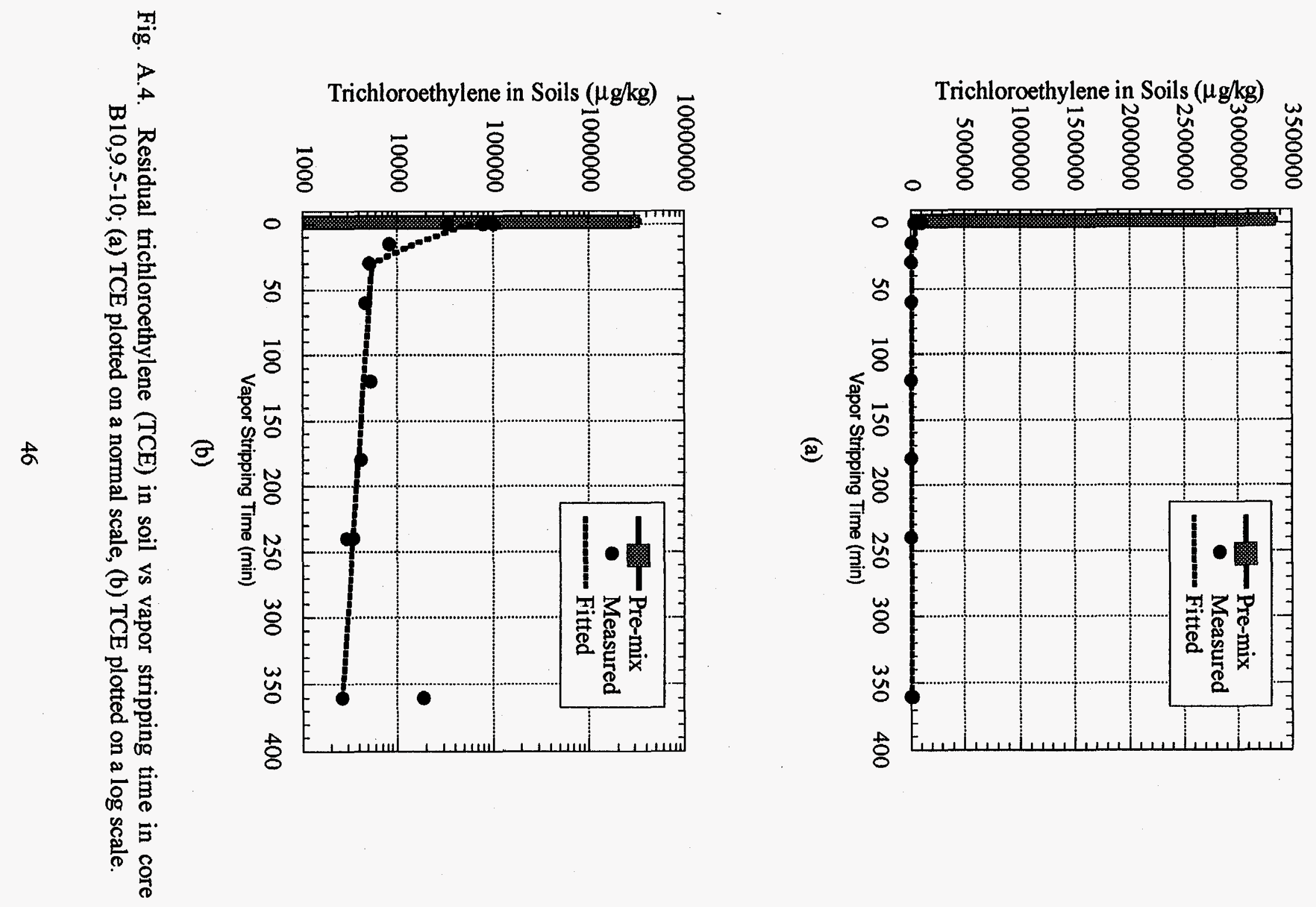


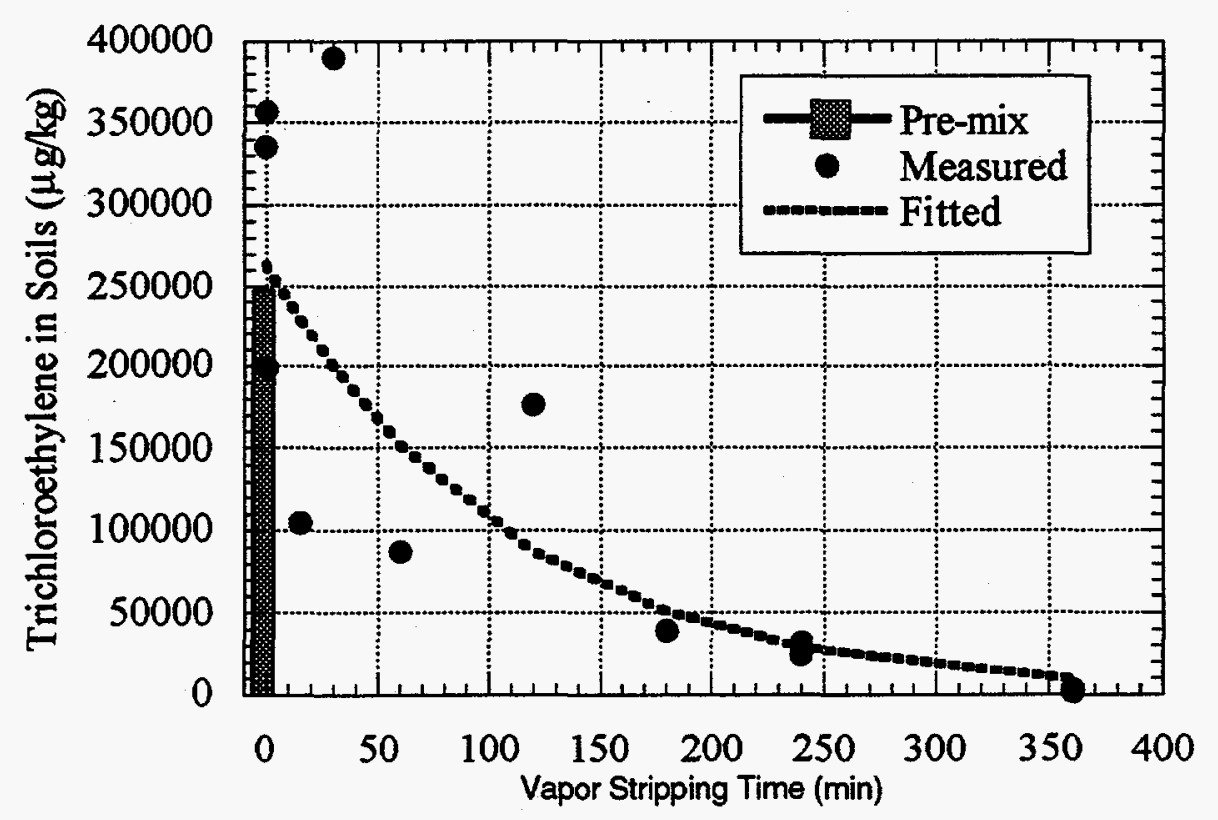

(a)

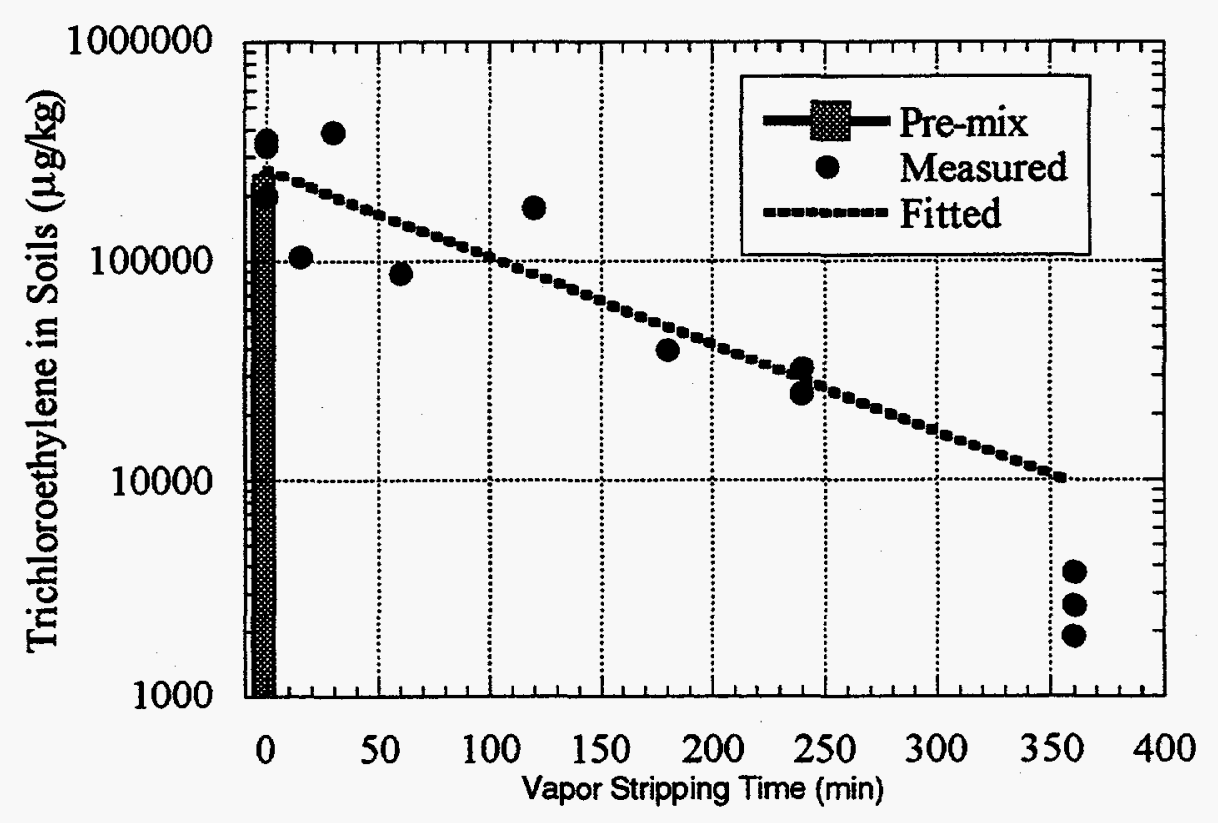

(b)

Fig. A.5. Residual trichloroethylene (TCE) in soil vs vapor stripping time in core B10,10.0-10.5; (a) TCE plotted on a normal scale, (b) TCE plotted on a log scale. 


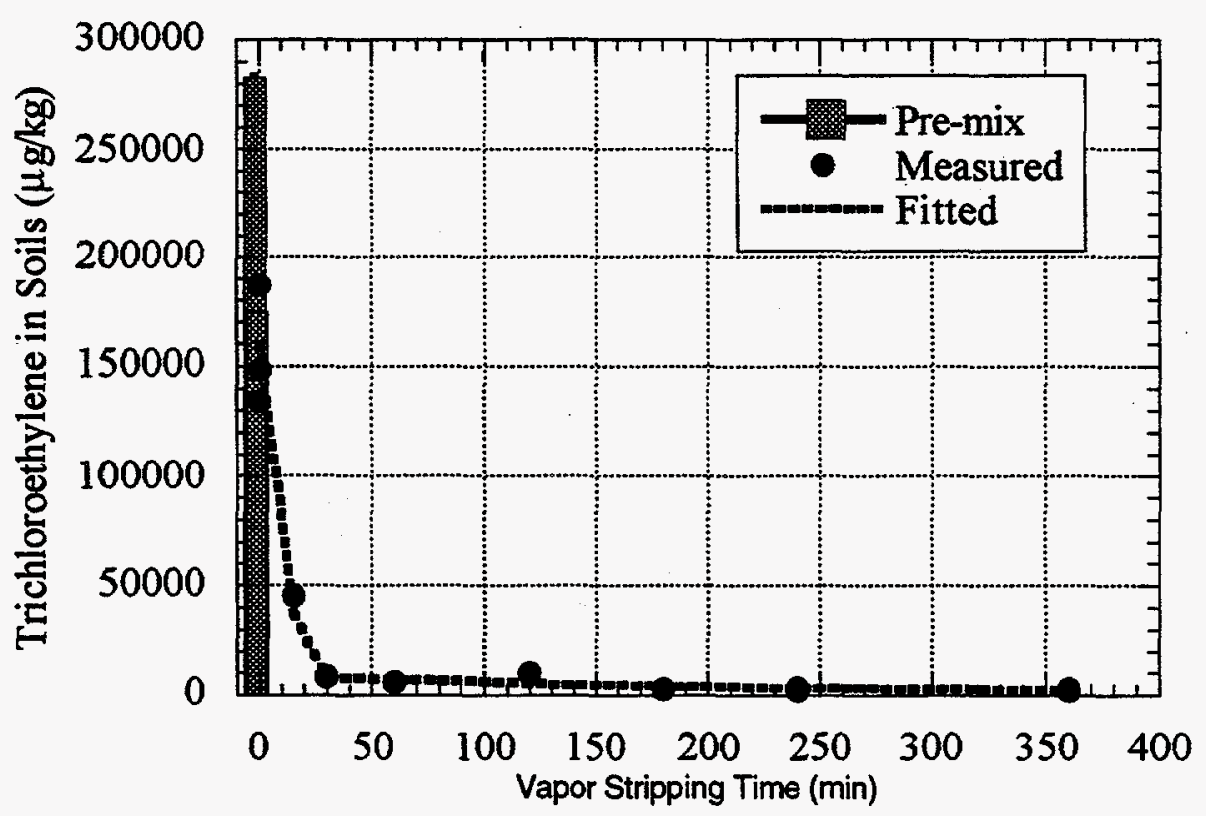

(a)

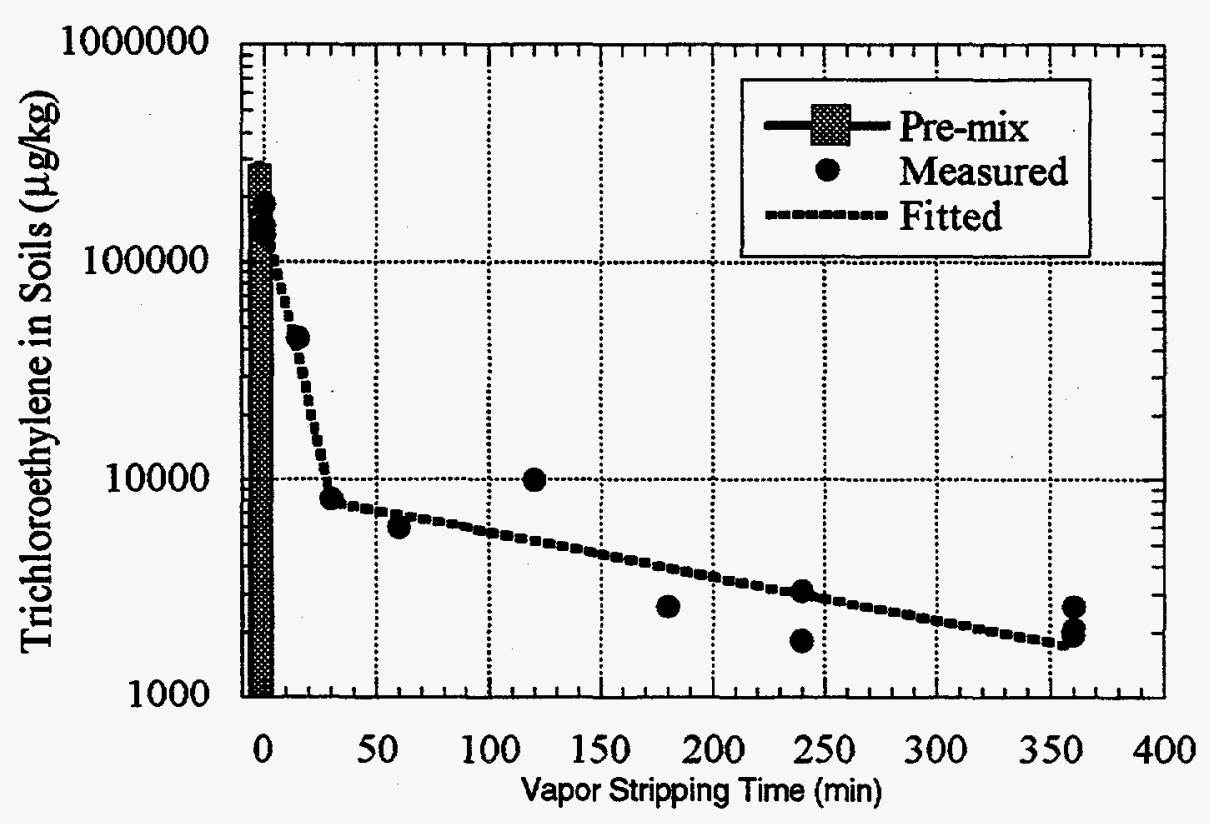

(b)

Fig. A.6. Residual trichloroethylene (TCE) in soil vs vapor stripping time in core B10,10.5-11.0; (a) TCE plotted on a normal scale, (b) TCE plotted on a log scale. 


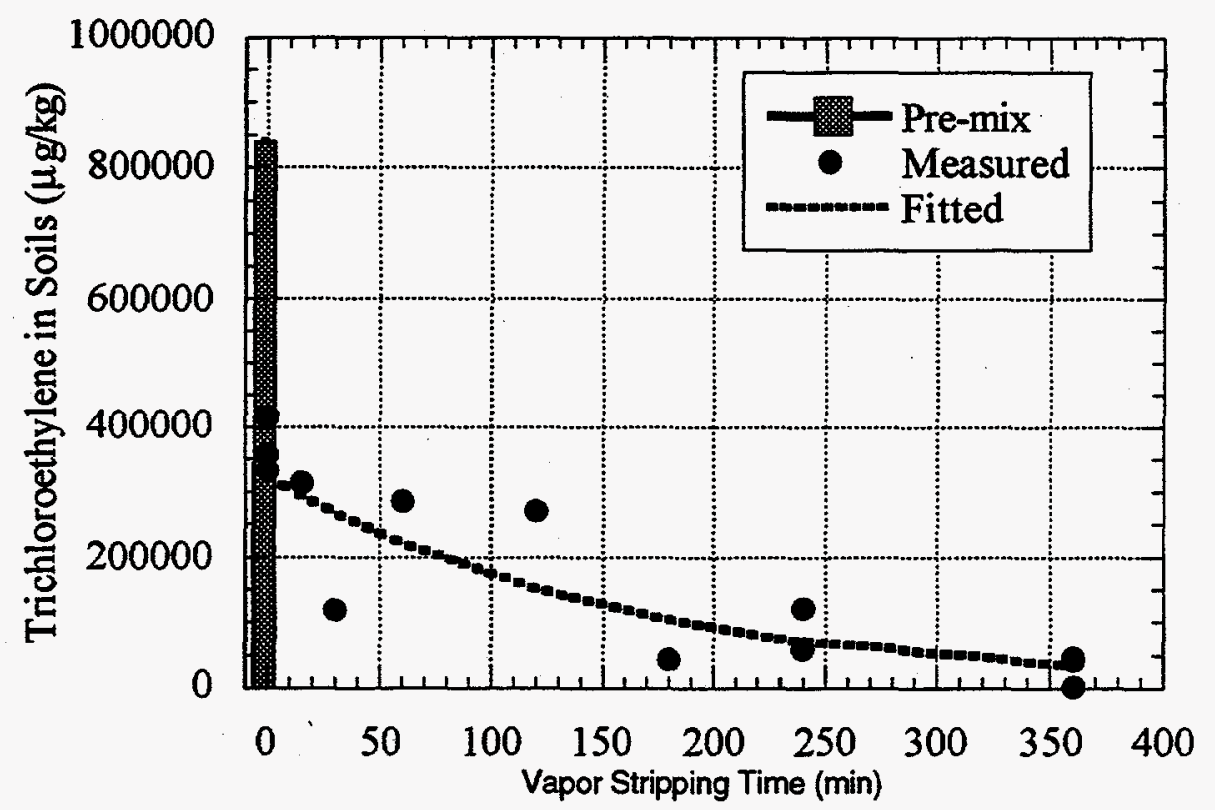

(a)

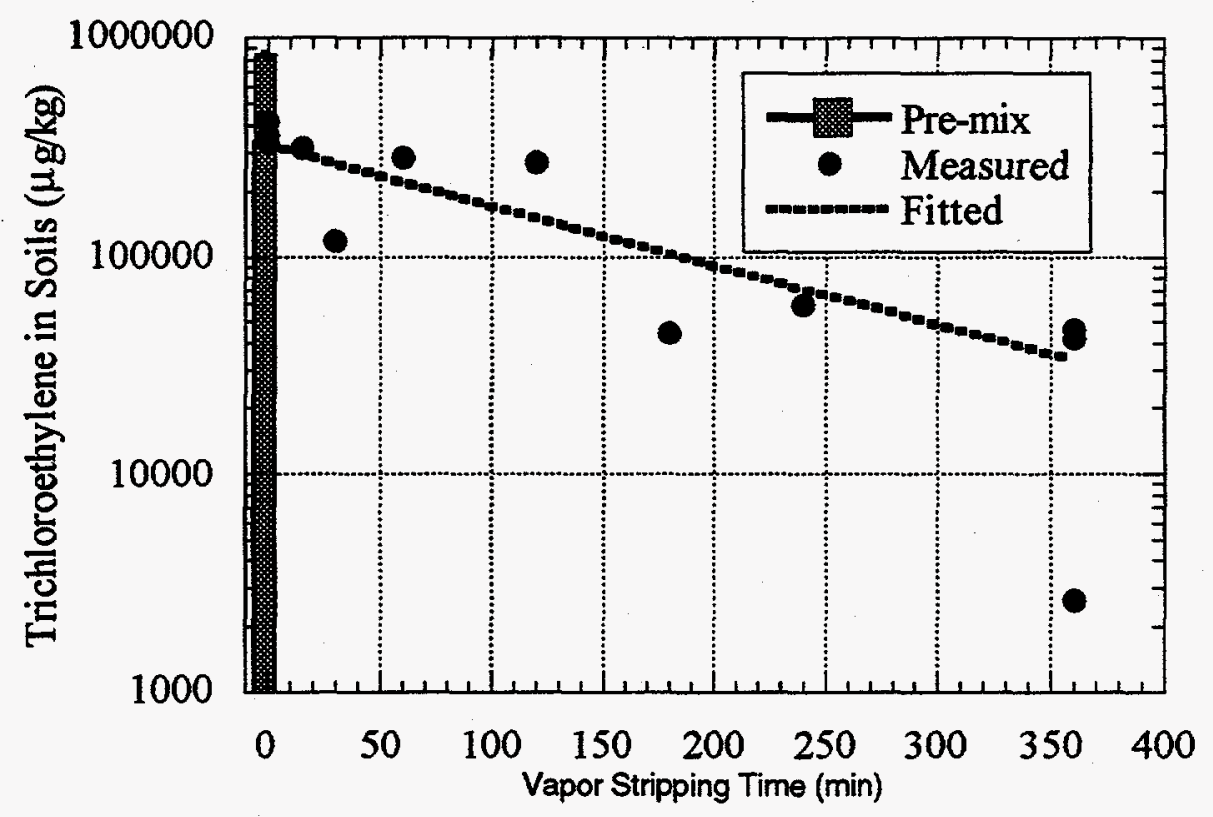

(b)

Fig. A.7. Residual trichloroethylene (TCE) in soil vs vapor stripping time in core B10,11.0-11.5; (a) TCE plotted on a normal scale, (b) TCE plotted on a log scale. 


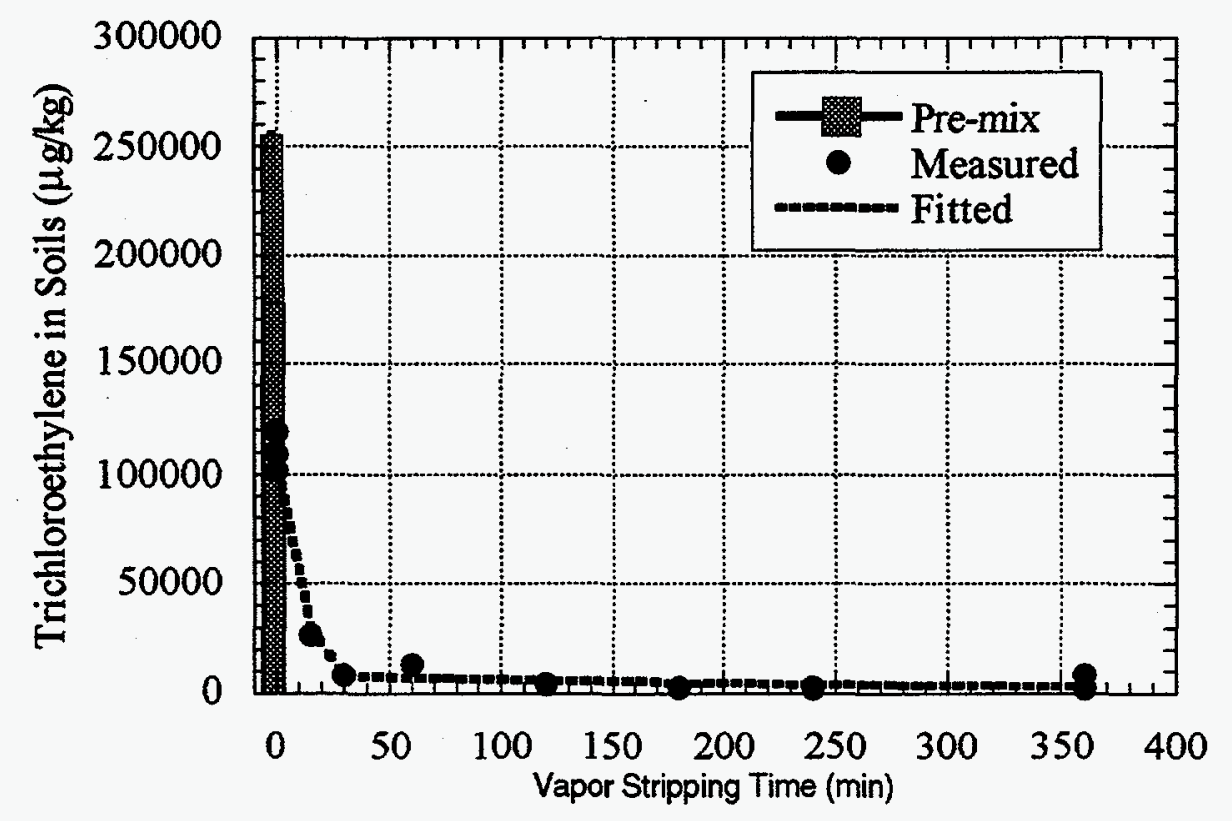

(a)

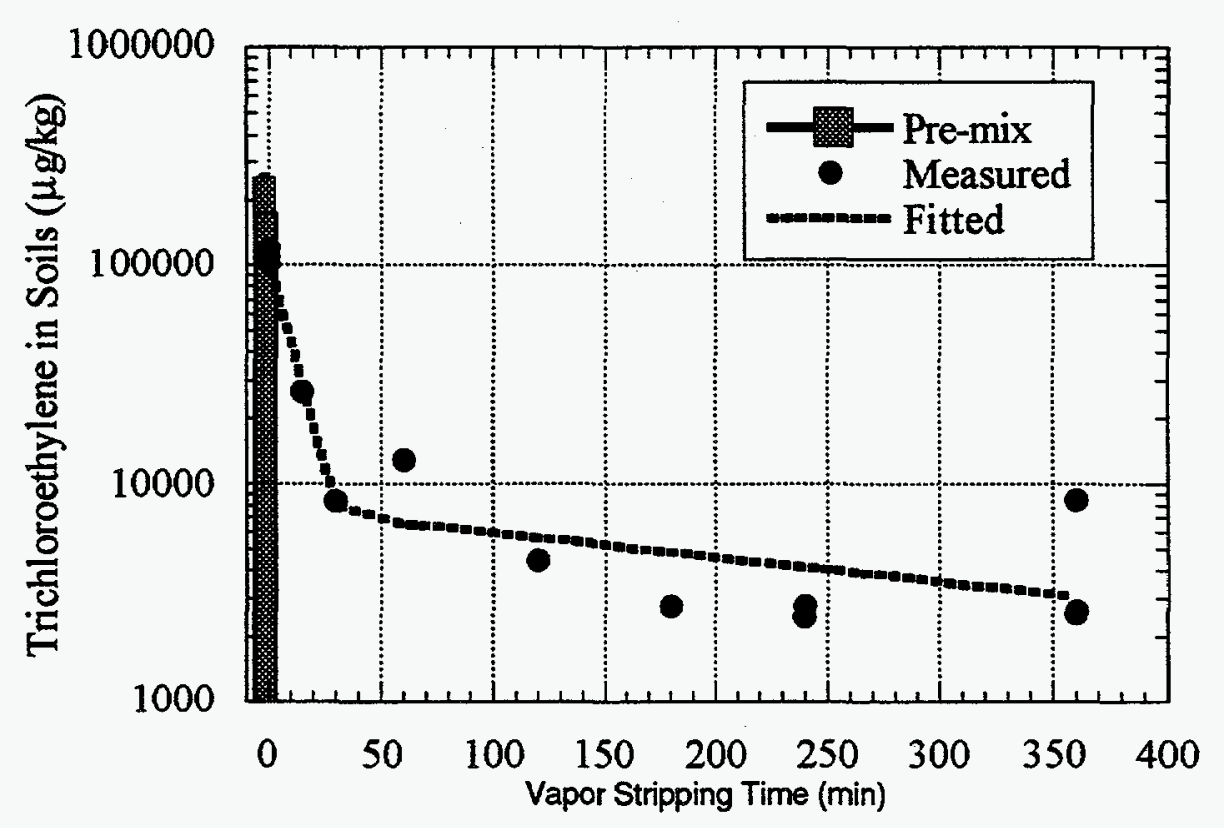

(b)

Fig. A.8. Residual trichloroethylene (TCE) in soil vs vapor stripping time in core B10,11.5-12.0; (a) TCE plotted on a normal scale, (b) TCE plotted on a log scale. 


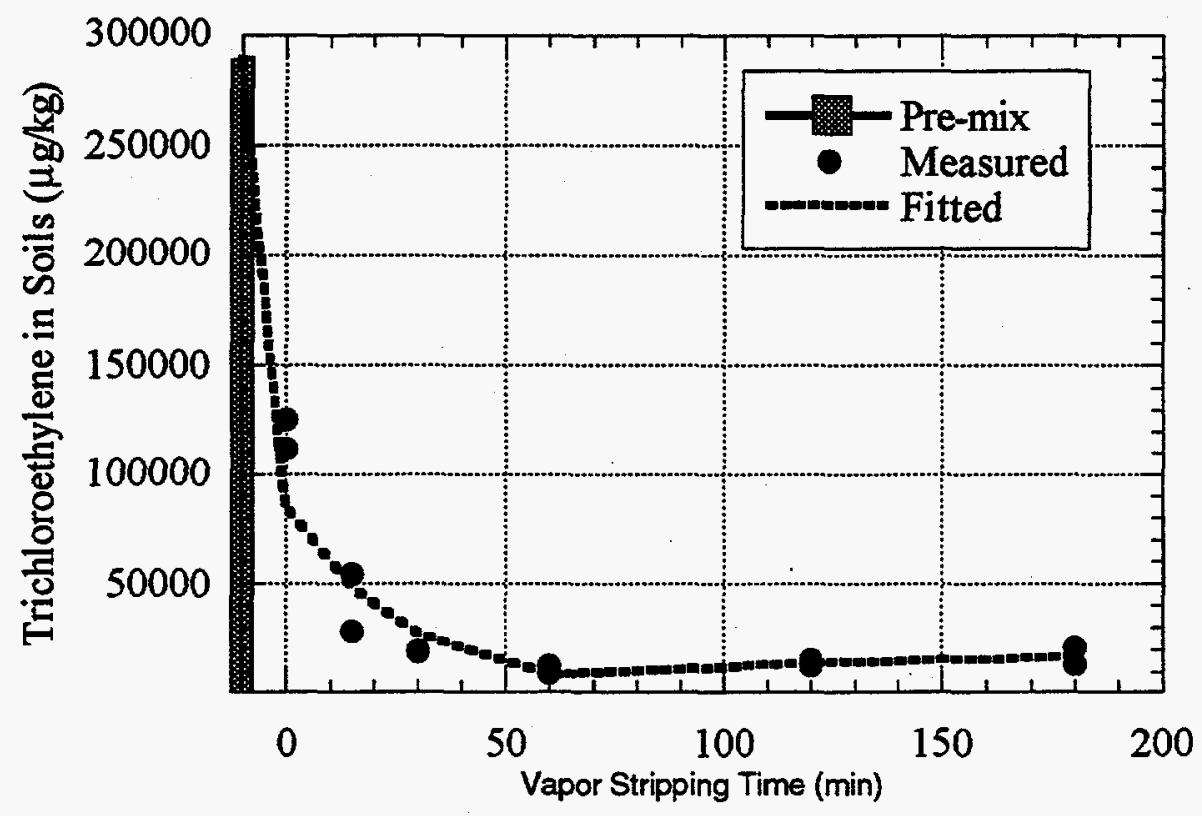

(a)

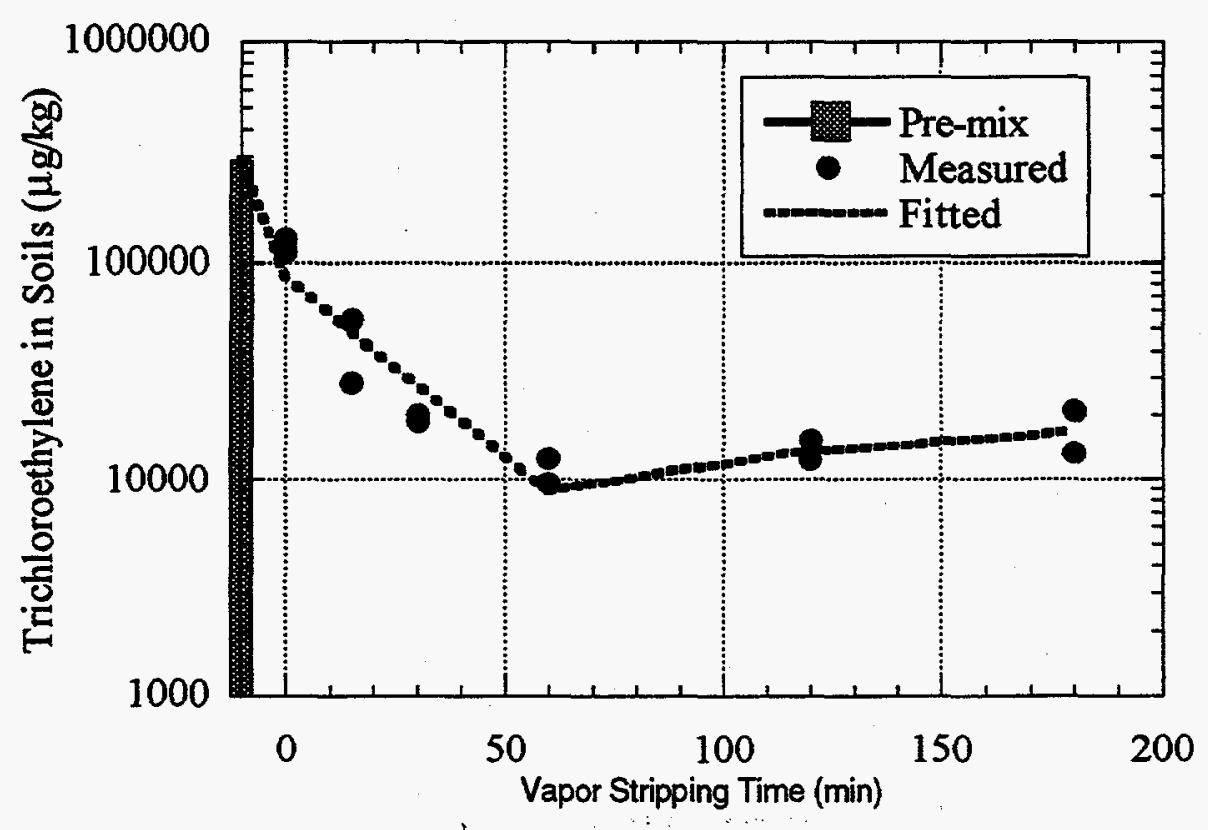

(b)

Fig. A.9. Residual trichloroethylene (TCE) in soil vs vapor stripping time in core B10,5.5-6.0; (a) TCE plotted on a normal-scale, (b) TCE plotted on a log-scale. 


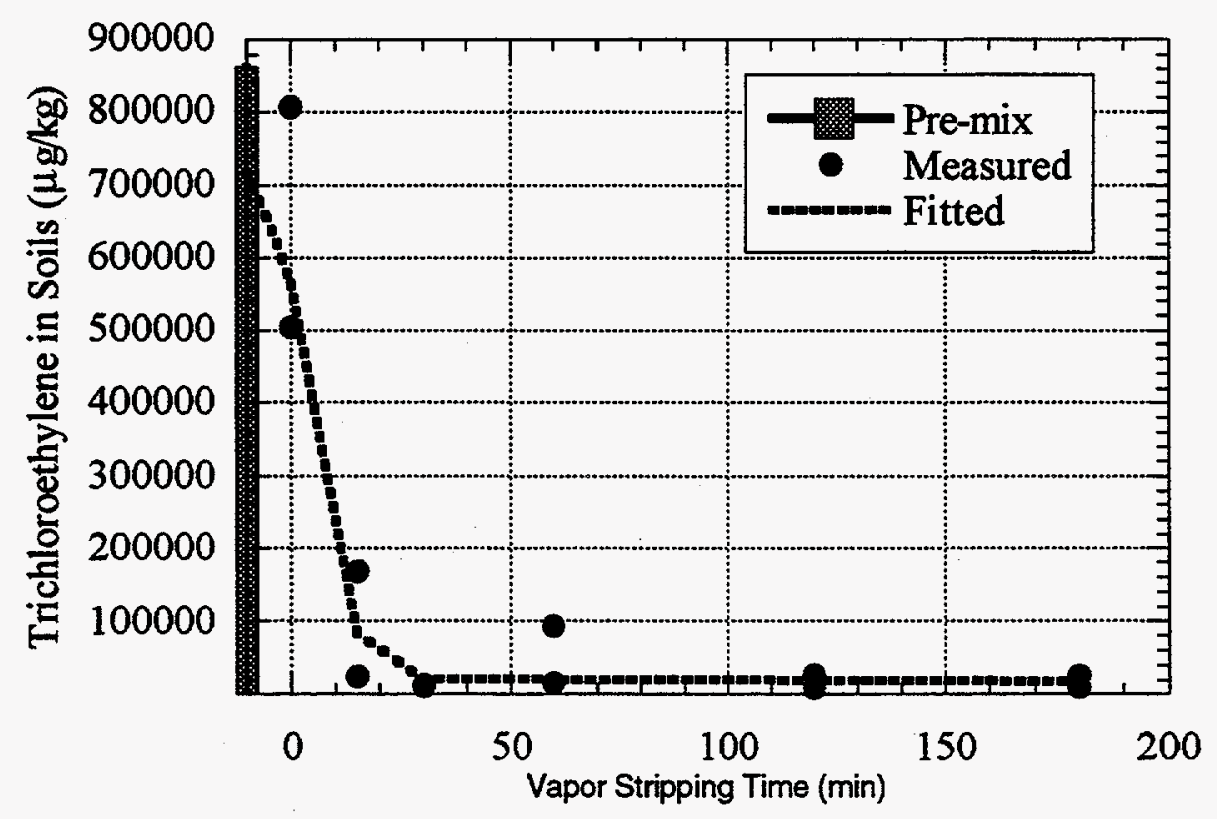

(a)

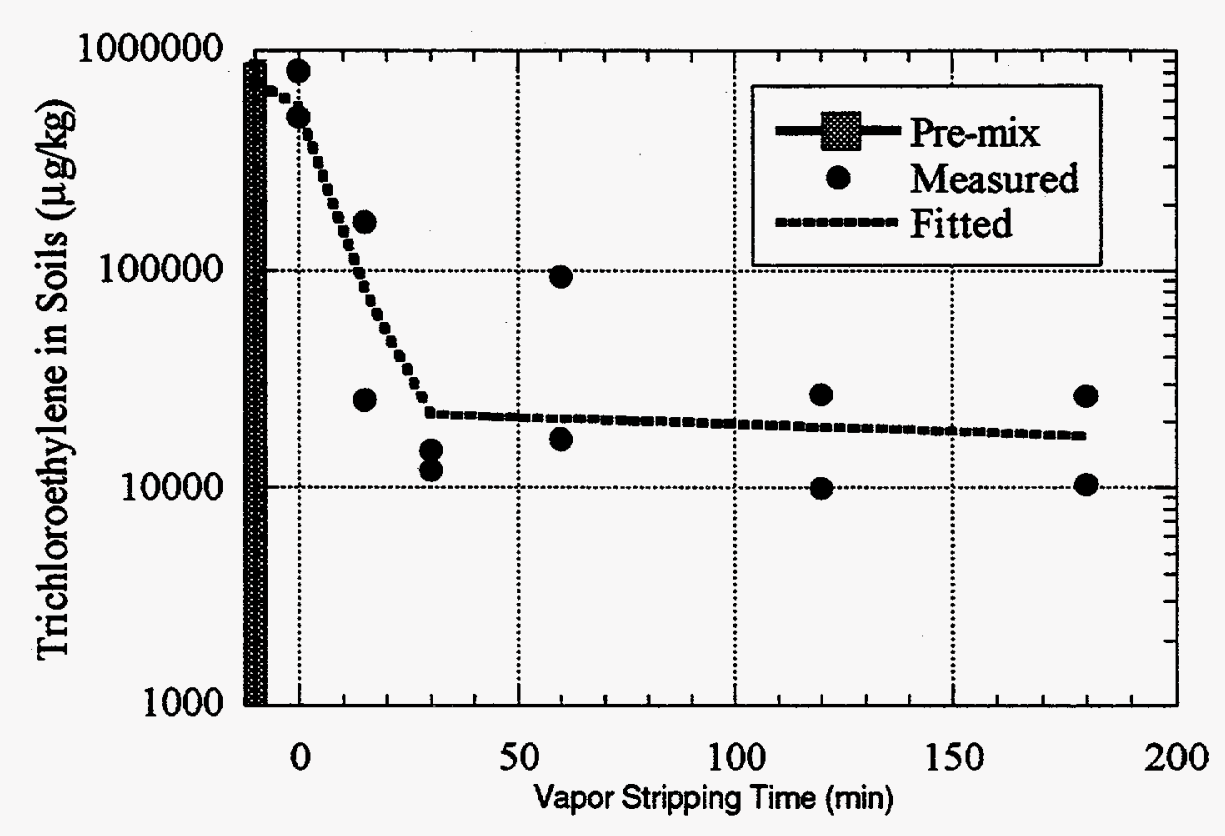

(b)

Fig. A.10. Residual trichloroethylene (TCE) in soil vs vapor stripping time in core B10,6.0-6.5; (a) TCE plotted on a normal scale, (b) TCE plotted on a log scale. 


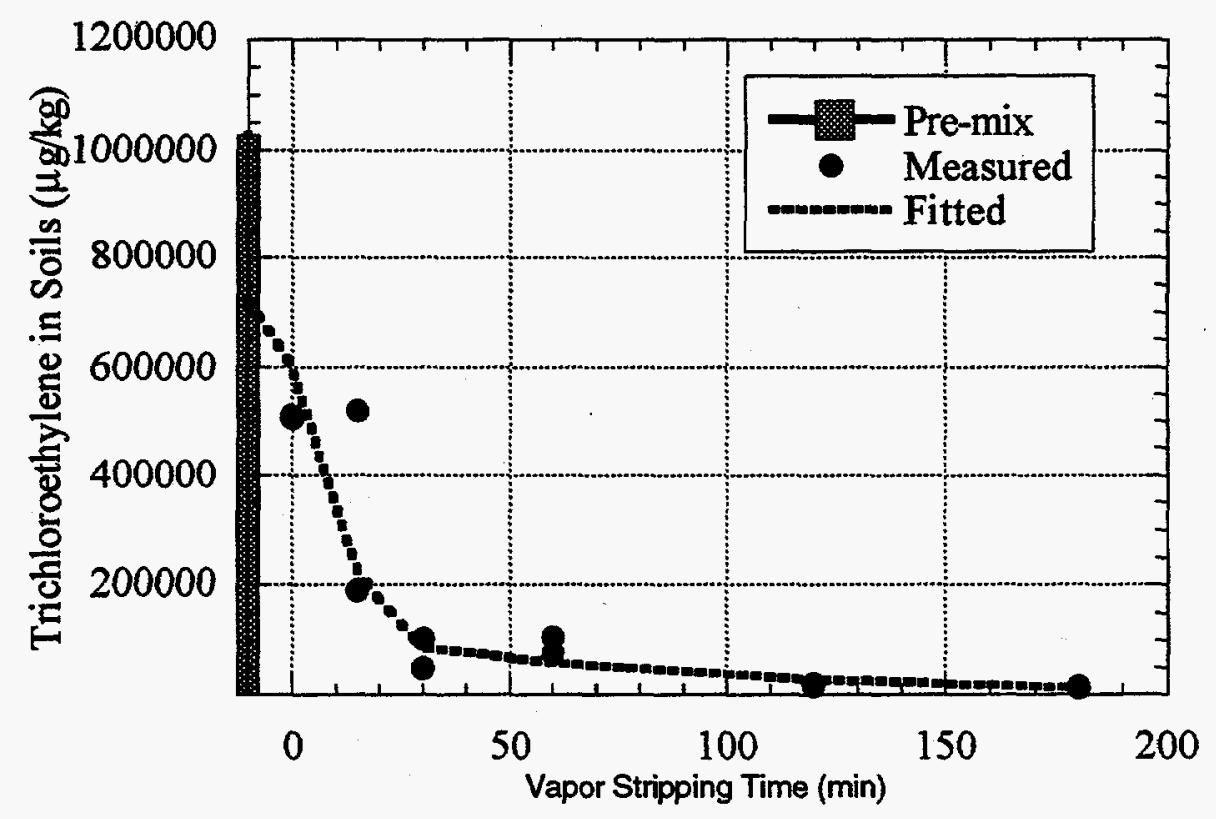

(a)

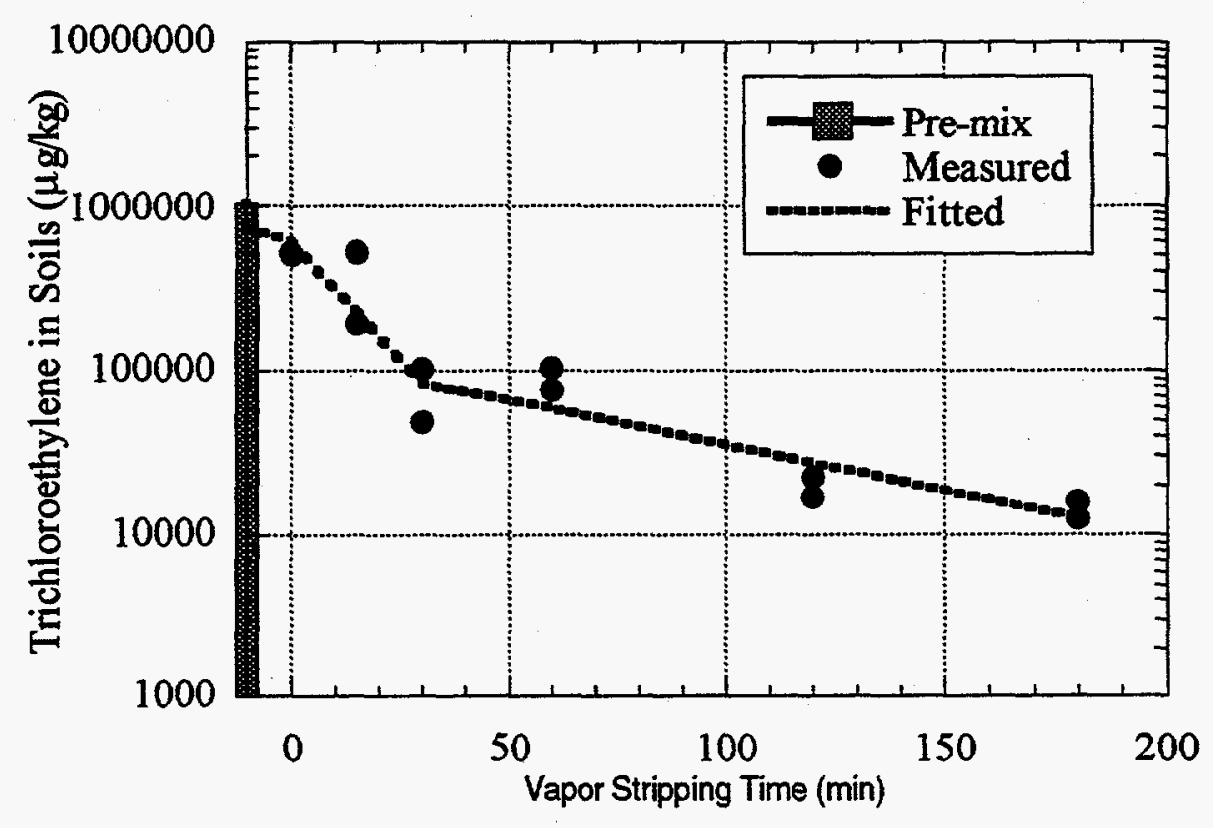

(b)

Fig. A.11. Residual trichloroethylene (TCE) in soil vs vapor stripping time in core B10,6.5-7.0; (a) TCE plotted on a normal scale, (b) TCE plotted on a log scale. 


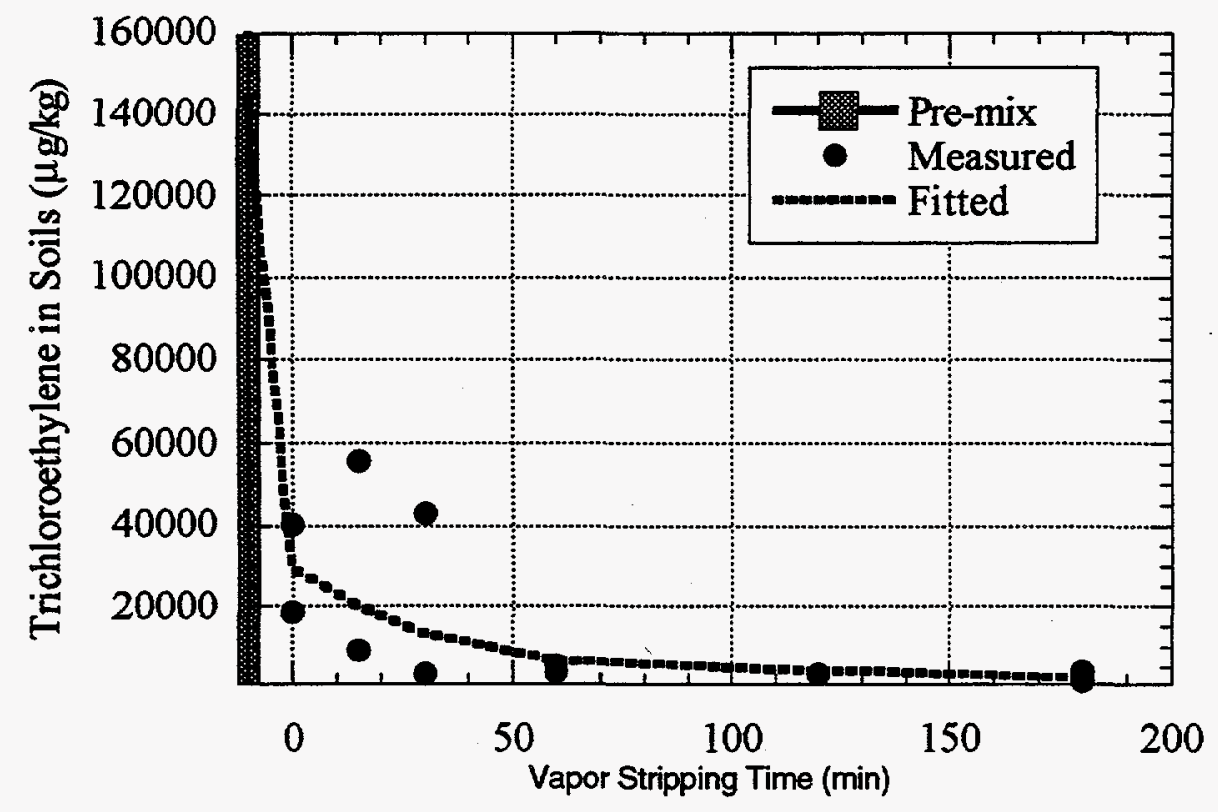

(a)

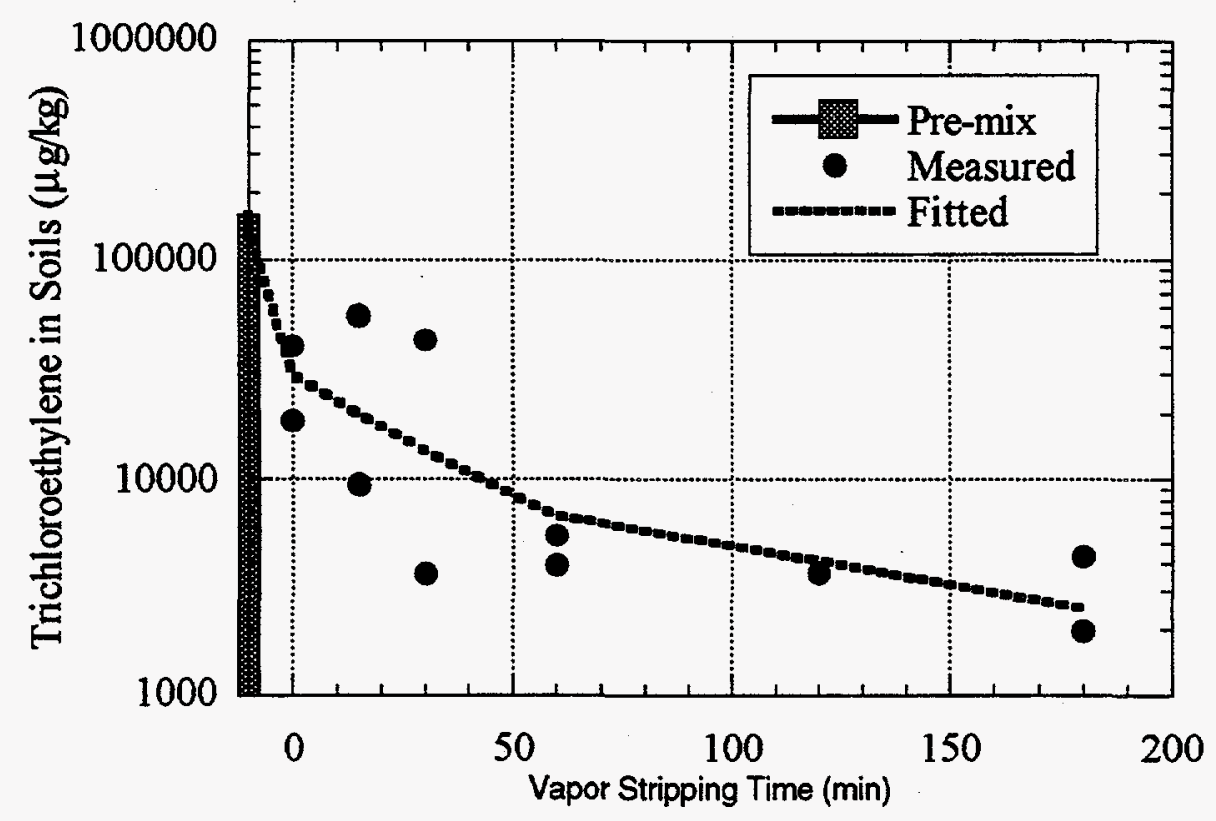

(b)

Fig. A.12. Residual trichloroethylene (TCE) in soil vs vapor stripping time in core B9,8.0-8.5; (a) TCE plotted on a normal scale, (b) TCE plotted on a log scale. 


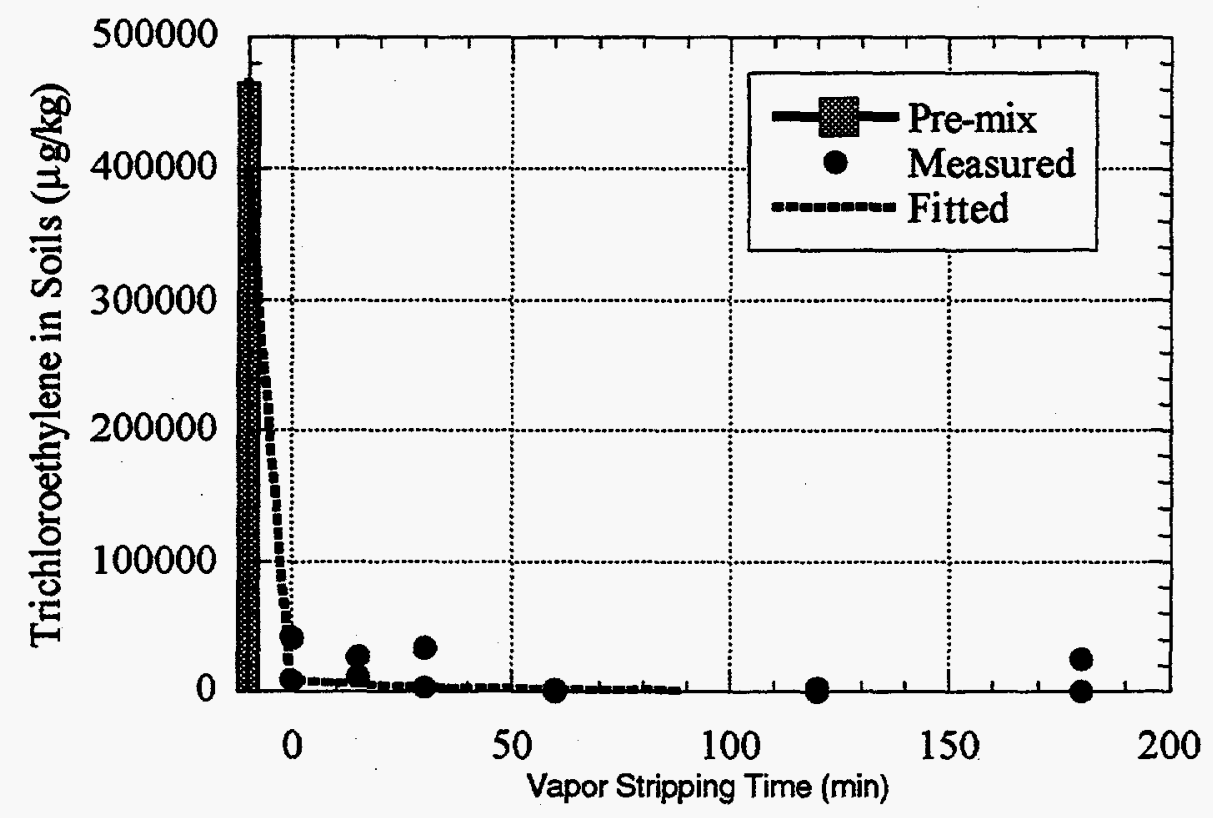

(a)

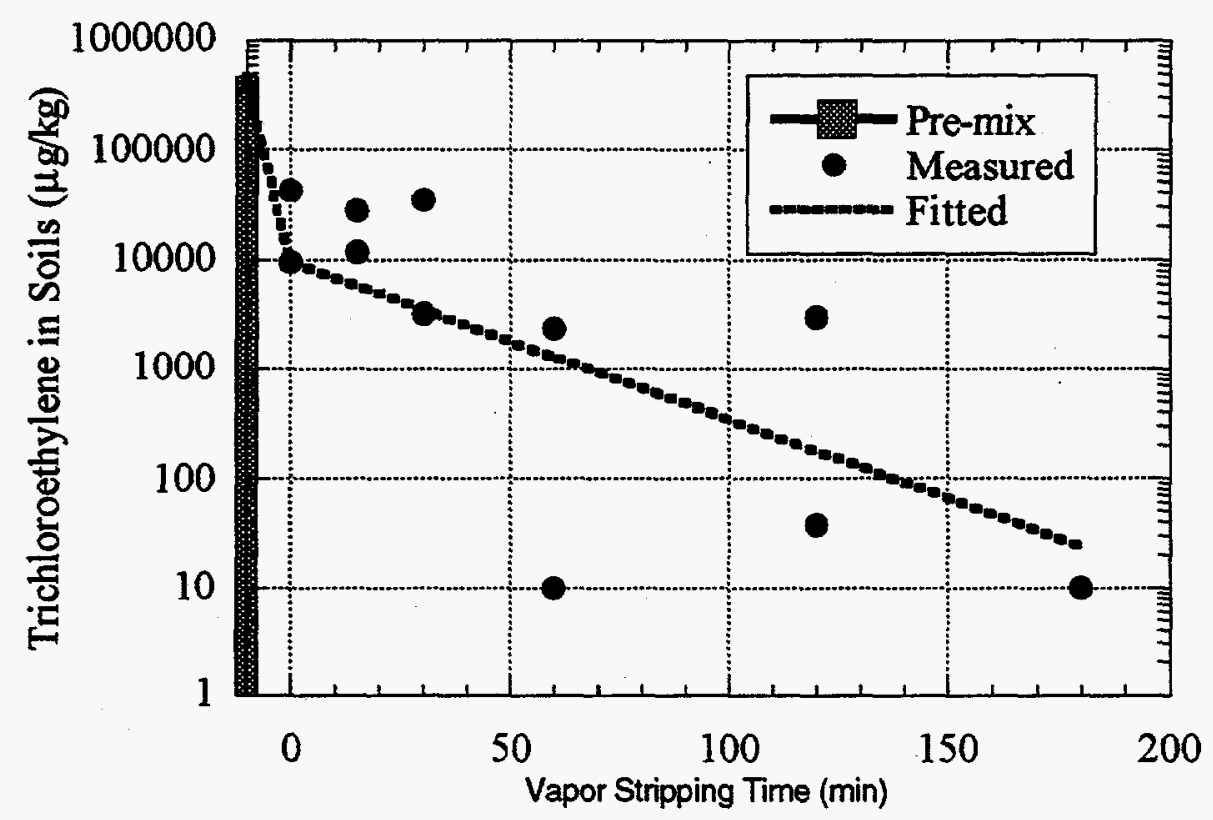

(b)

Fig. A.13. Residual trichloroethylene (TCE) in soil vs vapor stripping time in core B9,11.0-11.5; (a) TCE plotted on a normal-scale, (b) TCE plotted on a log-scale. 

APPENDIX B.

TEMPERATURE AND TRICHLOROETHYLENE REMOVAL VS VAPOR STRIPPING TIME 

- TCE (ug/kg) Temperature (C)

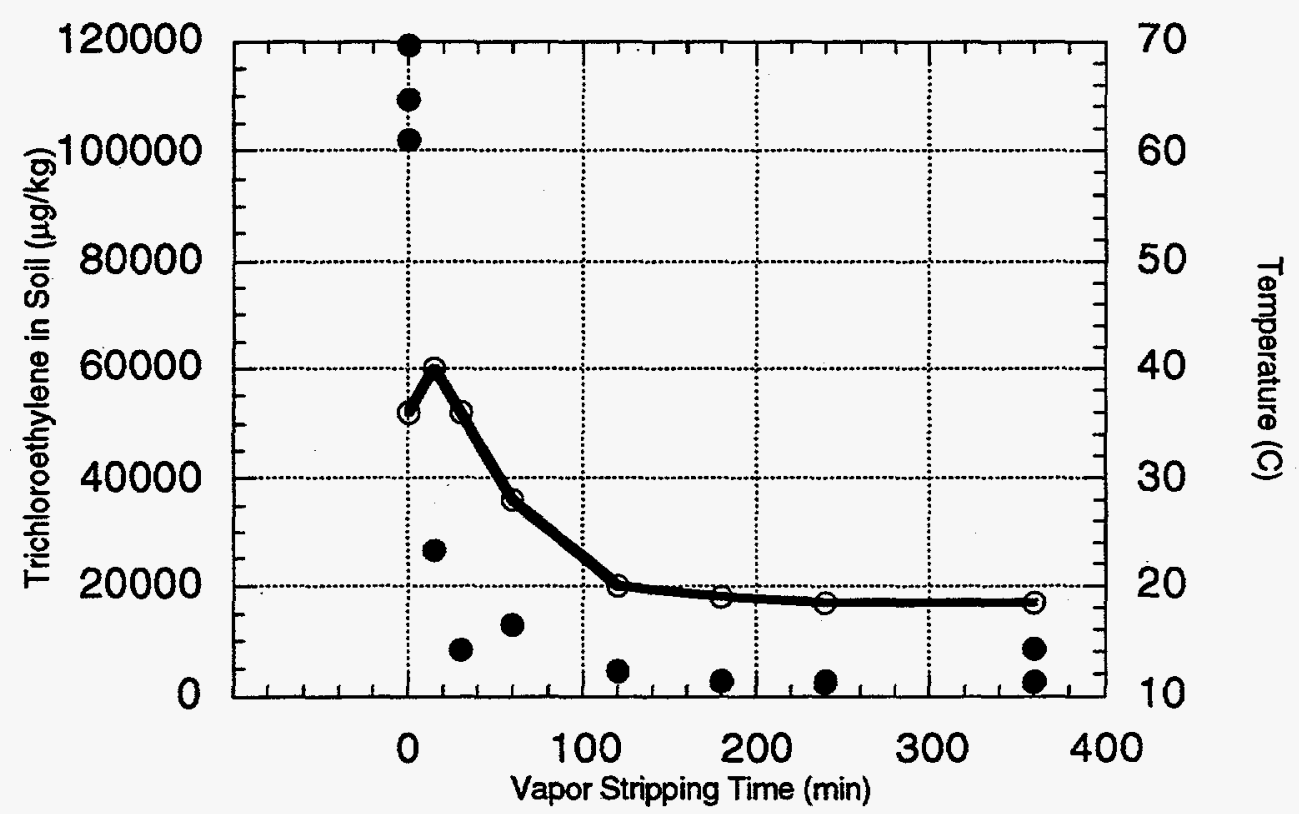

Fig. B.1. Temperature and residual trichloroethylene in soil vs vapor stripping time, core B10,11.5-12.

- TCE (ug/kg) - Temperature (C)

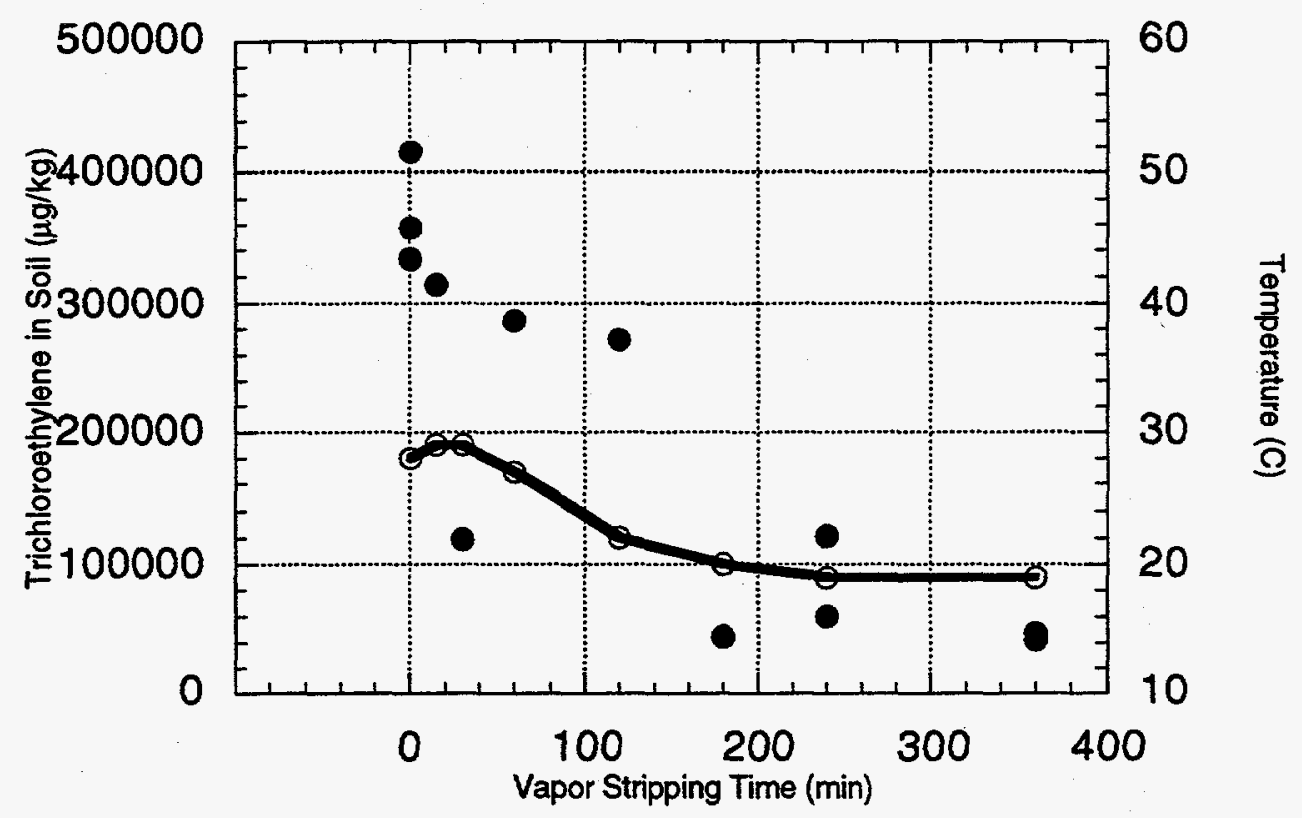

Fig. B.2. Temperature and residual trichloroethylene in soil vs vapor stripping time, core B10,11.0-11.5. 
- TCE (ug/kg) -Temperature

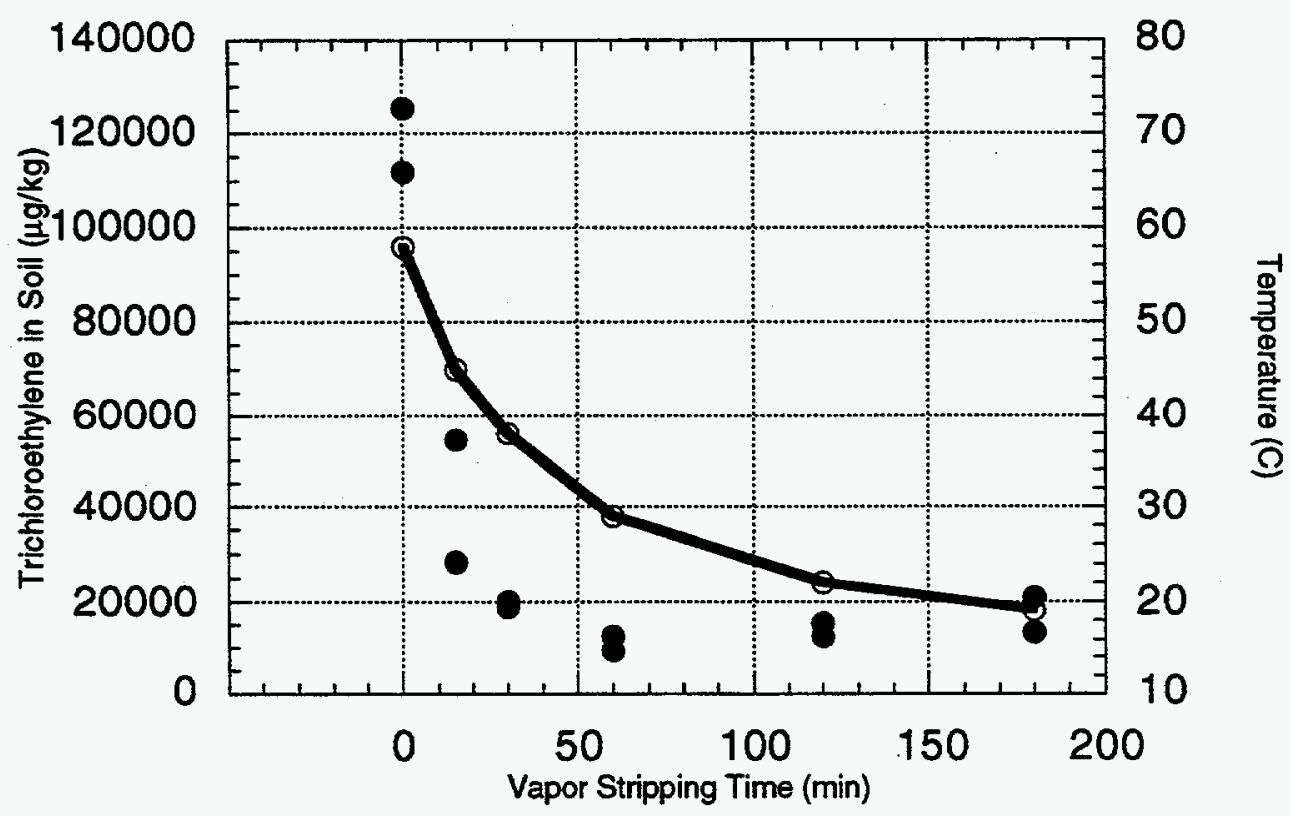

Fig. B.3. Temperature and residual trichloroethylene in soil vs vapor stripping time, core B10,5.5-6.0.

- TCE (ug/kg) Temperature

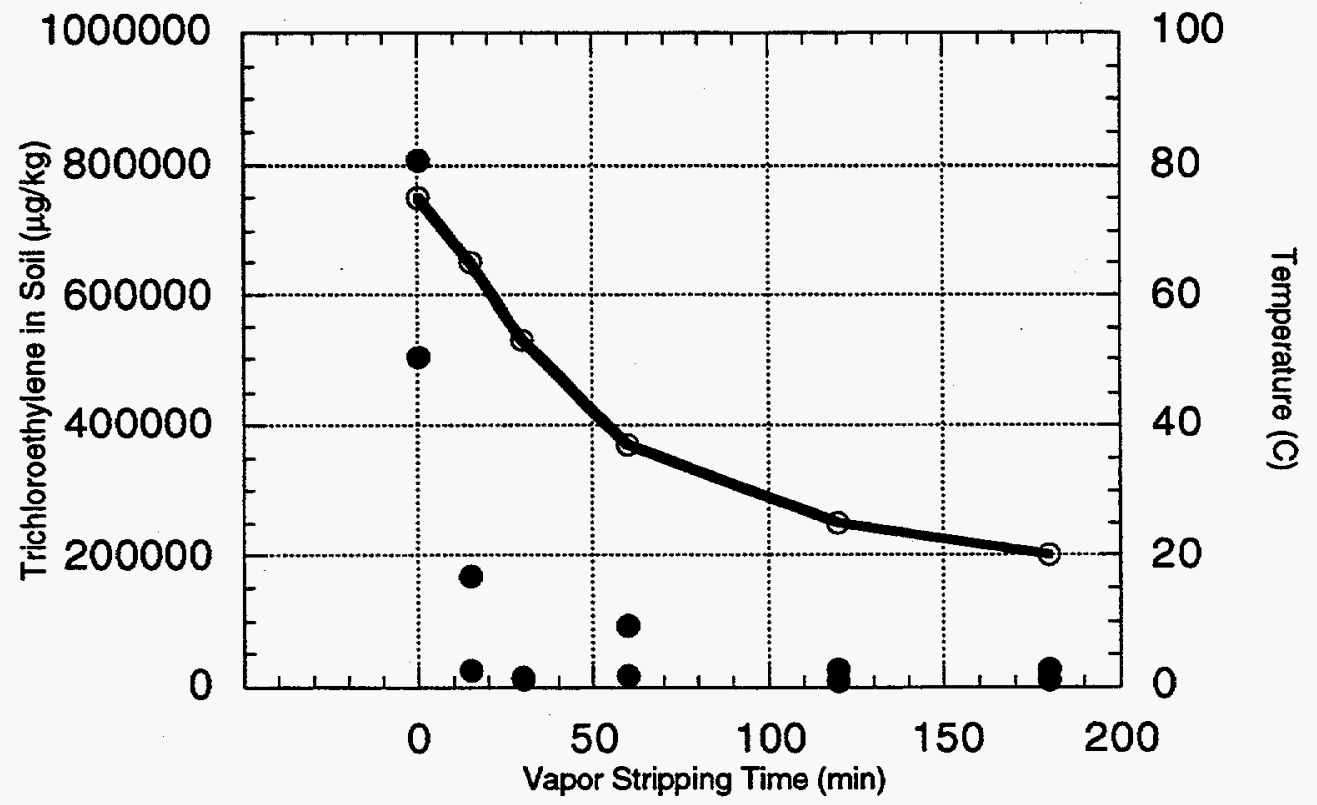

Fig. B.4. Temperature and residual trichloroethylene in soil vs vapor stripping time, core B10,6.0-6.5. 
- TCE (ug/kg) Temperature

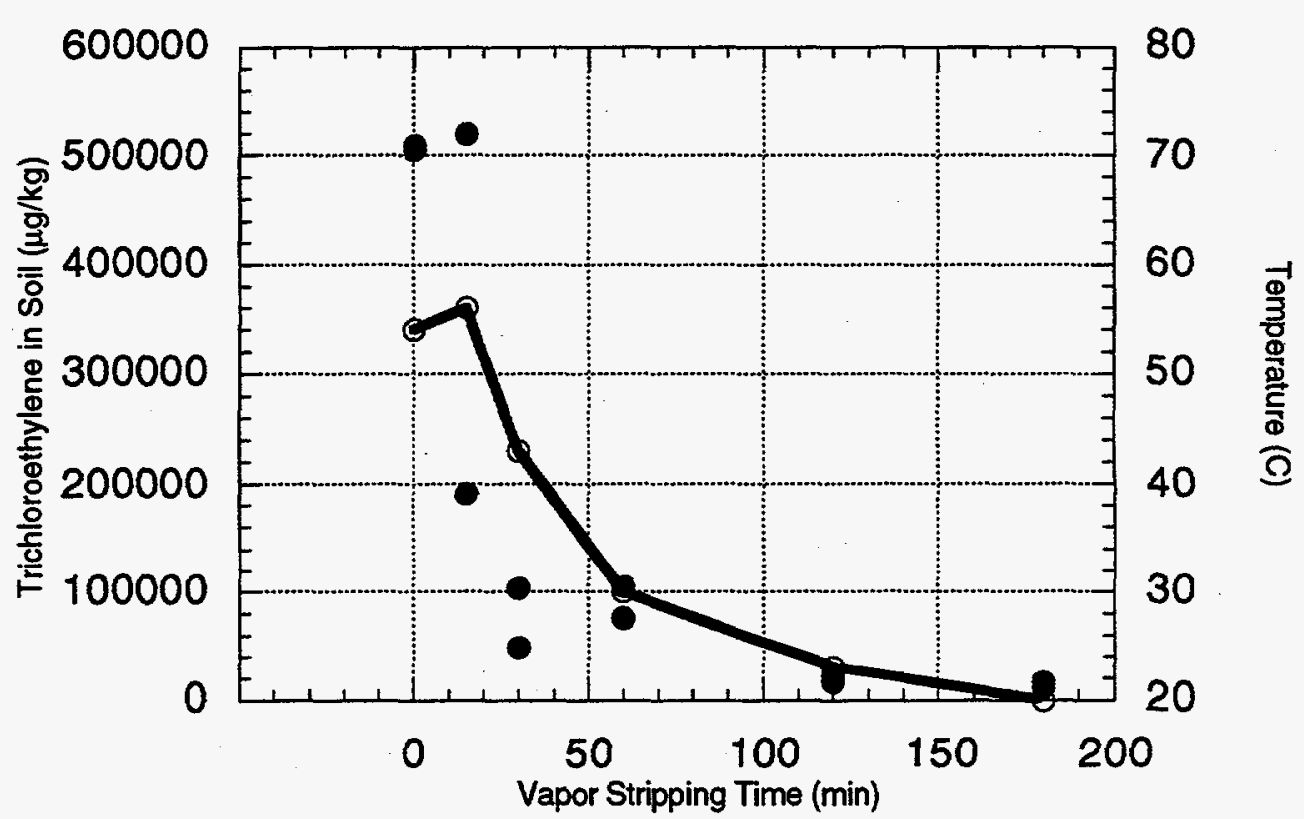

Fig. B.5. Temperature and residual trichloroethylene in soil vs vapor stripping time, core B10,6.5-7.0.

- TCE (ug/kg) Temperature

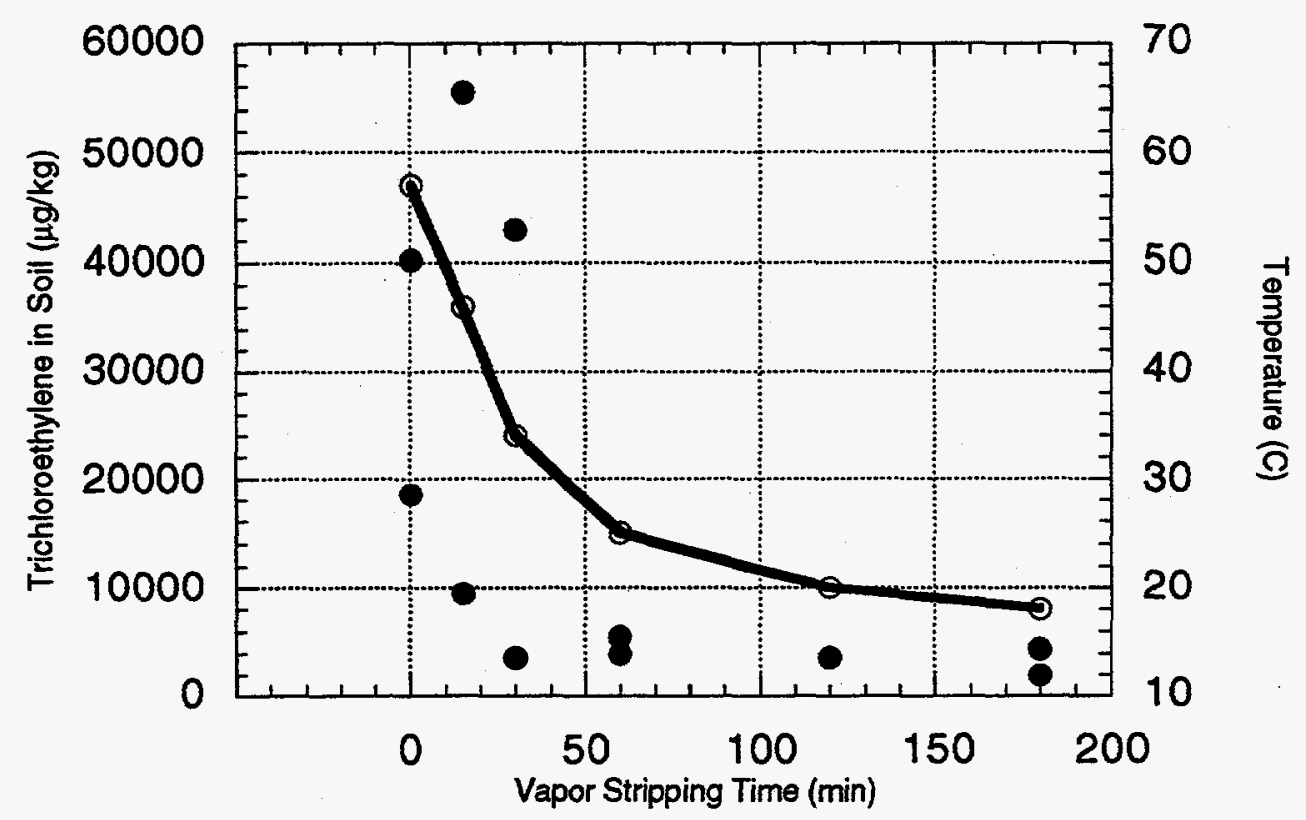

Fig. B.6. Temperature and residual trichloroethylene in soil vs vapor stripping time, core B9,8.0-8.5. 


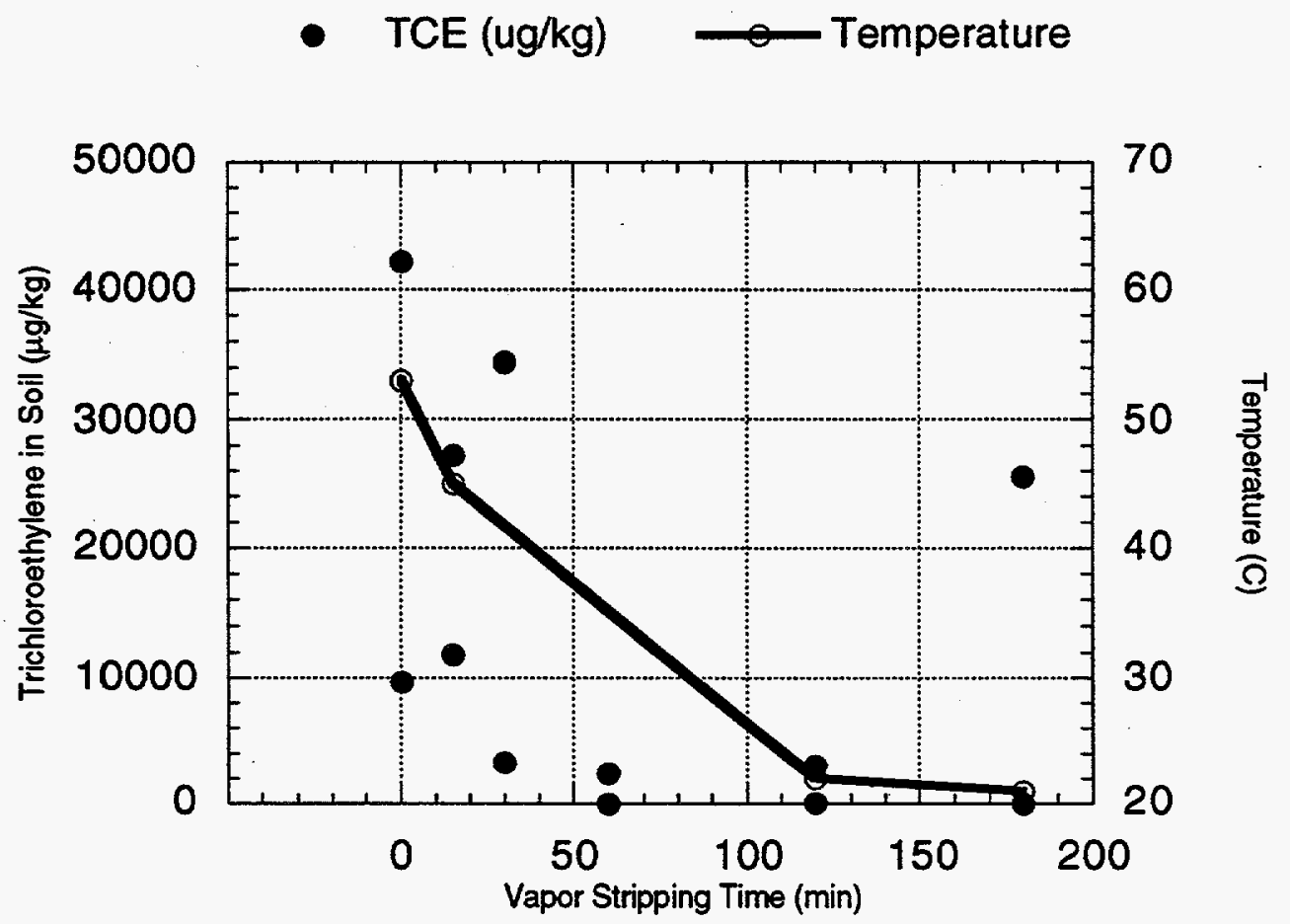

Fig. B.7. Temperature and residual trichloroethylene in soil vs vapor stripping time, core B9,11.0-11.5. 
APPENDIX C.

CONTOUR MAPS OF TRICHLOROETHYLENE CONTAMINATION IN SOILS UNDERLYING THE MICHOUD RINSEWATER IMPOUNDMENT 



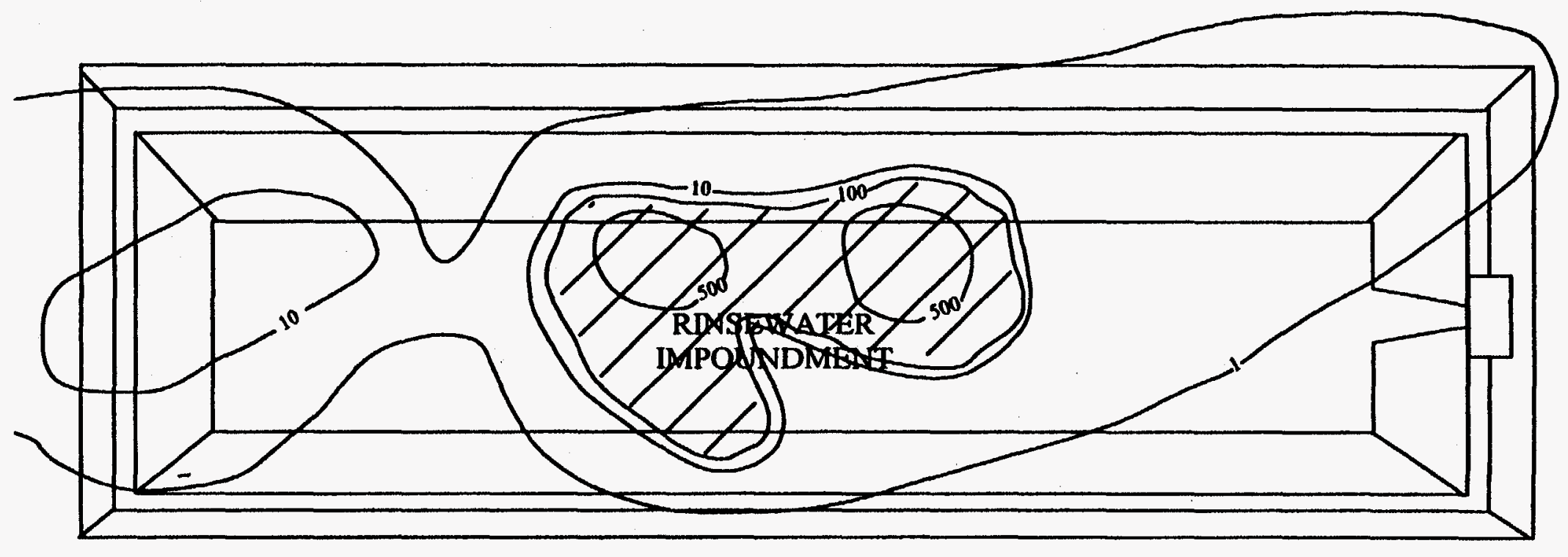

TCE concentrations $(\mathbf{m g} / \mathbf{k g})$

NOT TO SCALE

Fig. C.1. Trichloroethylene contamination in subsurface soils from 0 to $4 \mathrm{ft}$ below the bottom of the impoundment concrete liner.

Sources:

1. Lucero, A. J., Gilbert, V. P.; Hewitt, J. D.; Koran, L. J. Jr.; Jennings, H. L.; Donaldson, T. L.; West, O. R.; Cline, S. R.; Marshall, D. S. 1995. Treatability of TCE-contaminated clay soils at the rinsewater impoundment, Michoud Assembly Facility. ORNL/TM-12931. Oak Ridge National Laboratory.

2. $\mathrm{CH}^{2} \mathrm{M}$ Hill Southeast, Inc. 1990. Supplemental closure investigation: Field investigation and contaminant assessment, rinsewater impoundment and appurtenant structures, NASA Michoud Assembly Facility. Prepared for Martin Marietta Manned Space Systems, Facilities Engineering Department. 


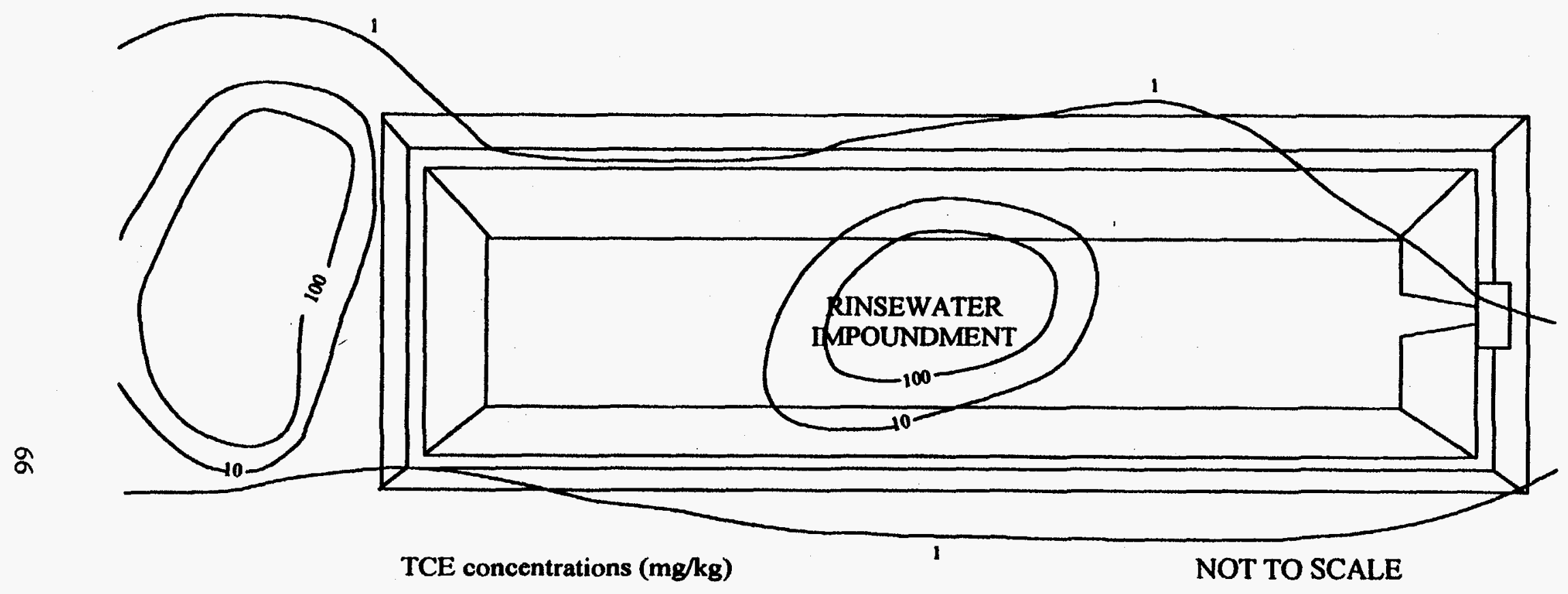

Fig. C.2. Trichloroethylene contamination in subsurface soils from 4 to $10 \mathrm{ft}$ below the bottom of the impoundment concrete liner.

Sources:

1. Lucero, A. J., Gilbert, V. P.; Hewitt, J. D.; Koran, L. J. Jr.; Jennings, H. L.; Donaldson, T. L.; West, O. R.; Cline, S. R.; Marshall, D. S. 1995. Treatability of TCE-contaminated clay soils at the rinsewater impoundment, Michoud Assembly Facility. ORNL/TM-12931. Oak Ridge National Laboratory.

2. $\mathrm{CH}^{2} \mathrm{M}$ Hill Southeast, Inc. 1990. Supplemental closure investigation: Field investigation and contaminant assessment, rinsewater impoundment and appurtenant structures, NASA Michoud Assembly Facility. Prepared for Martin Marietta Manned Space Systems, Facilities Engineering Department. 


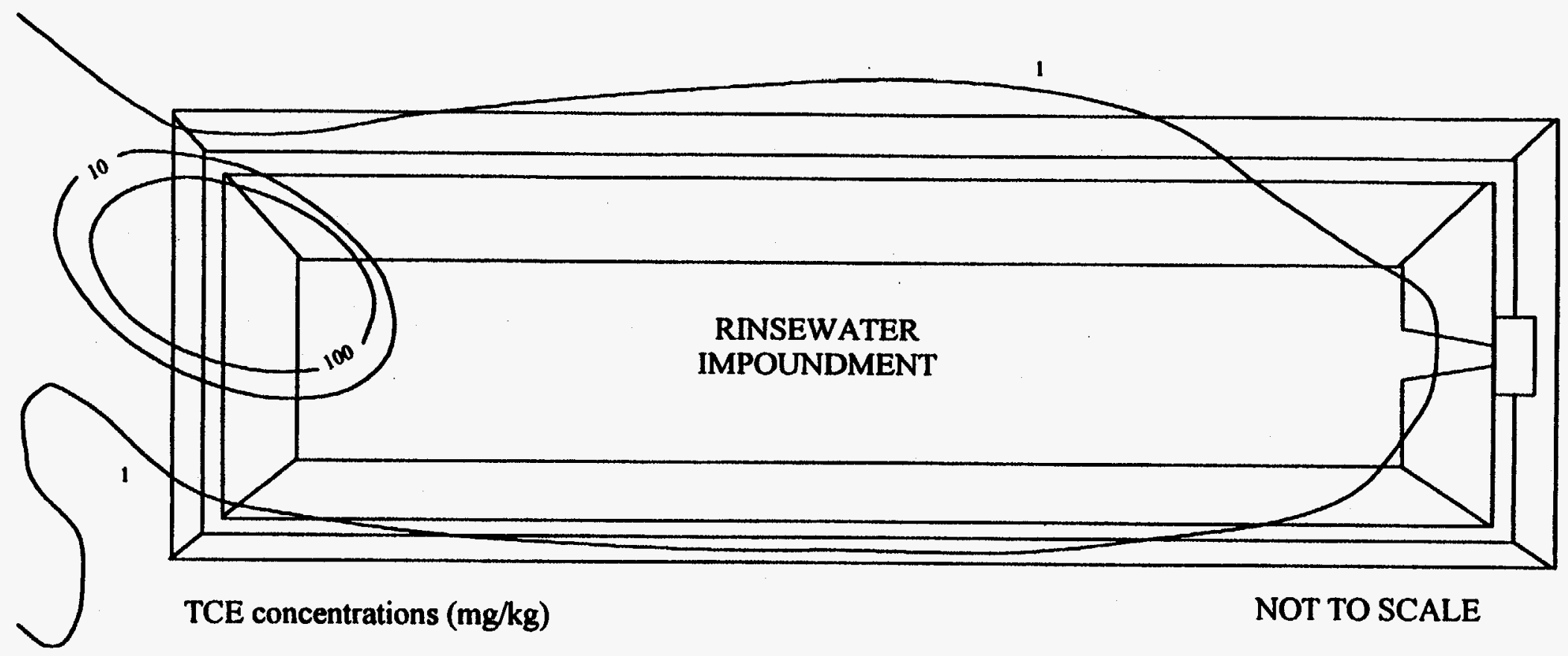

Fig. C.3. Trichloroethylene contamination in subsurface soils from 10 to $15 \mathrm{ft}$ below the bottom of the impoundment concrete liner.

\section{Sources:}

1. Lucero, A. J., Gilbert, V. P.; Hewitt, J. D.; Koran, L. J. Jr.; Jennings, H. L.; Donaldson, T. L.; West, O. R.; Cline, S. R.; Marshall, D. S. 1995. Treatability of TCE-contaminated clay soils at the rinsewater impoundment, Michoud Assembly Facility. ORNL/TM-12931. Oak Ridge National Laboratory.

2. $\mathrm{CH}^{2} \mathrm{M}$ Hill Southeast, Inc. 1990. Supplemental closure investigation: Field investigation and contaminant assessment, rinsewater impoundment and appurtenant structures, NASA Michoud Assembly Facility. Prepared for Martin Marietta Manned Space Systems, Facilities Engineering Department. 
APPENDIX D.

CLEANUP COST CALCULATIONS FOR REMEDIATION GOAL SPECIFIED AS A TARGET RESIDUAL TRICHLOROETHYLENE CONCENTRATION 

The following describes how remediation costs were estimated for cleanup goals specified as a target residual trichloroethylene concentration (Fig. 13). For a given target residual concentration and using the grid and the initial concentrations shown in Fig. 12:

1. For each $30 \mathrm{ft} \times 30 \mathrm{ft}$ sub-area, the percentage of TCE removal required to achieve the target residual concentration $(P)$ was calculated. For example, an initial concentration of $500 \mathrm{mg} / \mathrm{kg}$ would require a $99 \%$ to achieve a target residual concentration of $5 \mathrm{mg} / \mathrm{kg}$.

2. For each sub-area, the time required per soil column $\left(T_{c o l}\right)$ to achieve $P$ was estimated using Table D.1. Treatment times in Table D. 1 are partially based on the removal curve shown in Fig. 10. Treatment times for some target percentage removals are longer than what would have been obtained from Fig. 10.

Table D.1 Treatment times to achieve specified percentages of trichloroethylene removal Target Percentage Removal Treatment Time per Soil Column

\begin{tabular}{cc}
$(\%)$ & $(\min )$ \\
\hline \hline 0 & 0 \\
60 & 30 \\
80 & 30 \\
90 & 60 \\
95 & 60 \\
98 & 180 \\
99 & 300 \\
\hline
\end{tabular}

3. The time required to cleanup a square sub-area $\left(T_{\text {sub-area }}\right)$ was calculated as follows:

$$
T_{\text {sub-area }}=T_{c o l} * N_{c o l}
$$

where $N_{c o l}$ is the number of soil columns per sub-area. The latter is equal to 28 for an 8 ft-diam soil mixer.

4. The total time required to cleanup the Impoundment is calculated by summing $T_{c o l}$ over all the sub-areas $\left(\sum T_{c o l}\right)$. Assuming that the cost for operating a soil mixer per day is $\$ 10,000$, and that $4 \mathrm{~h}$ of a day is effectively used for treatment, the cost for operating a soil mixer per minute is $\sim \$ 42$. The total operational cost is then: 


$$
C_{\text {oper }}=\$ 42 \times \sum T_{\text {col }}
$$

5. The total volume of soil requiring treatment $\left(V_{\text {soil }}\right)$ is estimated from Fig. 12, and the total reagent cost is obtained as follows:

$$
C_{\text {reagent }}=\$ 27 \times V_{\text {soil }} \text {, }
$$

where $\$ 27 / \mathrm{yd}^{3}$ is the cost for a CaO loading of $400-500 \mathrm{~kg} / \mathrm{m}^{3}$.

6. Finally, the total cost for remediation is obtained by adding $C_{\text {oper }}$ and $C_{\text {reagent }}$. 


\section{INTERNAL DISTRIBUTION}

1. L. D. Bates

2. B. A. Berven

3. P. A. Cameron

4. R. B. Cook

5. A. G. Croff

6. J. H. Cushman

7. V.H. Dale

8. T. L. Donaldson

9. N. T. Edwards

10. D. E. Fowler

11. S. G. Hildebrand

12. G. K. Jacobs

13. P. Kanciruk

14. K. T. Klasson

15. L. J. Koran, Jr.

16. N. E. Korte

17. J. M. Loar

18.-32. A. J. Lucero (15)
33. A. P. Malinauskas

34. L. E. McNeese

35. M. I. Morris

36. C. A. Muhr

37. D. E. Reichle

38. S. M. Robinson

39. M. K. Savage

40. F. E. Sharples

41. D. S. Shriner

42. R. L. Siegrist

43.-52. O. R. West (10)

53. Central Research Library

54.-68. ESD Library (15)

69.-70. Laboratory Records Dept. (2)

71. Laboratory Records, ORNL-RC

72. ORNL Patent Section

73. ORNL Y-12 Technical Library

\section{EXTERNAL DISTRIBUTION}

74.-88. M. A. Rowland, Lockheed Martin Manned Space Systems, 13800 Old Gentilly Road, New Orleans, LA 40189

89. M. Broido, Acting Director, Environmental Sciences Division, Department of Energy, 19901 Germantown Road, Germantown, MD 20874

90. F. A. Donath, Director, Institute for Environmental Education, Geological Society of America, 1006 Las Posas, San Clemente, CA 92673

91. D. W. Freckman, Director, College of Natural Resources, 101 Natural Resources Building, Colorado State University, Fort Collins, CO 80523

92. A. Patrinos, Associate Director, Office of Health and Environmental Research, Department of Energy, G-165, Germantown, MD 20874

93. G. S. Sayler, Professor, 10515 Research Drive, Suite 100, The University of Tennessee, Knoxville, TN 37932-2567

94. F. J. Wobber, Environmental Sciences Division, Office of Health and Environmental Research, ER-74, Department of Energy, 19901 Germantown Road, Germantown, MD 20874 
95. Office of Assistant Manager for Energy Research and Development, U.S.

Department of Energy Oak Ridge Operations, P.O. Box 2001, Oak Ridge, TN 378318600

96.-97. Office of Scientific and Technical Information, P.O. Box 62, Oak Ridge, TN 37831 